Check for updates

Cite this: RSC Adv., 2022, 12, 5686

\title{
Evolution of graphene oxide (GO)-based nanohybrid materials with diverse compositions: an overview
}

\author{
Pampi Majumder ${ }^{a}$ and Rupali Gangopadhyay (iD *b
}

The discovery of the 2D nanostructure of graphene was in fact the beginning of a new generation of materials. Graphene itself, its oxidized form graphene oxide (GO), the reduced form of GO (RGO) and their numerous composites are associates of this generation. Out of this spectrum of materials, the development of GO and related hybrid materials has been reviewed in the present article. GO can be functionalized with metals ( $\mathrm{Ag}$ and $\mathrm{Mg}$ ) and metal oxides ( $\mathrm{CuO}, \mathrm{MgO}, \mathrm{Fe}_{2} \mathrm{O}_{3}, \mathrm{Ag}_{2} \mathrm{O}$, etc.) nanoparticles (NPs), organic ligands (chitosan and EDTA) and can also be dispersed in different polymeric matrices (PVA, PMMA, PPy, and PAn). All these combinations give rise to nanohybrid materials with improved functionality. An updated report on the chronological development of such nanohybrid materials of diverse nature has been delivered in the present context. Modifications in synthesis methodologies as well as performances and applications of individual materials are addressed accordingly. The functional properties of GO were synergistically modified by photoactive semiconductor NPs; as a result, the GO$\mathrm{MO}$ hybrids acquired excellent photocatalytic ability and were able to degrade a large variety of organic dyes (MB, RhB, MO, MR, etc.) and pathogens. The large surface area of GO was successfully complemented by the NPs so that high and selective adsorption capacity towards metal ions and organic molecules as well as improved charge separation properties could be achieved. As a result, GOMO hybrids have been considered effective materials in water purification, energy storage and antibacterial applications. GO-MO hybrids with magnetic particles have exhibited selective destruction of cancerous cells and controlled drug release properties, extremely important in the pharmaceutical field. Chitosan and EDTA-modified GO could form 3D network-like structures with strong efficiency in removing heavy metal ions and organic pollutants. GO as a filler enhanced the strength, flexibility and functional properties of common polymers, such as PVA and PVC, to a large extent while, GO-CP composites with polyaniline and polypyrrole are considered suitable for the fabrication of biosensors, supercapacitors, and MEMS as well as efficient photothermal therapy agents. In summary, GO-based hybrids with inorganic and organic counterparts have been designed, the unique properties of which are exploited in versatile fields of applications.

Received 7th September 2021 Accepted 30th December 2021

DOI: $10.1039 / \mathrm{d} 1 \mathrm{ra06731a}$

rsc.li/rsc-advances
(CNTs) and can be stacked into three dimensional (3D) graphite. It is graphene, the first 2D material (monolayer), which is the thinnest and hardest material ever known. ${ }^{2,3}$ Since its discovery, this material has drawn scientists from various disciplines to work on it and a great deal of research from both fundamental scientific and technical points of view has been accumulated on this material to explore its properties and applications.

As a result of extensive research over the last fifteen years, it is now known that this wonderful material is a zero band gap semiconductor gifted with a unique crystal structure, ${ }^{4}$ incredibly large surface area (ca. $\left.2630 \mathrm{~m}^{2} \mathrm{~g}^{-1}\right),{ }^{5}$ as well as flexibility and mechanical strength (Young's modulus of $c a$. $2.4 \pm 0.4 \mathrm{TPa}$ with a breaking strength of $\left.42 \mathrm{~N} \mathrm{~m}^{-1}\right) .{ }^{6,7}$ Its thermal conductivity as high as $c a$. $\sim 2000-5000 \mathrm{~W} \mathrm{~m}^{-1} \mathrm{~K}^{-1}$, its current density of $c a .10^{8} \mathrm{~A} \mathrm{~cm}^{-2}$ and pretty high electron mobility of $c a .10^{5} \mathrm{~cm}^{2}$
${ }^{a}$ A/515, H. B. Town, Purbayan, Sodepur, Kolkata 700110, West Bengal, India ${ }^{b}$ Department of Chemistry, Sister Nivedita University, Action Area I, DG Block, 1/2, New Town, Kolkata, 700156, West Bengal, India.E-mail: camrg@iacs.res.in 


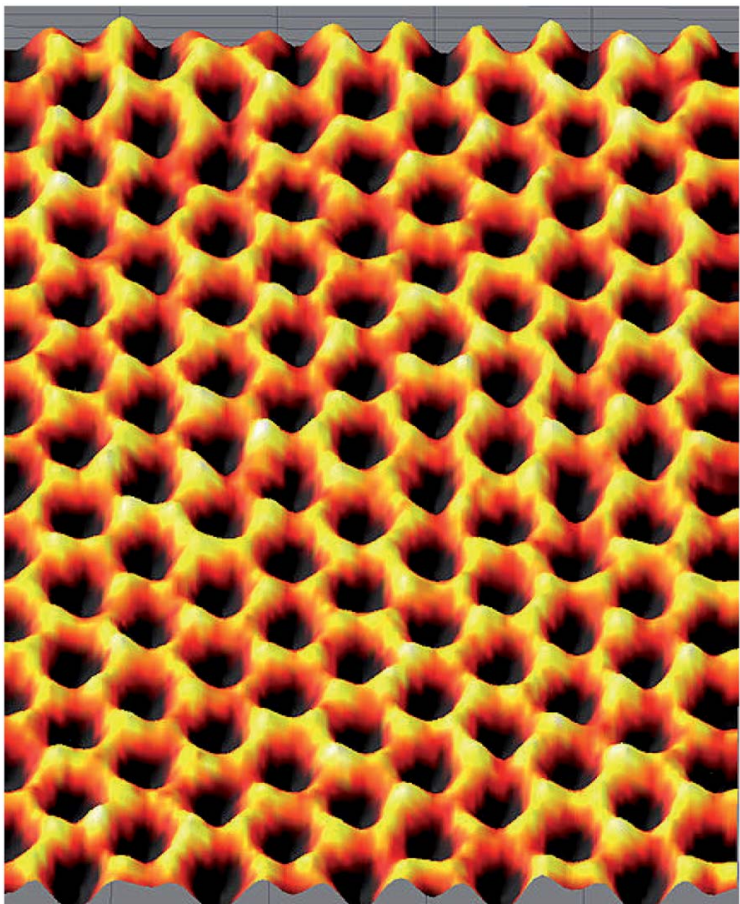

Fig. 1 Honeycomb structure of graphene: scanning probe microscope image [this figure has been adapted/reproduced with permission from https://www.flickr.com/photos/armymaterielcommand/ 6795812766]

$\mathrm{V}^{-1} \mathrm{~s}^{-1}$ (ref. 8-10) have made it suitable for application in electronic devices. Graphene absorbs $2.3 \%$ light over a broad wavelength range for each layer, which makes it transparent and suitable for specific optoelectronic applications. ${ }^{\mathbf{1 1 , 1 2}}$ All these unique properties have allowed people to design lightweight composites with extremely high strength and flexibility and nanocomposites with large surface area and reactivity. Graphene and its composites and nanocomposites have got widespread applications in solar cells, ${ }^{13}$ capacitors,${ }^{14}$ batteries,${ }^{15}$ flexible displays, ${ }^{16}$ water purification systems ${ }^{17,18}$ and biomedical devices. ${ }^{19,20}$

Properties and applications of graphene have been regularly reviewed over the last decade and good numbers of extensive reviews are available on different aspects of graphene in general or in particular. ${ }^{21-23}$ From these reviews, the span of the material can be assumed and the extent to which it has occupied the field of materials science can be estimated. ${ }^{24-30}$ In spite of all these unique properties high production cost of graphene added to its hydrophobic nature and strong tendency to agglomerate or even to be restacked into graphite (due to van der Waals interaction) has rendered its application difficult. To overcome these problems an alternative to graphene has been found out by forming graphene oxide (GO). GO is a monolayer of graphite oxide, which can be obtained by exfoliating graphite oxide into layered sheets through sonication or mechanical stirring. The graphene-based lattice and existence of various oxygencontaining groups (mainly epoxy and hydroxyl groups) endowed GO with ample fascinating properties. ${ }^{24,25}$ Structurally, graphene oxide is very much similar to graphene with its basal plane decorated by oxygen containing groups like epoxy, hydroxyl, carbonyl, etc. (shown in Fig. 2), which act as effective anchoring sites to immobilize various active species.

These oxygen containing functional groups have high affinity for water molecules, which makes graphene oxide
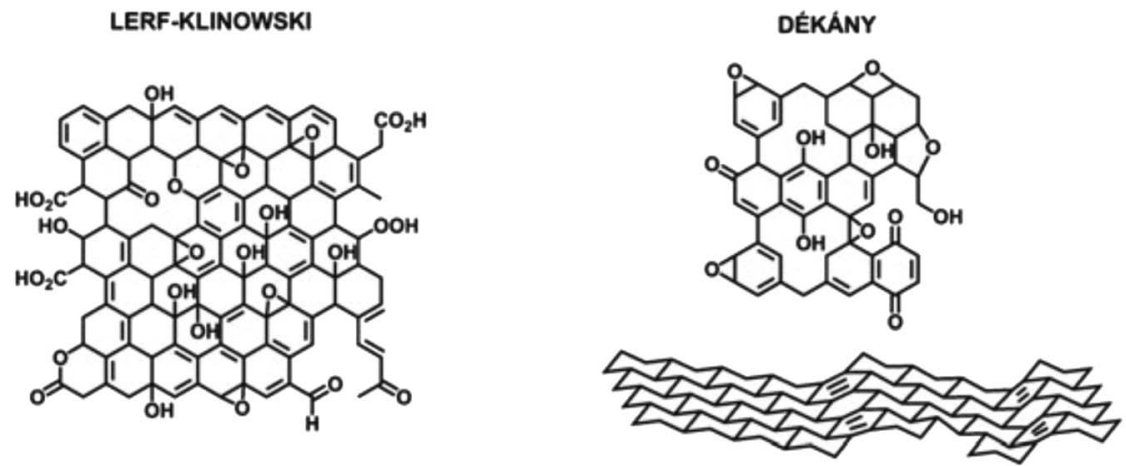

NAKAJIMA-MATSUO

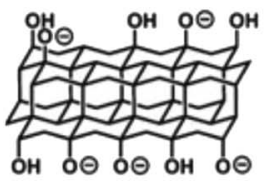

HOFMANN

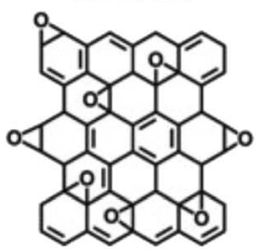

RUESS

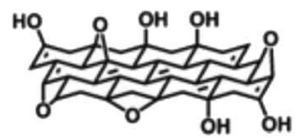

SCHOLZ-BOEHM

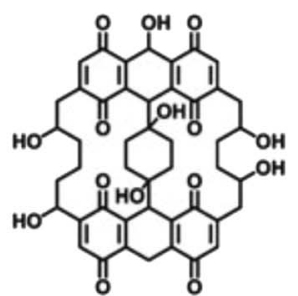

Fig. 2 Different structural aspects of GO including functional groups present [this figure has been reproduced from ref. 32 with permission from RSC, Copyright 2010]. 
Table 1 Overview of Graphene-based materials included in the text

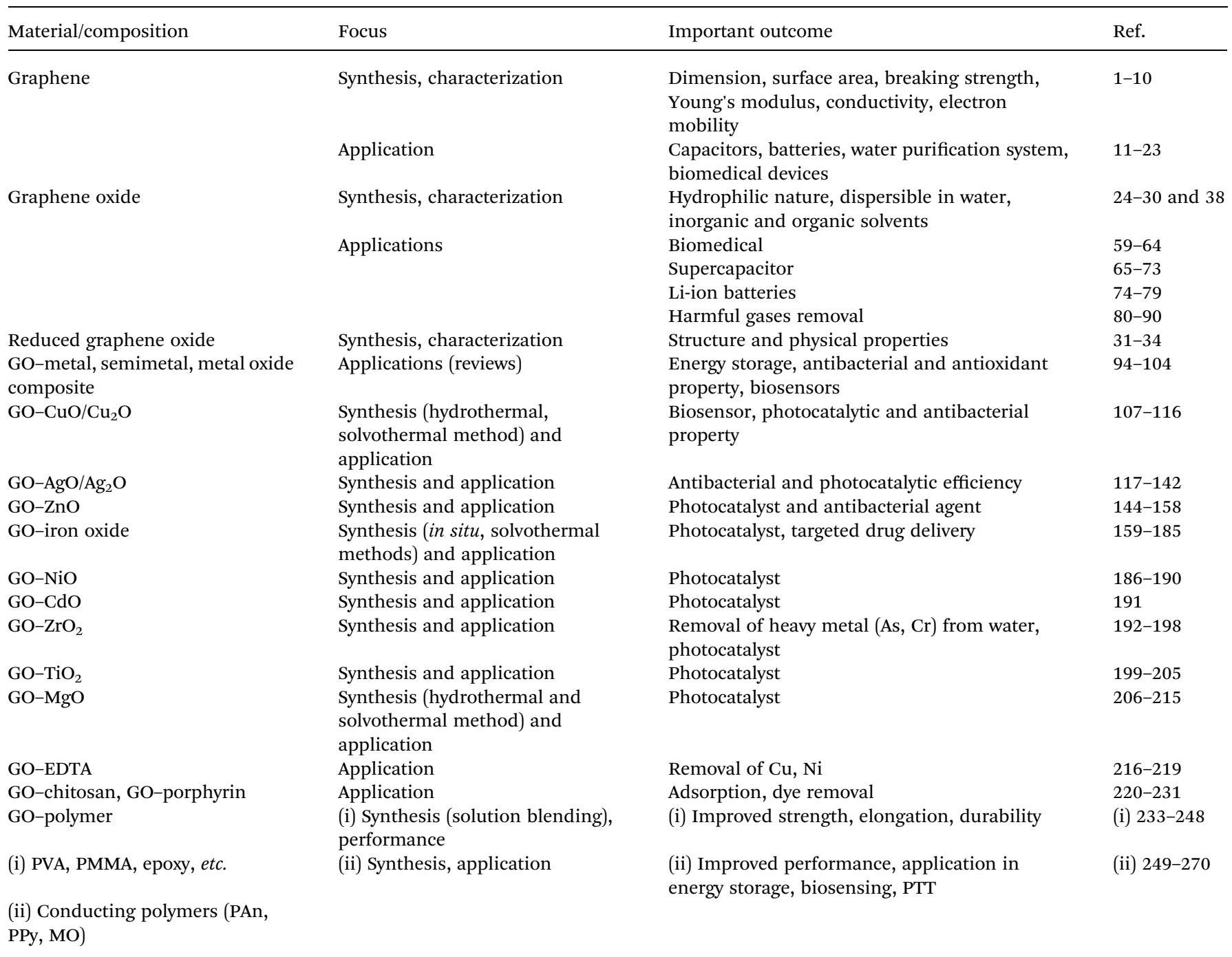

hydrophilic in nature and increases the interlayer distance of graphene oxide. ${ }^{26-28}$ By this way graphene oxide can be easily dispersible in water and other organic and inorganic solvents, ${ }^{29,30}$ few of which are stable for weeks. Furthermore, GO possesses tuneable electronic properties. Typically, GO is insulating due to the large portion of $\mathrm{sp}^{3}$ hybridized carbon atoms bonded with the oxygen-containing groups, which results in very high sheet resistance. However, after reduction, the sheet resistance of reduced GO (namely, rGO) can be degraded by several orders of magnitude, hence transforming the material into a semiconductor or even into a graphene-like semimetal. While rGO is more electrically conductive than GO (has fewer oxidative functional groups on the basal plane), the carrier mobility is substantially lower than that of pristine graphene because of highly distorted $\mathrm{sp}^{3}$ bonds left behind after the reduction step. It has been demonstrated that the band gap of GO can be tailored by controlling the coverage, arrangement, and relative ratio of the epoxy and hydroxyl groups. ${ }^{31-34}$
Therefore a highly attractive solution to get rid of the production cost as well as other drawbacks of graphene while preserving its excellent properties is to use an oxidized precursor such as GO (instead of graphene itself). Obviously, GO became a very attractive material immediately after its discovery and has drawn a large pool of research effort targeting its versatile application. The synthesis technique of GO has been revised from time to time and significant characteristics have also been revealed. On the other hand, GO has been combined with different functional materials to give rise to a series of nanocomposites of diverse nature and application. Based upon their application potential, GO and related nanocomposites have been reviewed several times over the last few years..$^{35,36}$ The different methods of functionalization of GO and applications of the resulting materials have also been reviewed very recently. ${ }^{37}$ However, an updated chronological report on the development of GO based materials viewed from their compositional perspective is not yet available. In the present article, the evolution of this group of materials with respect to their 
composition has been reviewed thoroughly. Starting from the GO itself, the development of different hybrid materials in which metal oxides, metal-organic frameworks, organic ligands and polymers have been combined with GO has been included in the review [Table 1]. Significant properties of the hybrids and their applications have also been mentioned in proper context.

\section{GO at a glance: synthesis, properties and applications}

\subsection{Synthesis}

GO is commonly prepared using the modified Hummers' method. ${ }^{38}$ This method combines chemical functionalization with physical exfoliation through vigorous stirring or sonication of commercially available graphitic precursors. During this procedure, structural defects containing oxygen functional groups decorate the surfaces and edges of the individual sheets of graphene. ${ }^{39}$ The resulting GO nanosheets are naturally functionalized with numerous oxidative functional groups including hydroxyls, epoxides, and carbonyls as mentioned earlier. Due to the extensive oxidation during the modified Hummers' method, GO is turned into an insulating and more hydrophilic material having poor thermal conductivity than graphene. Electrical and thermal conductivity, hydrophobicity and other properties could be partially restored by reducing GO to another form called reduced GO (rGO/RGO). Conversion of graphene to GO and RGO is schematically shown in Fig. 3. Poor thermal and electrical conductivity of GO is accounted for the large portion of oxygen functional groups present in the system, creating a barrier to electron transport as well as creating thermally insulating 'air pockets'. Reduction of GO to RGO partially restores the carbon structure of graphene and its characteristics as well. ${ }^{40}$ Properties of both GO and RGO are, however, largely dependent on the oxidation/reduction process and the nature of the reagents used.

GO has attracted the attention of researchers immediately after its synthesis as works of versatile interest were started using GO instead of graphene itself. The synthesis techniques were also modified in parallel. Jasim et al. ${ }^{41}$ have described the synthesis of graphene oxide from different graphitic materials like graphite powder (GO-p), graphite flakes (GO-f) and ground graphite (GO-g) using a modified Hummers' method and found the effect on the yield and structural characteristics of GO sheets. They found that the GO obtained from graphite powder
(GO-p) shows the largest lateral dimension and maximum efficient yields among all. Kotchey et $a .^{42}$ reported the redox method of preparation of GO films and extensively characterised the same; they introduced a new way of oxidation of graphene oxide catalysed by a combination of horseradish peroxidase (HRP) enzyme and hydrogen peroxide $(\sim 40 \mu \mathrm{M})$. It is found that HRP with its active 'heme' site comes closer to GO than reduced GO (RGO) and preferably binds to the basal plane of graphene oxide compared to the edges; this promotes the oxidation of the basal plane of GO, leading to the formation of holes in the basal plane of GO. Several authors have reported ${ }^{\mathbf{4 3}}$ the preparation of GO sheets by the modified Hummers' method. It was prepared from graphite flakes by the modified Hummers' method and the obtained product was dried at $60{ }^{\circ} \mathrm{C}$ to form GO sheets, which exhibited a very thin lamellar layer structure, good photoresponse in the UV and visible range and excellent thermal stability with increased opportunities for application.

\subsection{Properties}

As the journey with GO went on, different unique properties and relevant applications of GO were found out. ${ }^{\mathbf{4}}$ Besides its general properties GO also displays excellent optical and mechanical properties for a wide landscape of applications. Dutta et al. ${ }^{\mathbf{4 5}}$ for the first time mentioned a broad UV fluorescence of modified $\mathrm{GO}$, which is dependent on the excitation wavelength and $\mathrm{pH}$ of the medium. With the increase in $\mathrm{pH}$ a $32 \mathrm{~nm}$ blue shift occurred when excited at $240 \mathrm{~nm}$ and a $12 \mathrm{~nm}$ blue shift occurred when excited at $280 \mathrm{~nm}$ due to an increase in the value of band gap. This phenomenon can be applied in optoelectronic devices and $\mathrm{pH}$ sensing materials. The optical transmittance of GO films can be regularly tuned by varying the film thickness or the extent of reduction. ${ }^{\mathbf{4 6}}$ Generally, an aqueous suspension of GO films is dark brown to light yellow in colour, depending on the concentration, whereas that of reduced graphene oxide (RGO) thin films (with a thickness less than $30 \mathrm{~nm}$ ) is semitransparent. ${ }^{47}$ The optical absorption of GO is dominated by the $\pi-\pi *$ transitions, which gives rise to an absorption peak between 225 and $275 \mathrm{~nm}(4.5-5.5 \mathrm{eV})$. During reduction, the strength of optical absorption increases, while the plasmon peak shifts to $\sim 270 \mathrm{~nm}$, reflecting an increased $\pi$-electron concentration and structural ordering. ${ }^{48}$ Mechanical properties of GO depend on the specifics of sample viz. the degree of oxidation and thickness. ${ }^{49-52}$ The reported Young's modulus

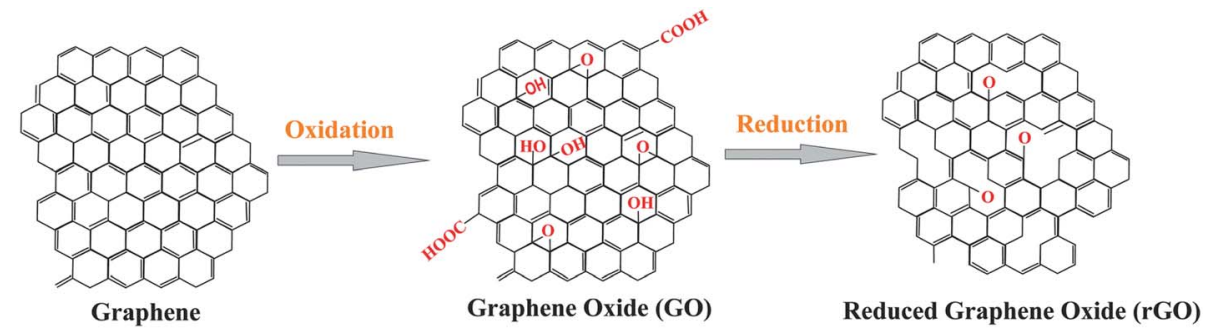

Fig. 3 Structure and relationship between graphene-based materials: graphene, GO and rGO [this figure has been reproduced with permission from 'Nanografi', Copyright 2021]. 
and breaking strength of GO sheets show a wide range of distributions of 6-42 GPa and 76-293 MPa, respectively. ${ }^{53}$ More details about the fundamental physical properties of GO can be found in a review article and a book. ${ }^{\mathbf{4 4 , 5 4}}$ Spectral characteristics of GO have also been investigated by some researchers. Luo et al. ${ }^{55}$ reported a visible broad photoluminescence peak of solid graphene oxide and the changes in photoluminescence with reduction of GO were accounted for the change in band gap and $\pi$-electron removal of GO. Konkena et al. ${ }^{56}$ reported that fluorescence spectra of dispersion (aqueous) of GO are pH dependent; for example, at $\mathrm{pH}$ 2.5, 5.5, 7.5 and 10.5 emission peaks were observed at $550 \mathrm{~nm}$ (as no functional groups ionised), $428 \mathrm{~nm}$ (due to ionisation of the carboxylic group), $515 \mathrm{~nm}$ (emission from $\mathrm{COO}^{-}$groups) and $470 \mathrm{~nm}$ (due to ionisation of phenolic groups) respectively. The reason for this variation originates from the oxygen containing groups present in GO and ionization of carboxylic and hydroxyl groups. Shang et al. ${ }^{57}$ reported the reason for fluorescence of aqueous dispersion of GO as the effect of electron-hole recombination and electronic transition between oxidized carbon (carboxylic and carbonyl) and non-oxidized carbon. pH-dependent fluorescence spectra of GO as a result of the presence of quasi-molecular fluorophores were reported by Galande et al. ${ }^{58}$

\subsection{Applications}

2.3.1. Biomedical. Fascinating properties of GO and GObased composites have been exploited for applications in different sectors viz. energy storage/conversion, environment protection, medicine and biomedical fields. Wu et al. ${ }^{59}$ in their review described in detail the applications of GO specifically in nanomedicine, which include drug delivery, antibacterial activity, cytotoxicity, cancer therapy, tissue engineering, etc. Large surface area (which determines the loading capacity), biocompatibility and low toxicity are three advantages of GO on which the drug delivery system depends; these properties are suitable for clinical tests and easy release of drugs in a controlled manner to target tumour cells achieving success of therapy. Moreover GO can protect DNA from enzymatic cleavage and thus is applied in gene delivery. It is also used to detect cancer cells by different imaging techniques namely Magnetic Resonance Imaging (MRI) and Computed Tomography (CT) imaging. Initially the researchers used to follow the colony counting method, which determines the number of bacteria killed by GONPs for monitoring the anti-bacterial activity of the GO hybrids. Krishnamoorthy et al. ${ }^{60}$ prepared GO nano-sheets and found their antibacterial activity by this method. The mechanism of antibacterial activity was determined by measuring the formation of reactive oxygen species (ROS) by electron spin resonance (ESR) spectroscopy and it was found that the prepared nanosheets were more efficient antibacterial agents towards Gram positive bacteria than Gram negative bacteria. This result indicates the nanosheets to be used in the field of nanomedicine in future.

Later on the antibacterial activity of GO was revealed using spectrophotometry by some researchers such as Nanda et al. ${ }^{\mathbf{6 1}}$ who used Raman spectroscopy to describe the mechanism of interaction of GO with the bacteria Escherichia coli (E. coli) and Enterococcus faecalis (EF). From their studies it was found that GO can trap the inner and outer membrane of the bacterial cell, which results in an increase in adenine and protein concentration in the culture medium due to bacterial death. As a result the Raman band intensified and this way the antibacterial activity of GO was determined. Similarly Ning Zhang et al. ${ }^{62}$ in a contemporary work used mass spectroscopy to check the antibacterial activity of GO instead of the time consuming colony counting method. They determined the mass spectra of extracted metabolites of different bacterial strains of $E$. coli with GO before and after incubation. They correlated the metabolism disorder of bacteria that is the release of phosphatidyl ethanolamine, phosphatidyl glycerol and glutathione, which indicates the bacterial death and antibacterial activity of GO. Gupta et $a l .{ }^{63}$ on the other hand investigated the antibacterial activity of GO NPs against Gram positive and Gram negative bacteria Bacillus subtilis (BS), Staphylococcus epidermidis (SE), Pseudomonas aeruginosa (PA) and Enterobacter aerogenes (EA). They determined the antibacterial activity of GO $\left(100 \mu \mathrm{g} \mathrm{ml} \mathrm{ml}^{-1}\right)$ by measuring the zone of inhibition and compared the value with the same concentration of the standard antibiotic drug streptomycin. The highest inhibition zone $(12 \mathrm{~mm})$ is observed when GO is treated against EA and SE, whereas a lower value of inhibition zone is found in the case of BS $(9 \mathrm{~mm})$ and PA (7 $\mathrm{mm}$ ). They proposed the formation of hydrogen bonds between lipopolysaccharides of the bacterial cell and oxygen containing functional groups of GO as the reason for cytotoxicity of GO-NPs against bacteria, which resist the nutrient uptake of the bacteria cell, resulting in the damage and death of the cell. Barbolina et al. ${ }^{64}$ explored a new factor on which the antibacterial activity of GO was dependent. They found that the purity of GO plays a very important role in its antibacterial activity; for example, a highly purified or gently washed GO sample had no effect on the inhibition or stimulation of growth of $E$. coli or SA bacteria of concentration $1 \mathrm{mg} \mathrm{ml}^{-1}$. However, an insufficiently purified GO sample mainly due to the chemical impurities and acidic $\mathrm{pH}$ showed significant antibacterial activity. Moreover in their studies they found no effects of GO on the growth of $E$. coli when the lateral sizes of GO flakes are varied. So, they suggested a standard protocol of washing the GO sample to study the biological properties and to avoid erroneous results.

\subsubsection{Energy storage}

(a) Hydrogen storage. There have also been a lot of efforts in developing GO-based materials for various kinds of $\mathrm{Li}$ batteries and supercapacitors, whereas there are also certain activities on hydrogen generation/storage as well as purification of water and air using GO-based materials. Owing to its cleanliness and renewable property hydrogen energy and its storage have become very important. The storage happens in two ways: (i) chemical storage, i.e. by forming hydrides and (ii) physical storage, i.e. by adsorption. In the former method storage content is high but release is unsatisfactory, while in the latter method storage capacity is poor. ${ }^{65}$ To overcome these deficiencies graphene and graphene derivatives (GO) played vital roles. Guo et al. ${ }^{66}$ reported hierarchical graphene with micropores, mesopores and macropores of $0.8 \mathrm{~nm}, 4 \mathrm{~nm}$ and $50 \mathrm{~nm}$, respectively, 
which showed an enhanced hydrogen storage capacity compared to that of pristine graphene sheets reported by $\mathrm{S}$. Patchkovskii et al. ${ }^{67}$ Storage of molecular hydrogen into the GO frameworks was reported by Chan et al. ${ }^{68}$ In their study different GO frameworks named GOF-6, GOF-28, GOF-66 and GOF-120 have shown hydrogen uptake of $c a .0,6.33,2$, and 1.68 (wt\%) respectively. Maximum hydrogen storage capacity as shown by GOF-28 is accounted for by the presence of benzene diboronic acid between the graphene sheets; the latter provides porous spaces and mechanical support to the molecular structure as well as higher binding energy to the stored hydrogen molecules compared to the other GO frameworks.

The hydrogen storage capacity was improved further when ${ }^{69}$ thermally annealed multilayered GO with $6.5 \AA$ interlayer distance was used under an optimum condition. Similarly Kim et l. $^{70}$ reported that the hydrogen storage capacity of GO and RGO (surface pore size $6.7 \AA$ ) was enhanced to $5 \%$ upon annealing at $\sim 300$ to $600{ }^{\circ} \mathrm{C}(\mathrm{GO})$ and $400{ }^{\circ} \mathrm{C}$ (rGO). Moreover decorations of a metal on the GO surface where lot of metal cations and oxygen anions are present also increase the hydrogen storage capacity and hydrogen binding energy. Chu Chen et al. ${ }^{71}$ reported the $\mathrm{Mg}$-doped GO composite for hydrogen storage. Usually an electric field is produced around the metal ion and oxygen to adsorb hydrogen molecules; the metal site is more active to adsorb hydrogen than oxygen sites and the hydroxyl group present on the GO surface lowers the hydrogen storage due to formation of water. In this study hydroxyl is reduced by $\mathrm{Mg}$ metal and the $-(\mathrm{C}-\mathrm{O})-\mathrm{Mg}$ bond increases hydrogen storage. When eight hydrogen molecules are adsorbed by Mg-doped GO, a high value of (5.3 wt\%) hydrogen storage is reached at $200 \mathrm{~K}$ without external pressure. Wang et $a .^{72-74}$ reported that GO decorated with Pd enhanced the hydrogen storage capacity compared to pristine GO. Moreover transition metal oxides dispersed on $\mathrm{GO}^{73}$ like $\mathrm{GO} / \mathrm{V}_{2} \mathrm{O}_{5}$ (1.36 wt\%) and $\mathrm{GO} / \mathrm{TiO}_{2}(1.26 \mathrm{wt} \%)$ also have increased the hydrogen storage capacity compared to that for bare $\mathrm{V}_{2} \mathrm{O}_{5}$ $(0.16 \mathrm{wt} \%)$ and $\mathrm{TiO}_{2}(0.58 \mathrm{wt} \%)$. The $\mathrm{Ti}-\mathrm{GO}$ composite was also reported, in which the hydroxyl group of GO was combined with metallic Ti; the composite exhibited an increase in the hydrogen storage capacity.

(b) Li ion batteries. GO and rGO based composite materials can act as a cathode and anode and show good electrochemical performances in lithium ion battery, which is an important energy storage device. $\mathrm{Mn}_{3} \mathrm{O}_{4} / \mathrm{RGO}$ and $\mathrm{Zn}_{2} \mathrm{GeO}_{4} / \mathrm{GO}$ composites for example show large specific capacity, and good cycling stability. ${ }^{75,76}$ On the other hand due to small sizes and synergetic effects the FeS/RGO nanocomposite shows better conductivity than bare FeS-NPs. ${ }^{77}$ Moreover due to the structural defects and the oxygen containing functional groups present in GO and RGO, the latter shows high adsorption of sulphur, which leads to high reversible capacities of Lithium sulphur batteries. ${ }^{78,79}$ GO based materials, e.g. $\mathrm{GO} / \mathrm{MnO}_{2}$, can also be used as good supercapacitors and show higher $(84.1 \%)$ retention of super capacitance than pure $\mathrm{MnO}_{2}$ nanoparticles (69\%). ${ }^{\mathbf{8 0}}$

2.3.2. Harmful gas removal. Owing to the large surface area and presence of oxygen containing groups, GO itself and GObased materials can capture and entrap $\mathrm{CO}_{2}$ and a few other gases in their structure; this property has been successfully utilized by scientists to design materials capable of removing harmful gases. A good portion of the related literature has been covered by M. Seredych et al., who had started the work by revealing the ammonia absorption capability of exfoliated GO itself. ${ }^{81}$ They have shown that $\mathrm{NH}_{3}$ gas is adsorbed on the GO surface (dry and moist) under ambient conditions through intercalation between layers as well as via acid-base reaction between carboxylic acid and $\mathrm{NH}_{3}$. Maximum adsorption was achieved under dry conditions with little amount of water, which favours acid-base reaction via dissociation of carboxylic groups. In the presence of a large amount of water, adsorbed ammonia has to compete with water for active sites which decreases the ammonia absorption capacity. Later on the same group of investigators reported the fabrication of a series of materials in which GO has been combined with oxides and hydroxides of $\mathrm{Mn}, \mathrm{Zn}$ and $\mathrm{Zr}$ and different metal-organic frameworks (MOF) for efficient adsorption of $\mathrm{SO}_{2}, \mathrm{CO}, \mathrm{CO}_{2}, \mathrm{NO}_{2}$ and $\mathrm{H}_{2} \mathrm{~S}^{82-85}$

T. Yumura et al. ${ }^{86}$ used density functional theory to investigate the energetics of the migration of carbon dioxide within graphene oxide (hydrated or anhydrated). This study revealed that when carbon dioxide enters into anhydrous GO, repulsive electrostatic interaction takes place, which increases the interlayer spacing of GO layers; this repulsive interaction is lowered by insertion of water into GO containing carbon dioxide due to the presence of attractive hydrogen bonds among water molecules. In a different approach L. Wang et al. ${ }^{87}$ have used DFT based techniques to model GO decorated with Ti for adsorption of CO. After studying the adsorption properties of a group of four gases viz. $\mathrm{CH}_{4}, \mathrm{~N}_{2}, \mathrm{CO}_{2}$ and $\mathrm{CO}$, they have shown maximum adsorption energy and adsorption concentration for $\mathrm{CO}$ ( $70 \mathrm{~kJ} \mathrm{~mol}^{-1}$ and $\sim 7 \mathrm{mmol} \mathrm{g}^{-1}$ ) on Ti sites, which is much above those of the other three gases. This was attributed to the $\mathrm{p}^{-}$ d hybridization between CO molecules and Ti. Similarly Chen et $a{ }^{88}$ have reported DFT based techniques to simulate the adsorption of acidic gases like $\mathrm{CO}_{2}, \mathrm{SO}_{2}$, and $\mathrm{NO}_{2}$ on $\mathrm{GO}$ decorated with light metals ( $\mathrm{Li}$ and $\mathrm{Al}$ ). In contrast to $\mathrm{GO} / \mathrm{Ti}, \mathrm{GO} /$ Li exhibits a comparable adsorption ability and binding energy of acidic gases, but a much smaller interaction with $\mathrm{O}_{2}$. 2.85$3.98 \mathrm{eV}$ lowering in binding energy is observed for $\mathrm{O}_{2}$ which implies that $\mathrm{GO} / \mathrm{Li}$ and $\mathrm{GO} / \mathrm{Al}$ may be useful and promising for collection and filtration of exhaust gases. Moreover GO has adsorption capacity of different heavy metal (Cd, Co, Au, Pd, and $\mathrm{Pt}$ ) pollutants from waste water. Zhao et al. ${ }^{89}$ showed that adsorption of $\mathrm{Cd}$ (II) and $\mathrm{Co}$ (II) on GO nanosheets is maximum at $\mathrm{pH} 6.0 \pm 0.1$ and at $303 \mathrm{~K}$ due to the presence of oxygeneous groups, which can be applied for cleaning up of heavy metals as pollutants.

In addition to gaseous and metallic pollutants GO can also remove different organic contaminants, e.g. dyes and pathogens, from water. S. T. Yang et al. ${ }^{\mathbf{9 0}}$ reported excellent dye (methylene blue, MB) removal efficiency of GO from aqueous solution at low temperature and high $\mathrm{pH}$ of the medium, which can be applied for treating contaminated water and industrial effluent. In another report, G. K. Ramesha et al. ${ }^{91}$ showed the adsorption efficiency of Exfoliated GO (EGO) and reduced GO 
(rGO) towards different cationic and anionic dyes such as Rhodamine B (RB), MB, Methyl Orange (MO) and Methyl Violet (MV) from aqueous solution. It is seen that EGO having hydroxyl, epoxy, ketone and carboxyl groups in its basal as well as edge planes is more effective towards cationic dyes, while rGO is an efficient adsorbent towards anionic dyes.

\section{GO-metal oxide (MO) based nanocomposites}

Metallic and metal oxide nanoparticles (NP) having high surface area, unique electrical and optical properties are also very important inclusions in materials science. They have been applied in various fields like catalysis, energy storage, chemical sensing, and nanomedicine and also as antibacterial agents. It is known that GO can be exfoliated under appropriate treatment, forming quasi-two-dimensional carbon nanosheets. These exfoliated GO sheets possess large surface area and thus may act as potential support materials to load NPs. In addition, the oxygenated functional groups in GO can also be utilized as nucleation centres to anchor NPs. Therefore, it is feasible to synthesize graphite oxide-nanoparticle composites (GONP) by depositing the NPs onto GO sheets, leading to a possible integration of the properties of the two components (GO and NPs) in the new materials. Numerous composites of graphene and GO with a spectrum of metal and metal oxide (MO) nanoparticles viz. $\mathrm{ZnO}, \mathrm{CuO}, \mathrm{TiO}_{2}, \mathrm{MgO}, \mathrm{NiO}, \mathrm{ZrO}_{2}$, etc. have so far been synthesized. Very often it is found that some metal oxides acquire improved reactivity in nanostructures compared to the bulk phase. ${ }^{92}$ At the same time these NPs can bring about modifications to the properties of preformed nanostructures such as zeolite, montmorillonite (MMT) clay, and also to graphene and GO. Structure and properties of the graphene and GO nanocomposites with intercalation of metal and metal oxide NPs have created a separate section in the unit of graphene based materials.

\subsection{Applications of GO-MO in general}

Different synthesis techniques, properties and applications of graphene/GO based hybrid materials have been regularly upgraded and reviewed by different groups of scientists. ${ }^{93-101}$ It's quite obvious that the frontier of the graphene based nanocomposites is ever-expanding, due to their uniqueness in combining complementary properties of a wide variety of the building blocks for targeted applications. All these applications could be broadly classified into three major sectors (with several subsections of each) viz. water purification, pharmaceutical and energy storage applications as collectively shown in Fig. 4. In the present article the current status of the GO based materials with diverse composition has been reviewed; the role of the individual composites towards different applications will be discussed in proper context.

Due to large surface area GO has high drug loading capacity and presence of several groups on the plane of GO enhanced the possibilities of forming bonds with different drug molecules like folic acid, transferrin, doxorubicin (an anticancer drug), etc.
Moreover GO with the drug can be applied to targeted drug delivery systems so that it becomes more effective on affected cells (cancer or tumour) than normal healthy cells. ${ }^{93}$ Graphene based materials (GM) themselves have demonstrated a broad range of antibacterial activity toward bacteria, fungi and viruses. These antibacterial activities are attributed mainly to the direct physicochemical interaction between GMs and bacteria that causes the destruction of cellular components, viz. proteins, lipids, and nucleic acids. In fact, GMs have a high affinity for the membrane proteoglycans where they accumulate, leading to membrane damage. Similarly they can also interact with bacteria RNA/DNA, interrupting their replication. Moreover, GMs can indirectly determine bacterial death by activating the inflammatory cascade due to active species generation after entering in the physiological environment. ${ }^{94}$ All these activities of GO/GM itself are favoured by the embedded MO-NP via the synergistic effect of GO-MO combination, resulting in more effective antibacterial activity in the latter. ${ }^{95-97}$ For example in $\mathrm{GO}-\mathrm{TiO}_{2}$ the antimicrobial activity can be derived using various mechanisms viz. (i) electron-hole pair generation on the $\mathrm{TiO}_{2}$ surface, via the reaction of photogenerated holes with the adsorbed $\mathrm{H}_{2} \mathrm{O}$ or $-\mathrm{OH}$, (ii) producing highly reactive hydroxyl radicals, and (iii) destruction of microorganisms by active oxygen species, attached to the $\mathrm{TiO}_{2}$ surface. In GO-ZnO, on the other hand, the antibacterial mechanism may take place through two pathways: (i) Reactive Oxygen Species (ROS) production and (ii) the interruption of the membrane and cellular functions as a result of accumulation of ZnNP on the bacterial surface and/or inside the bacterial cytoplasm. Richtera et al. ${ }^{97}$ have prepared a GO based metal/ semimetal ( $\mathrm{Mn}, \mathrm{Zn}, \mathrm{Ag}, \mathrm{Cu}$, and $\mathrm{Se}$ ) nanocomposite to exhibit an antimicrobial effect on different bacterial strains such as Staphylococcus aureus (SA), E. coli and methicillin-resistant SA (MRSA). Identical concentrations $(300 \mu \mathrm{M})$ of the composites were applied to all strains, out of which GO-Se nanocomposites were found to show maximum inhibition (87.4\%) against the growth of SA. With the increase in concentration of $\mathrm{GO} / \mathrm{Se}$ composite increasing antibacterial effect on Gram positive bacteria (SA and MRSA) was found but interestingly in the case of Gram negative bacteria ( $E$. coli) the antibacterial effect was found at the highest applied concentration. With the help of these antibacterial studies researchers found applications of GO in nanomedicine, drug delivery and also for designing antibiotics. In a very recent report Ahmed et al. ${ }^{98}$ synthesised a GO-metal oxide $\left(\mathrm{TiO}_{2}\right)$ nanocomposite and showed its scavenging ability/anti-oxidant property by either donating electrons or giving hydrogen atoms to react with 2,2-diphenyl-1picrylhydrazyl (DPPH) free radicals; they also explored the anti-inflammatory property for the first time by incorporation of metal oxide on GO and suggested its application in improving protein denaturation inhibition ability.

Most of the semiconductor NPs exhibit high photosensitivity but poor visible-light response, due to which their photocatalytic efficiency is not satisfactory. Because of their higher band gap excitation of electrons from the valence band to the conduction band requires high energy so that photoexcitation in those materials is not possible in the visible light region. 


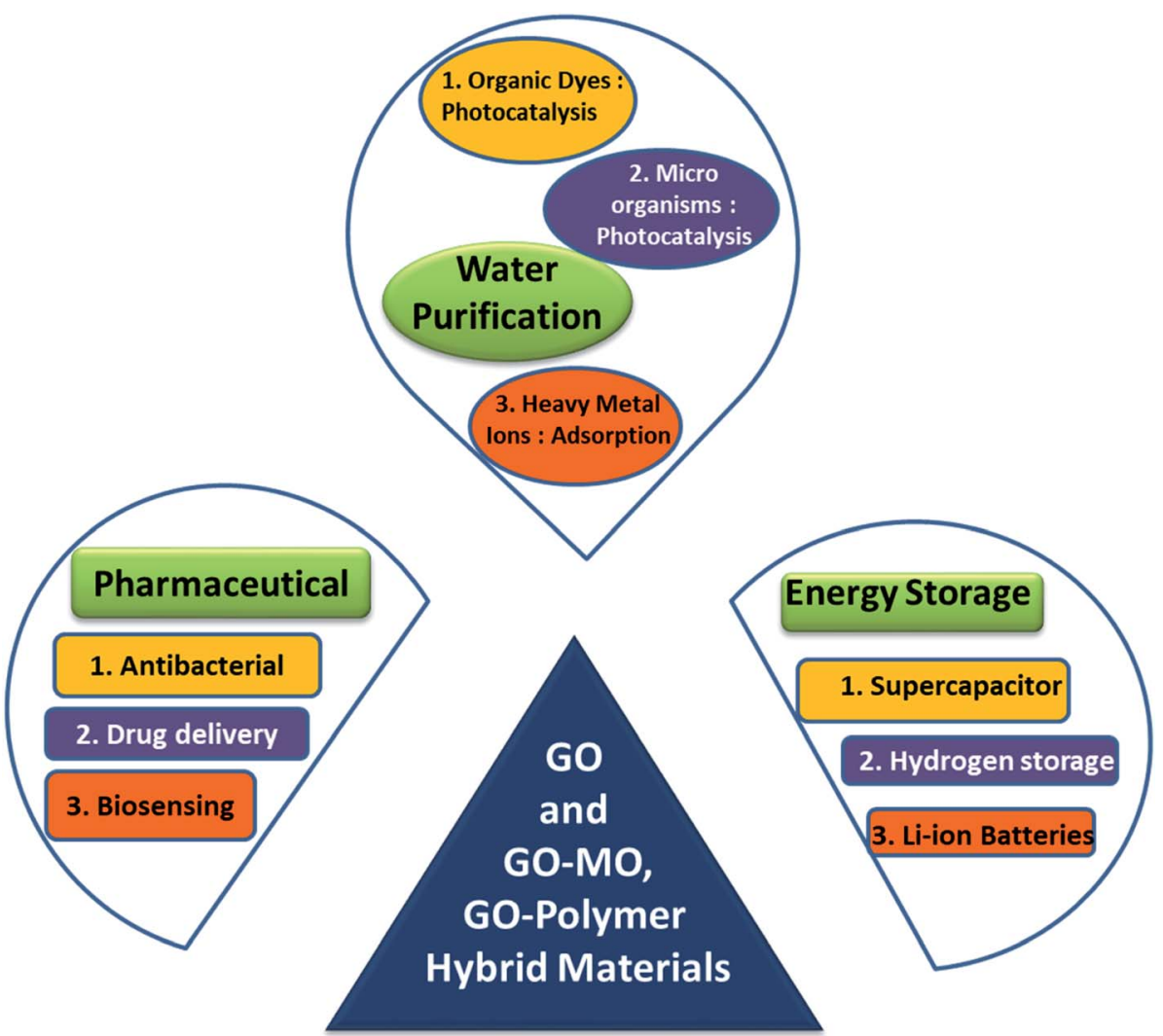

Fig. 4 Three most important groups of applications of GO and GO-MO hybrid materials at a glance.

Efficient intercalation of various tuneable band gaps semi- heterogeneous catalysis especially in photocatalytic degradaconductor NP in GO shows a significant enhancement of pho- tion of organic dyes.99,100 Both GO and rGO can be utilized to tocatalytic efficiency of the semiconductor $\mathrm{NP}(\mathrm{CuO}, \mathrm{ZnO}, \mathrm{MgO}, \quad$ fabricate photocatalysts via formation of some binary or ternary $\mathrm{TiO}_{2}, \mathrm{ZrO}_{2}$, etc.) and successful use of the hybrid materials in heterojunctions. Embedded MO-NP very often undergoes

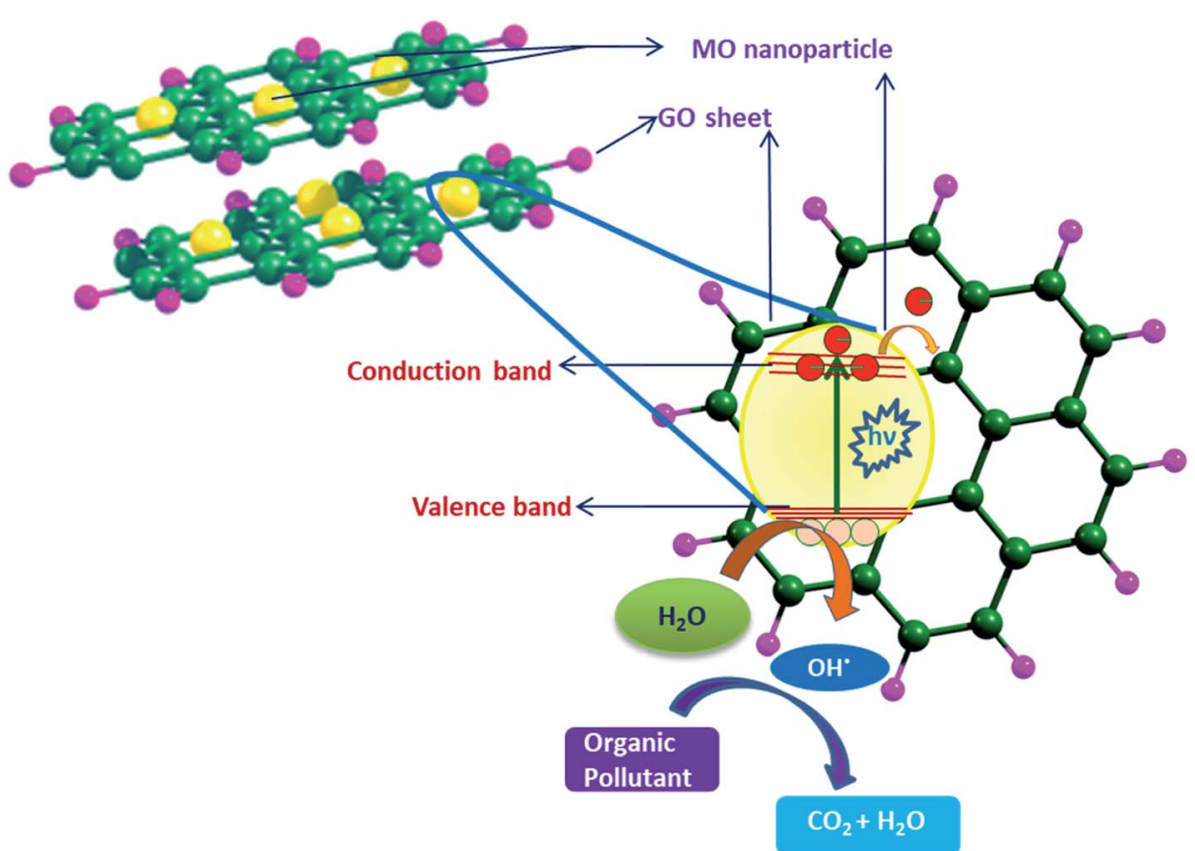

Fig. 5 Synergistic effect exhibited by the GO-MO nanocomposite and the photocatalytic degradation of organic pollutants. 
electron transfer to the support GO matrix under UV-vis radiation; this interaction creates free radicals, which can result in degradation of organic molecules. Owing to this synergistic effect between the components, as shown schematically in Fig. 5, these nanocomposites possess unique electronic, photocatalytic and optoelectronic properties that have attracted significant attention over the last few years. Development of such nanocomposites and their utilization in photo catalytic degradation of some toxic organic dyes/molecules for water depollution have been reported by different authors, ${ }^{\mathbf{1 0 1}, 102}$ details of which will be discussed in respective sections.

On the other hand fabrication of chemical sensors, electrochemical biosensors and energy storage devices has also been possible with GO/M and GO/MO hybrid materials, representative examples of which are cited ${ }^{\mathbf{1 0 3 - 1 0 6}}$ here. An interesting report was published by Wei Cui et al. ${ }^{105}$ describing the fabrication strategy of an 'artificial nacre' via cross linking of GO sheets by dopamine. The nacre prepared by an evaporation-induced process exhibits tensile strength 1.5 times and toughness twice that of natural nacre along with its excellent electrical conductivity. This type of material with excellent strength and toughness can be widely used in aerospace as well as in development of artificial muscles, supercapacitors, etc. Apart from modifying the properties, the NPs also act as stabilizers against the aggregation of the graphene layers. Continuous efforts for seeking new strategies to synthesize graphene-based nanocomposites are therefore indispensable. Henceforth the discussion will be continued with the development of individual GO-MO nanocomposites.

\subsection{GO-CuO nanocomposites}

Among all metal oxides $\mathrm{CuO}$ has been reported to be one of the best metal oxides that can be grown on graphene sheets. $\mathrm{CuO}$ is a narrow band gap $\left(E_{\mathrm{g}} \sim 1.2 \mathrm{eV}\right)$, p-type semiconductor having large surface area, ability to promote electron transfer reaction, excellent solar light absorbance, photocatalytic properties and good electrochemical activity. It has manifold applications in solar energy transformation, electronics, sensors, batteries, etc. Initially chemical synthesis and microwave assisted techniques were followed for synthesis of highly reduced graphene oxide (HRG)-CuO hybrids where GO (HRG) was a unique support material to prevent the breakdown of the $\mathrm{CuO}\left(\right.$ or $\left.\mathrm{Cu}_{2} \mathrm{O}\right)$ anode in high performance Lithium Ion Batteries (LIB) ${ }^{75,76,107}$ Later on facile hydrothermal synthesis techniques were introduced to hybridize graphitic materials with $\mathrm{CuO}$ and the resulting composites were found to offer efficient catalytic and biosensing (glucose sensing) activity. ${ }^{108}$ Zhu et al. ${ }^{107}$ were the first to report a simple (template free) chemical technique for preparation of GO-CuO nanocomposites in water/isopropanol mixed solvent. They could obtain well-ordered nanocomposites with spherical and spindle shaped $\mathrm{CuO}$ nanoparticles (diameter 40$60 \mathrm{~nm}$ ) decorating the GO surface. Intercalation or adsorption of $\mathrm{Cu}^{2+}$ on $\mathrm{GO}$ sheets followed by the growth of $\mathrm{CuO}$ leading to the exfoliation of GO is the underlying mechanism behind the nanocomposite formation. The material exhibited excellent catalytic activity for thermal decomposition of ammonium perchlorate. A similar work was also published by A. Pendashteh et al. ${ }^{\mathbf{1 0 8}}$ who used the sonochemical precipitation method followed by thermal treatment to grow $\mathrm{CuO}$ nanoparticles on GO sheets. The composite was observed to have improved supercapacitive behavior and lower charge transfer resistance than its components in terms of cycle ability and rate capability. It also shows better specific capacitance $\left(245 \mathrm{~F} \mathrm{~g}^{-1}\right)$ at a current density of $0.1 \mathrm{~A} \mathrm{~g}^{-1}$ compared to the pure components $(125 \mathrm{~F}$ $\mathrm{g}^{-1}$ for $\mathrm{CuO}$ and $120 \mathrm{~F} \mathrm{~g}^{-1}$ for GO). In a contemporary work the hydrothermal technique (in which $\mathrm{CuO}$ NPs were prepared at $120{ }^{\circ} \mathrm{C}, 150{ }^{\circ} \mathrm{C}$ and at $180{ }^{\circ} \mathrm{C}$ for $10 \mathrm{~h}$ ) was introduced by Song et al. ${ }^{109}$ who prepared GO-CuO nanocomposites with different fractions of loading of CuO NPs. They investigated the influence of hydrothermal temperature, GO sheet, and fraction of $\mathrm{CuO}$ on the particle size and structure of $\mathrm{CuO}$ as well as biosensing activity of the composite in detail. The growth of the CuO NPs was partly prevented by the presence of GO, which was helpful to their monodispersion. The as-prepared samples were used to construct nonenzymatic glucose sensors, with the $\mathrm{CuO} / \mathrm{GO}$ modified electrodes that exhibited greater potential for biosensing. The optimal $\mathrm{CuO} / \mathrm{GO}$ composite was found to exhibit high sensitivity and a larger linear range compared to the other samples and also showed high stability, good reproducibility, excellent selectivity, and measurement accuracy in vitro and also in vivo. The improved sensing properties for $\mathrm{CuO} / \mathrm{GO}$ (compared to pure $\mathrm{CuO}$ ) could be attributed to the increased electroactive surface area of CuO-NPs on GO sheets and the synergistic effect of $\mathrm{CuO}$ NPs and GO. Schematic representation of the construction of the biosensor and its amperometric response to glucose are shown in Fig. 6.

Pseudomonas syringae pv. tomato (Pst) is a bacterium that causes bacterial speck disease of tomatoes and destroys huge production of tomatoes every year. In the year 2017 a group of researchers Yadong Li et al. ${ }^{\mathbf{1 1 0}}$ found antibacterial activity in GO-CuO nanocomposites against Pst. They compared the activity of the prepared nanocomposite with a reference Kocide 3000 and found that GO-CuO NPs are devoid of phytotoxicity and were a 16 times more efficient antibacterial agent than Kocide 3000. From experiments it is seen that the nanocomposite damaged the bacterial cell structure, reduced the DNA content, and increased the reactive oxygen species level.

In a contemporary work S. R. Kirankumar et al. ${ }^{\mathbf{1 1 1}}$ prepared a GO-CuO nanocomposite (NC) via the hydrothermal method. They prepared a bare carbon paste electrode (BCPE) by mixing graphite powder and silicone oil and modified carbon paste electrode (MCPE) by mixing NCS with graphite powder and silicone oil. The NCS shows remarkable reproducibility of the voltammetric response after 20 successive cyclic voltammetric scans. The MCPE can be used to construct simple electrochemical devices for the diagnosis of dopamine (DA) deficiency via observation of oxidation peak potentials of DA at the BCPE and MCPE. Antibacterial activity of the prepared NCS was also examined against different pathogens like SA, BS (Gram positive bacteria), E. coli (Gram negative bacteria) and strains of fungi ( $A$. flavus and C. albicans). It was further observed that the NCS is very toxic to human cancer cells but non-toxic to normal cells. From these works it is obvious that electrochemical response of 


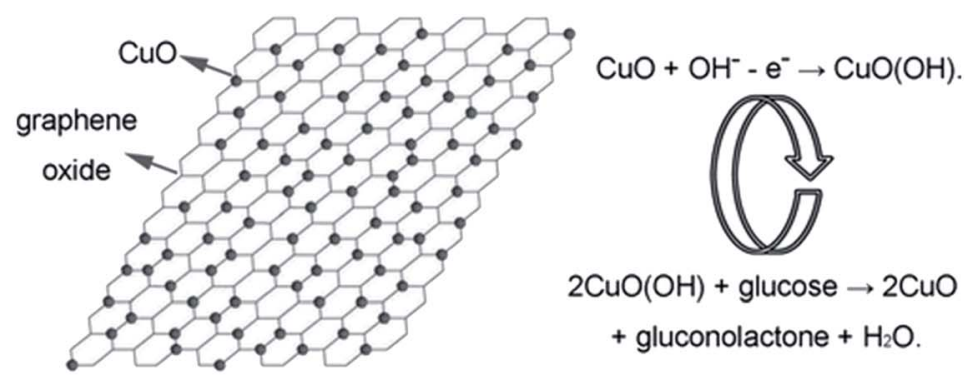

(A)
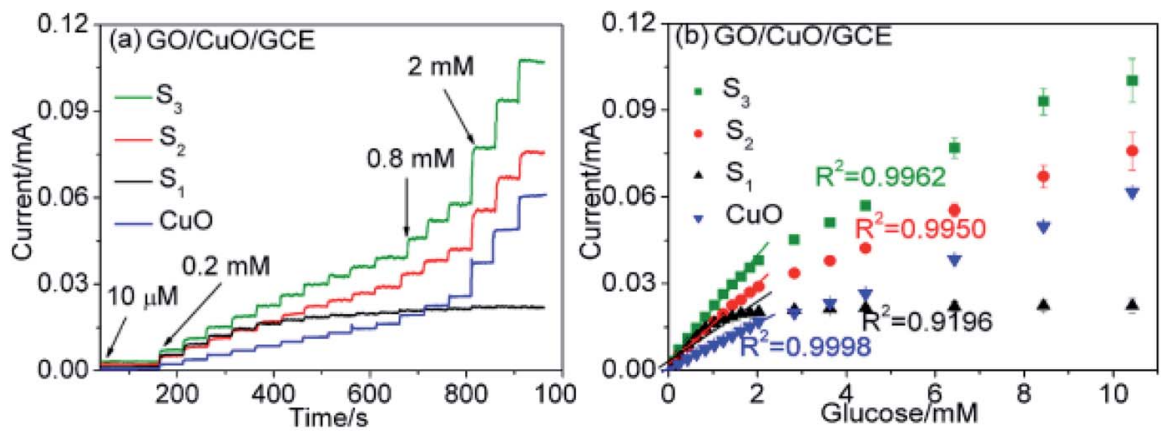

(B)

Fig. 6 (A) Illustration of the non-enzymatic glucose sensing mechanism using the CuO/GO composite. (B) Amperometric responses of GO$\mathrm{CuO}$ electrodes with increasing $\mathrm{CuO}$ loading $\left(\mathrm{S}_{1}-\mathrm{S}_{3}\right)$ to the successive addition of glucose [this figure has been reproduced from ref. 109 with permission from American Chemical Society, Copyright 2013].

the GO-CuO composite has improved over time and has been exploited for fabrication and upgradation of biosensing devices.

Very important pharmaceutical application of CuO-GO was reported by Ganeshan et al. ${ }^{112}$ who could impart both anticancer property and photocatalytic dye degradation property to the nanocomposite. They have synthesized $\mathrm{CuO}$ via a unique 'green' method using Acalypha Indica leaves and incorporated it into GO following simple co-dispersion and stirring. The obtained nanocomposite was found to exhibit photocatalytic degradation of MB up to $83.20 \%$. It has also shown appreciable cytotoxicity $(\sim 65 \%)$ against human colon cancer cells (HCT116) with a concentration of $35 \mu \mathrm{g} \mathrm{ml}{ }^{-1}$. In a contemporary report Zhang et al. ${ }^{113}$ prepared a $\mathrm{CuO}-\mathrm{GO}$ nanocomposite and found its high catalytic activity to the reduction of nitroaromatics to amino aromatics. The nanocomposite was first applied to the reduction of 4-nitrobenzene with aqueous $\mathrm{NaBH}_{4}$ solution and the yield of the product 4-aminobenzene was $98 \%$. Comparing the catalytic activity of the nanocomposite in case of various nitroaromatics ( $p$-nitroaniline (PNA), $o$-nitroaniline (ONA), 4-bromonitrobenzene, etc.) very high yield of product (more than 90\%) was found. Surprisingly from the experiment it was found that the catalyst (NC) selectively reduces the nitro group to the amino group, leaving other functional groups unaffected. The activity of the CuO-GO nanocomposite was less than that of the other noble metal (Pt and Pd) based heterogeneous catalysts. But considering the low cost of copper with appreciable reusability of the nanocomposite after six consecutive cycles and high yield (85\%) of product it can be used as a very effective catalyst. This work has been succeeded by
Bhattacharjee et al. ${ }^{114}$ who could synthesize a GO-CuO nanocomposite via a greener method under microwave irradiation using sugar cane juice. The composite exhibited excellent antioxidant ability as well as efficiency towards reduction of aromatic nitro compounds viz. PNA, ONA, $p$-nitrophenol (PNP), and 2,4,6-trinitrophenol (TNP). The synergistic effect of GO and MO and the mechanism of degradation of any organic pollutant (dye or microorganism) are schematically shown in Fig. 5. In a recent report GO-CuO nanocomposites, synthesized from GO and copper acetate precursors, via a wet chemical process have been utilized for removal of $\mathrm{Pb}$ (II) pollutants via photocatalytic oxidation. ${ }^{115}$ Photocatalytic property and concomitant degradation capability of different GO-MO nanocomposites are collectively shown in Table 2, all of which will be discussed gradually.

In a relatively different approach ${ }^{116}$ GO-coated $\mathrm{CuO}$ nanoparticles have been exploited for functionalization with antiinflammatory drugs viz. acetylsalicylic acid (ASA/aspirin) and diclofenac (DC) using the ultrasonic method $(20 \mathrm{kHz}, 18 \mathrm{~W}$ $\mathrm{cm}^{-2}$ ). These flower-like nanoparticles (mean diameter $<340$ $\mathrm{nm}$ ) are positively charged consisting of a pure $\mathrm{CuO}$ phase. Ultrasound causes complexation of each drug with these nanoparticles, and as a consequence, new advanced pharmaceutical nanocomposites, ASA-GO-CuO and DC-GO-CuO, are formed. The surface composition and electronic molecular structure of these nanocomposites involving $\mathrm{Cu}-\mathrm{O}, \mathrm{C}-\mathrm{H}$, and $\mathrm{H}-$ bond formation with the $-\mathrm{COOH}$ and - $\mathrm{CO}$ - groups of ASA, DC, and GO are found to vary with $\mathrm{pH}$ (1 to 8). 
Table 2 GO-MO hybrids with degradation/adsorption/photocatalytic properties to organic molecules (dyes or others) and metal ions

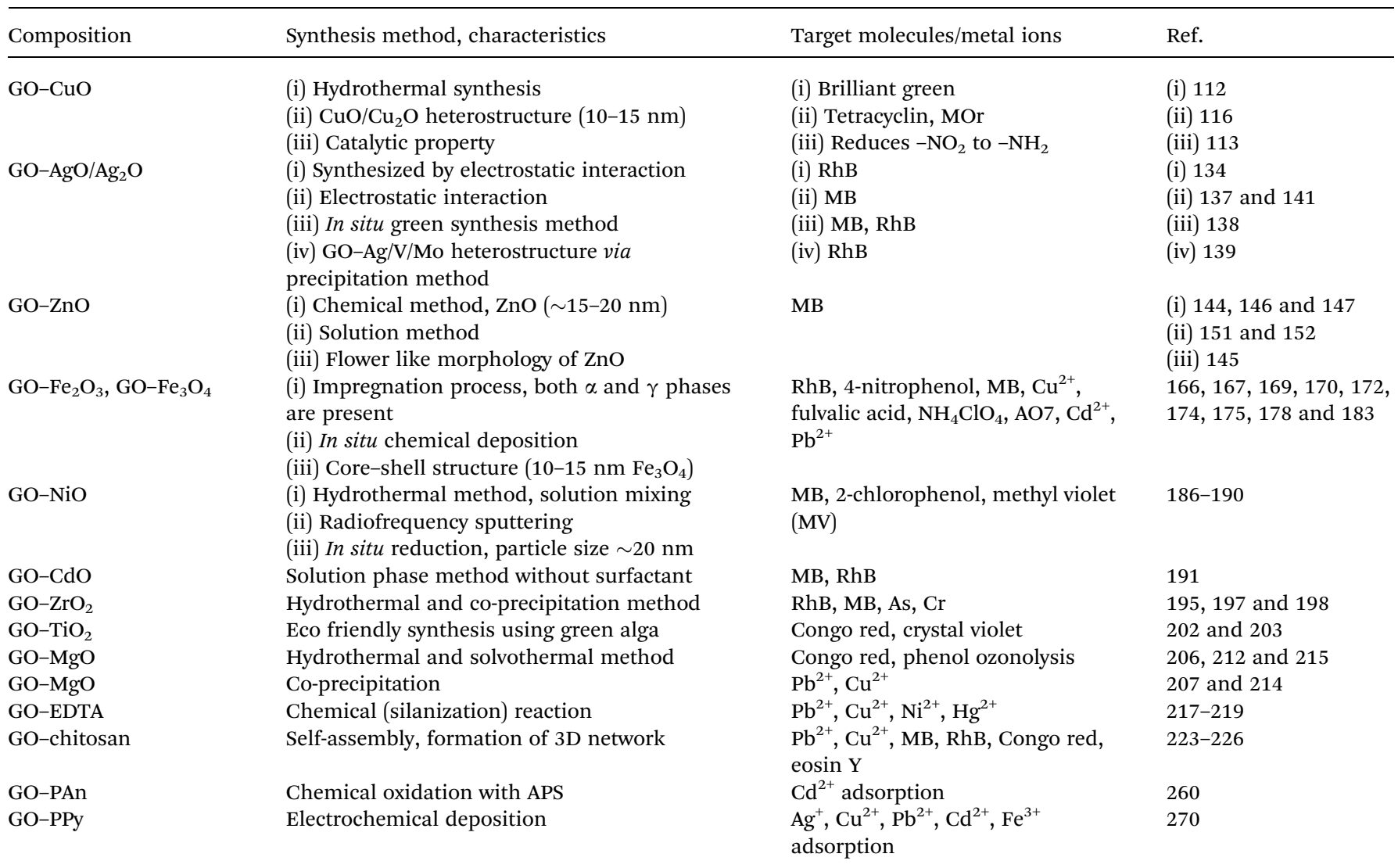

Very recently mixed oxides or double oxides have also been combined with GO for different purposes. The hydrothermal synthesis technique was followed by Zhang et al. ${ }^{117}$ for in situ synthesis of $\mathrm{CuO}-\mathrm{Cu}_{2} \mathrm{O}-\mathrm{GO}(10-15 \mathrm{~nm})$ from $\mathrm{Cu}(\mathrm{OAc})_{2}$. The material has shown excellent dual function catalytic ability for the rapid catalytic oxidation of tetracycline (TC) and methyl orange (MOR). The degradation ratios of TC and MOR reached 90\% and 95\% after 120 min (under visible light), respectively. The high catalytic activity could be attributed to the excellent photogenerated electron-hole transfer properties of the NC. On the other hand the electrochemical method was followed for deposition of $\mathrm{a} \mathrm{Cu}_{2} \mathrm{O}$ film on GO-modified $\mathrm{ZnO}$, which formed an efficient heterojunction solar cell. ${ }^{118}$ The modification of the $\mathrm{ZnO} / \mathrm{Cu}_{2} \mathrm{O}$ interface with $\mathrm{GO}$ nanosheets and annealing treatment results in improved interface properties, varying morphology and defects in the $\mathrm{ZnO}$ lattice that further lead to enhanced performance of the proposed solar cells. The results indicated that the properties of the GO coating could be tailored for improved performance of the heterojunction and a synergetic effect of the GO addition and annealing treatment on the photoelectric properties is also achieved.

\section{3. $\quad \mathrm{GO}-\mathrm{Ag}_{2} \mathrm{O}$ nanocomposites}

$\mathrm{Ag}$ is a noble metal and $\mathrm{Ag}_{2} \mathrm{O}$ is a very important metal oxide due to its smaller band gap, which results in increased visible light absorption properties at higher wavelength. High photocatalytic activity of silver halides, ${ }^{119,120} \mathrm{Ag}_{3} \mathrm{PO}_{4},{ }^{121,122}$ and $\mathrm{Ag}_{2} \mathrm{O}^{123-125}$ resulting in oxidation of water and photodecomposition of organic dyes (e.g. MO) in aqueous solution under visible light irradiation along with very efficient antibacterial property was reported by different groups of investigators. All these properties of $\mathrm{Ag}$ and Ag-based compounds led the scientists to combine GO with them. Xu et al. ${ }^{\mathbf{1 2 6}}$ were the first to report the synthesis method of water soluble Ag-RGO nanocomposites without any additional surfactants, which results in better antibacterial activity than pure silver nanoparticles or antibacterial drug ampicillin. The efficiency and biocompatibility of the prepared nanocomposite as an antibacterial agent were investigated by a skin irritation test both in vitro and in vivo on Sprague Dawley (SD) rats; the nanocomposite exhibited an excellent inhibition property against bacterial growth and no obvious skin irritation was observed. In a contemporary work Jizhen Ma et al. ${ }^{127}$ prepared GO decorated with Ag nanoparticles by the glucose reduction method in the presence of ammonia at room temperature and the prepared nanocomposite has shown high antibacterial activity against E. coli bacteria. J. Cui et al. ${ }^{128,129}$ prepared GO/Ag nanocomposites and nanowires and found antibacterial activity and cell compatibility against Xanthomonas oryzae pv. Migration of Ag nanoparticles from the GO$\mathrm{Ag}$ (33 wt\%) nanocomposite to other carbon frameworks viz. GO or multiwalled carbon nanotubes was reported for the first time by KAS Fernando et al. ${ }^{\mathbf{1 3 0}}$ 
In a different synthesis method Vi et al. ${ }^{\mathbf{1 3 1}}$ have prepared GO$\mathrm{Ag}$ NPs via grafted thiol ( $\mathrm{g}$-SH) groups and found AgNPs attached to GO layers having a quasi spherical shape. They prepared GO-Ag composites with different concentrations (0.1 M, 0.2 M, and 0.25 M) and checked their antibacterial activity against MRSA. The nanocomposite with the highest antibacterial activity exhibited $48.77 \%$ bacterial inhibition after 4 hours of incubation. The synthesis method was further modified to exclude reducing agents or stabilizers ${ }^{\mathbf{1 3 2}}$ and the product $\mathrm{GO}-\mathrm{Ag}-\mathrm{g}-\mathrm{SH}$ exhibited antibacterial activities on both SA (Gram-positive bacteria) and PA (Gram-negative bacteria). Varying the concentrations of $\mathrm{AgNO}_{3}$ solution $\mathrm{Ag}$ content in nanocomposites was varied; out of these nanocomposites one with $43 \% \mathrm{Ag}$ was found to exhibit the highest antibacterial efficiency. $10 \mathrm{ppm}, 20 \mathrm{ppm}$ and $100 \mathrm{ppm}$ of the sample could result in $\sim 8 \%, \sim 49 \%$ and ultimately almost $100 \%$ bacterial inhibition of both Gram-positive (SA) and Gram negative (PA) bacteria, which are much higher than that of pristine GO. In a contemporary work S. Jaworski et al. ${ }^{133}$ used ultrasonic technologies to prepare polyurethane foil coated with GO, AgNPs and GO-Ag NPs respectively. They checked the antibacterial activity of the composites against $E$. coli, SA, SE, and $C$. albicans (Yeast strain) and found that GO-Ag nanocomposite coated foil exhibited stronger antibacterial activity (up to $88.6 \%$ for $E$. coli) than GO and bare Ag NPs. Antibacterial activity of GO based nanocomposites of diverse composition is tabulated in Table 3 and will be discussed in respective sections.

In parallel with AgNP, combination of GO with other silver compounds has also been studied. Q. Liang et al. ${ }^{134}$ reported the preparation and enhanced photocatalytic efficiency of GO$\mathrm{Ag}_{3} \mathrm{PO}_{4}$ towards the degradation of rhodamine $\mathrm{B}(\mathrm{RhB})$ under visible light irradiation. Silver halides $(\mathrm{AgBr})$ in combination with AgNP were reported by Zhu et al. and Wang et al. ${ }^{\mathbf{1 3 5 , 1 3 6}}$ to result in formation of $\mathrm{GO} / \mathrm{Ag} / \mathrm{AgBr}$ plasmonic photocatalysts (which are energized by the sunlight) via oil/water and water/oil emulsion and their photocatalytic efficiency was explored for dye (MO) degradation. The $\mathrm{GO}-\mathrm{Ag}_{2} \mathrm{O}$ nanocomposite prepared by $\mathrm{Z}$. Ji et al. ${ }^{137}$ via electrostatic interactions was found to possess photocatalytic activity towards degradation of Methylene Blue (MB). The same $\mathrm{GO}-\mathrm{Ag}_{2} \mathrm{O}$ nanocomposite was also prepared by Ahmad et al. ${ }^{\mathbf{1 3 8}}$ via an eco-friendly in situ synthesis method. They prepared GO nanocomposites with different volume fractions ranging from $20 \%$ to $40 \%$ and compared their photocatalytic activities. As per their observation the $\mathrm{Ag}_{2} \mathrm{O} / \mathrm{GO}$ nanocomposite $\mathrm{AG}-3\left(35 \% \mathrm{Ag}_{2} \mathrm{O}\right)$ has shown the maximum photocatalytic efficiency under visible light irradiation towards photodegradation of $\mathrm{MB}$ and $\mathrm{RhB}$ and it is found to be even more efficient than the benchmark photocatalyst $\mathrm{TiO}_{2}$ (P25).

The system became complicated gradually and multiphase heterostructured nanocomposites viz. GO- $\mathrm{Ag}_{2} \mathrm{O} / \mathrm{Ag}_{3} \mathrm{VO}_{4} / \mathrm{AgVO}_{3}$ or $\mathrm{Ag}_{2} \mathrm{MoO}_{4} / \mathrm{Ag} / \mathrm{AgBr} / \mathrm{GO}$ with enhanced photocatalytic activity to the degradation of $\mathrm{RhB}$ and $\mathrm{MO}$ compared to the pure nanoparticles were prepared by Ran et al. ${ }^{\mathbf{1 3 9}}$ and Bai et al. ${ }^{\mathbf{1 4 0}}$ via a different approach. Recently ${ }^{\mathbf{1 4 1}}$ a GO-Ag nanocomposite was prepared via a sonochemical method by S. Kumari et al. and its enhanced thermoluminescence property was explored by irradiation with gamma ray at $1 \mathrm{kGy}$. The sample also possesses enhanced dye degradation capacity towards MB. In a contemporary publication ${ }^{\mathbf{1 4 2}}$ Wang et al. explored the anticancer activity of the GO-Ag nanocomposite towards lung cancer and brain tumour cells. The nanocomposite shows no cytotoxicity to normal cells but can effectively kills the cancer cells through formation of ROS. In another work N. El-Shafai et al. ${ }^{143}$ have compared GO-Ag, with two heterostructures GO-TiO ${ }_{2} @ \mathrm{ZnO}$ and $\mathrm{GO}-\mathrm{Ag}-\mathrm{TiO}_{2} @ \mathrm{ZnO}$ in terms of their antibacterial activity against two Gram-positive and two Gram-negative bacteria. The results showed that both the nanocomposites could inhibit the growth of adhered microbial cells, and consequently prevent the process of biofilm formation in food packaging and medical devices. To confirm the antibacterial activity the GOnanocomposites were examined through their interactions with bovine serum albumin (BSA) and circulating tumor DNA (ctDNA) by steady-state fluorescence spectroscopy (Fig. 7). Upon addition of different amounts of fabricated GOnanocomposites, the fluorescence intensities of the singlet states of BSA and ctDNA were considerably quenched. The higher quenching was observed with the GO-Ag-TiO ${ }_{2} @ Z n O$ nanocomposite compared with other control composites. This result correlates with antibacterial activity via rupture of the bacterial membrane leading to cell death by $\mathrm{ZnO}$ and $\mathrm{TiO}_{2}$ entities and the results suggest that the multiple heterostructure is more effective in this respect.

\subsection{GO-ZnO nanocomposites}

$\mathrm{ZnO}$ is a low cost and low band gap metal oxide with high chemical, thermal and photostability. It has many other beneficial properties viz. large electrochemical coupling coefficient, high bond energy, electron mobility, wide radiation absorption range, good transparency and luminescence at room temperature. Moreover $\mathrm{ZnO}$ is a semiconductor whose properties are in the boundary region between covalent and ionic semiconductors. All these advantages of $\mathrm{ZnO}$ have been exploited in fabrication of gas detectors, solar cells (the transparent conductive coating), piezoelectric transducers, electronic and optoelectronic devices. Therefore combining $\mathrm{ZnO}$ with GO/RGO is considered to be a highly promising approach towards development of a series of nanostructured materials with widespread application potential. ${ }^{\mathbf{1 4 4}}$

It is Wenbin et al. ${ }^{\mathbf{1 4 4}}$ who first prepared GO-ZnO nanocomposites by a simple chemical method; the lamellar graphite oxide sheets in this composite were dispersed in ethylene glycol and $\mathrm{Zn}$-acetate under ultrasonication followed by heating (120 ${ }^{\circ} \mathrm{C}$ ) and vigorous stirring. This made GO sheets exfoliated and decorated randomly by in situ synthesized $\mathrm{ZnO}$ nanoparticles ( $20 \mathrm{~nm})$. The GO-ZnO nanocomposites displayed good photocatalytic activity towards degradation of $\mathrm{MB}$ under UV light irradiation. This work was followed by Li et al. ${ }^{\mathbf{1 4 5}}$ who have reported the synthesis of $\mathrm{ZnO} / \mathrm{GO}$ by a facile chemical deposition route resulting in the formation of flower like ZnO NP. They performed the $\mathrm{N}_{2}$ adsorption/desorption measurement and pore size distribution plot of the $\mathrm{GO} / \mathrm{ZnO}$ composite calculated by the Barrett-Joyner-Halenda (BJH) method. The $\mathrm{ZnO} / \mathrm{GO}$ nanocomposite has a high surface area and hierarchical 
Table 3 GO-MO hybrids with pharmaceutical/antibacterial/biosensing applications

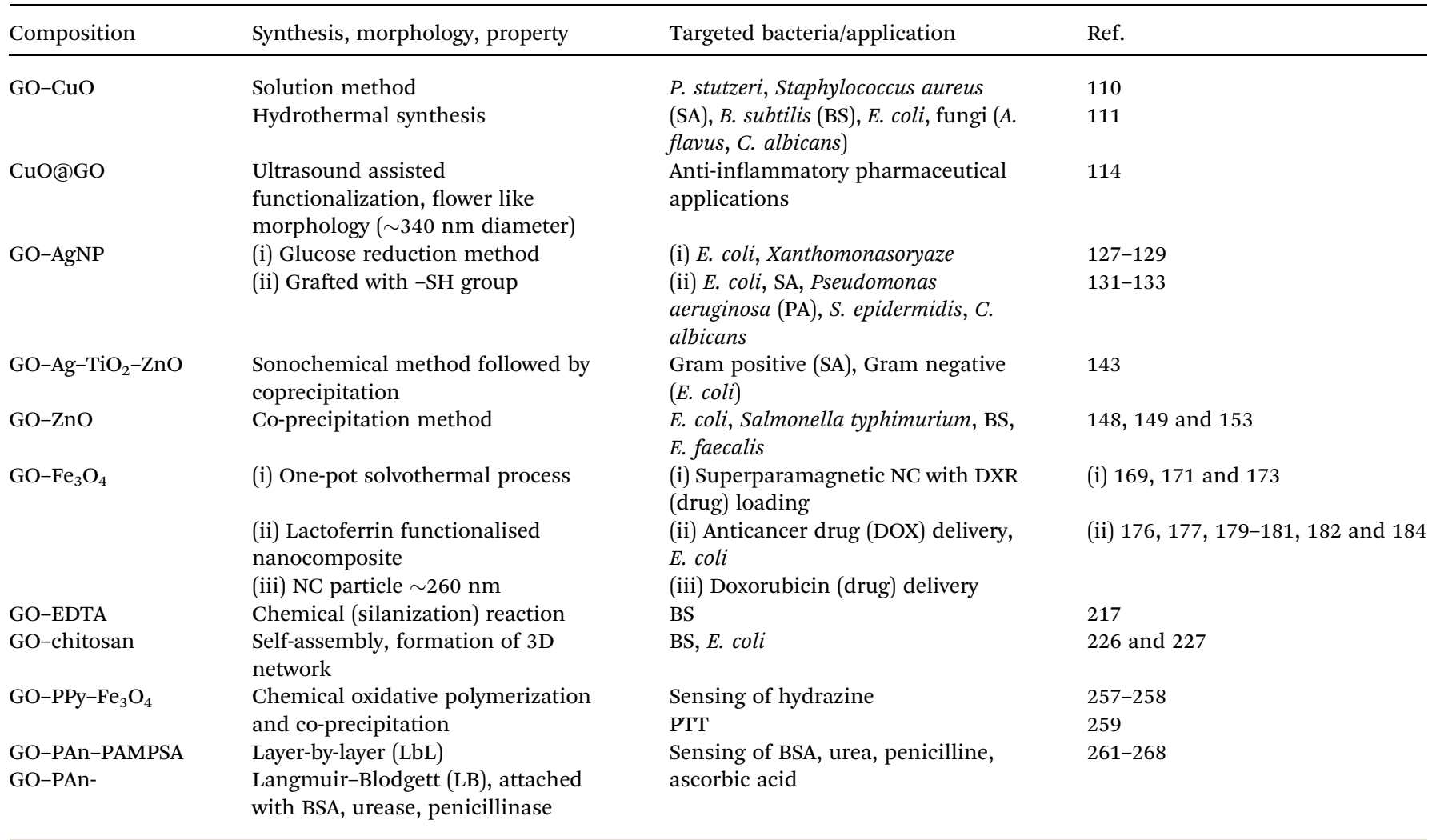

porosity, which favours adsorption and mass transfer of dye and oxygen species. The photocatalytic activity of the prepared $\mathrm{ZnO} /$ GO nanocomposite was also measured and compared with that of pure $\mathrm{GO}$ and $\mathrm{ZnO}$ particles with respect to the degradation of $\mathrm{MB}$. The $\mathrm{ZnO} / \mathrm{GO}$ nanocomposite was found to show very prominent photocatalytic activity (98.1\%) after visible-light
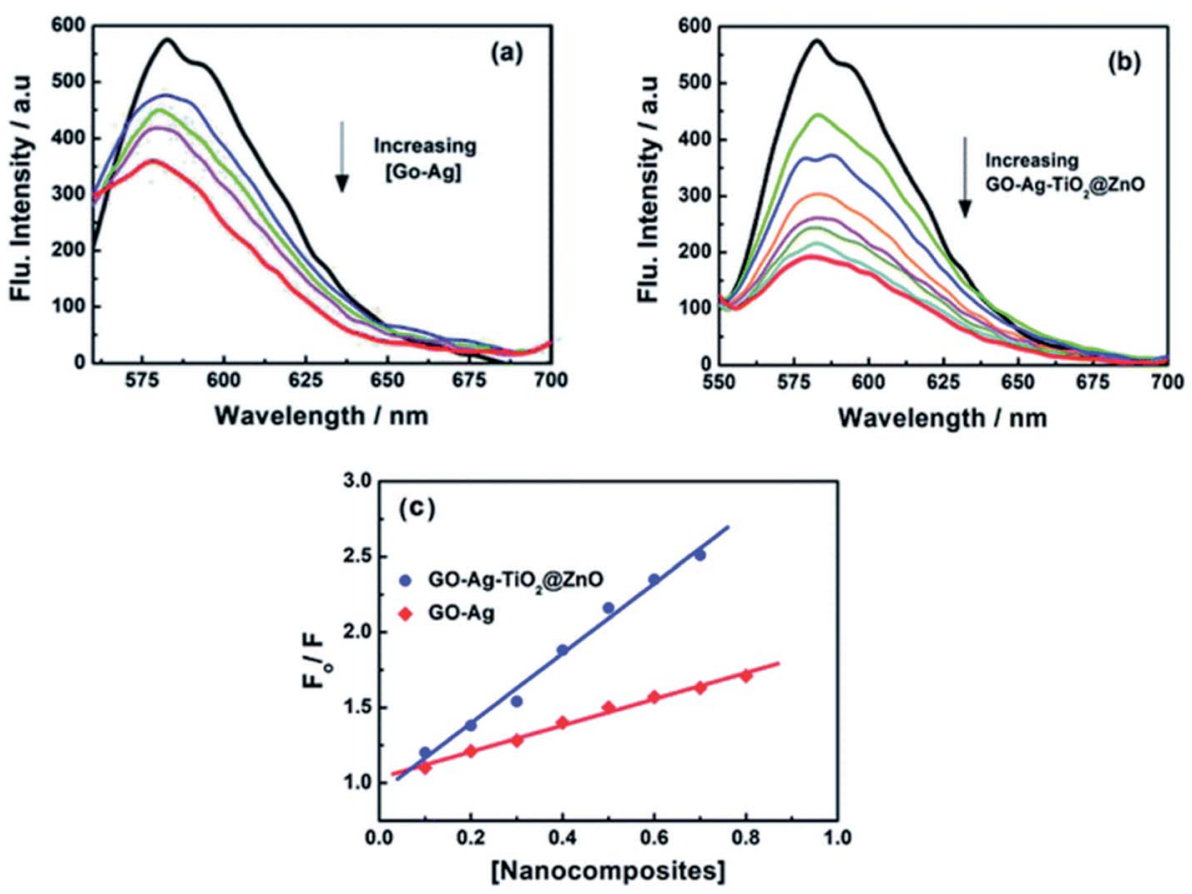

Fig. 7 Fluorescence quenching of ctDNA with different concentrations of (a) $\mathrm{GO}-\mathrm{Ag}$ and (b) $\mathrm{GO}-\mathrm{Ag}-\mathrm{TiO}_{2} \mathrm{QZnO}$ in Tris- $\mathrm{HCl}$ buffer; $\lambda_{\mathrm{ex}}=$ $260 \mathrm{~nm}$; (c) Stern-Volmer plots this figure has been reproduced from ref. 143 with permission from Royal Society of Chemistry, Copyright 2019]. 
irradiation for $60 \mathrm{~min}$. Photocatalytic efficiency of the sample could be further improved by annealing under a $\mathrm{N}_{2}$ atmosphere; 97.9\% photodegradation of $\mathrm{MB}$ was observed after $40 \mathrm{~min}$ irradiation time. The nanocomposite has shown excellent reusability after 5 repeated experiments. Later on, S. M. Jilani et al. ${ }^{\mathbf{1 4 6}}$ prepared a series of GO-ZnO composites by varying $\mathrm{ZnO}$ loading from $5 \mathrm{wt} \%$ to $25 \mathrm{wt} \%$ into the GO matrix. The electrical conductivity was found to vary with $\mathrm{ZnO}$ loading; at lower fraction ( $5 \mathrm{wt} \%$ ) of $\mathrm{ZnO}$ it behaved like a p-type semiconductor, while with increasing fraction of $\mathrm{ZnO}$ n-type semiconductor behaviour was observed. Therefore the electrical property of GO in this work was changed from an insulator (pure GO) to a ptype to n-type semiconductor with an increase in the amount of $\mathrm{ZnO}$. This unique electrical behaviour was accounted for by the reduction of $\mathrm{C}-\mathrm{OH}$ groups by increasing the fraction of $\mathrm{ZnO}$. The dye degradation (photocatalytic) efficiency of GO-ZnO has been further improved and nicely demonstrated by R. Atchudan et $a .^{147}$

They have reported a wet chemical method combining nearly spherical $\mathrm{ZnO}$ particles ( 15 nm) with a wrinkled surface with GO to get the nanocomposite. The photocatalytic activity of the synthesized ZnO@GO composite towards the degradation of MB was examined using UV-vis spectroscopy. Fig. 8 shows the effect of the GO-ZnO (ZnO@GO) hybrid on the colour and time dependent spectra of MB. After the addition of $\mathrm{ZnO} @ G O$ to $\mathrm{MB}$ under UV-light, the blue color and absorbance intensity of $\mathrm{MB}$ at 612 and $664 \mathrm{~nm}$ decreased gradually (right side figure). Without UV-light, the degradation of MB however did not occur, but some adsorption of MB on GO takes place, resulting in little lowering in the absorbance intensity of MB. With an increase in irradiation time the solution turns colorless and the degradation efficiency of $92 \%$ and $98.5 \%$ were reached in $12 \mathrm{~min}$ and 15 min respectively. This result reveals that the synthesized ZnO@GO composite shows excellent photocatalytic activity towards the degradation of MB.

In a contemporary publication Wang et al. ${ }^{\mathbf{1 4 8}}$ prepared two composites viz. $\mathrm{ZnO} / \mathrm{GO}-1$ and $\mathrm{ZnO} / \mathrm{GO}-2$ (the mass ratio of
$\mathrm{ZnO} / \mathrm{GO}$ was $3: 1$ and $2: 1$ respectively) and found improved antibacterial activity against $E$. coli compared to ZnO NPs. The antibacterial efficiency of the composite was found to depend on the $\mathrm{ZnO}$ content, while cytotoxicity of the prepared sample (applied to HeLa cells) was quite low compared to that of equal amount of pure $\mathrm{ZnO}$ nanoparticles. The nanocomposite is therefore a highly prospective ingredient of any disinfectant to inhibit bacterial growth and propagation on various substrates. In the consecutive year Zhong et al. ${ }^{149}$ prepared a ZnO/GO nanocomposite with $15 \mathrm{~nm} \mathrm{ZnO}$ nanoparticles by a low cost high yield solution precipitation method. The composite was found to show improved electrochemical response by showing a redox peak at $0.025 \mathrm{mV}$ (in cyclic voltammetry) due to formation of covalent bonds between graphene oxide and $\mathrm{ZnO}$ particles, which results in strong electron transfer at the redox centres of GO. On the other hand no redox peaks appeared in the potential range $-0.15 \mathrm{~V}$ to $+0.25 \mathrm{~V}$ in the case of bare Au-PCB (gold printed circuit board) and $\mathrm{Au}-\mathrm{PCB} /$ graphene oxide. Improved electron transfer between $\mathrm{ZnO}$ and GO made the composite show good antibacterial activity too. The electrons on the GO surface absorb oxygen and form various Reactive Oxygen Species (ROS) on the surface of composites and GO strongly interacts with the lipid bilayer of the bacterial membrane. So lipid molecules are separated from the bacterial membrane, leading to the damage of the membrane and the death of bacteria in turn. Minimum Inhibitory Concentration (MIC) values for E. coli and Salmonella typhimurium were found to be $6.25 \mu \mathrm{g} \mathrm{ml}{ }^{-1}$, while for BS and EF this value was $12.5 \mu \mathrm{g} \mathrm{ml}$ and $25 \mu \mathrm{g} \mathrm{ml}^{-1}$ respectively.

Later on Salih et al. ${ }^{150}$ prepared a $\mathrm{GO} / \mathrm{ZnO}$ nanocomposite and used the same as the electrode to measure the electrochemical signal. GO/ZnO was found to show the highest electrochemical signals compared to the unmodified electrode, which might be the effect of conjugation of $\mathrm{GO}$ and $\mathrm{ZnO}$ nanoparticles that increased the rate of electron transfer. This characteristic was exploited to construct amperometric $\mathrm{H}_{2} \mathrm{O}_{2}$ sensors by monitoring the redox reaction of ferricyanide (FCN).

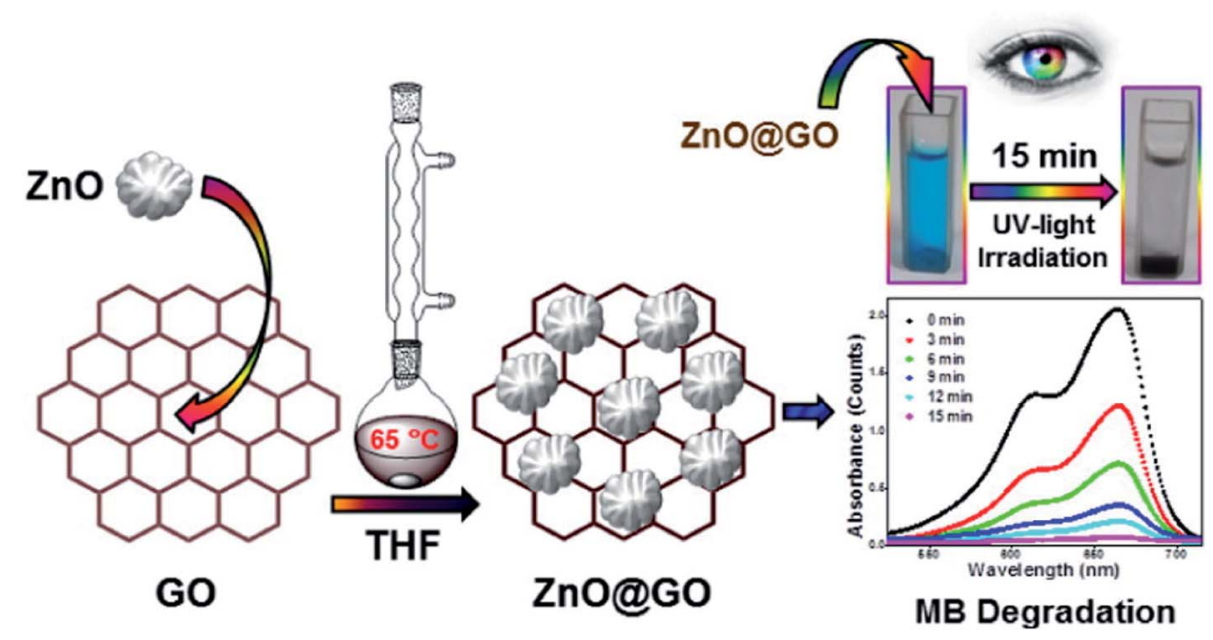

Fig. 8 Schematic diagram of the synthesis and time-dependent UV-vis spectra of MB in the presence of the GO-ZnO composite under UV-light irradiation [this figure has been reproduced from ref. 147 with permission from Elsevier, Copyright 2016]. 
Electrodes were prepared by changing the concentration of $\mathrm{GO} /$ $\mathrm{ZnO}$ gradually from 5 to $20 \%(\mathrm{w} / \mathrm{w})$ and at $10 \%(\mathrm{w} / \mathrm{w})$ concentration the signal was found to reach maxima (Fig. 9). The electrochemical response was further increased with the increase in the FCN concentration. The GO/ZnO composite sensor shows a much higher response compared to the $\mathrm{ZnO}$ based sensor or bare carbon paste electrodes (CPEs). The developed $\mathrm{ZnO} / \mathrm{GO}$ modified CPE presents high sensitivity, low potential and long-term stability towards the detection of $\mathrm{H}_{2} \mathrm{O}_{2}$, which could be a promising approach for the development of non-enzymatic $\mathrm{H}_{2} \mathrm{O}_{2}$ sensors.

In two contemporary publications Hosseini et al. ${ }^{151,152}$ have reported the preparation of a $\mathrm{GO} / \mathrm{ZnO}$ composite by the solution method and have applied the same for the removal of a dye (MB) from water following adsorptive and photocatalytic techniques respectively. In the first publication ${ }^{\mathbf{1 5 1}}$ adsorption efficiency was monitored and nanocomposites were observed to exhibit the highest (97\%) efficiency of removal of MB at 5 ppm concentration under optimum conditions: $\mathrm{pH}$ 6, adsorption time $8.5 \mathrm{~min}$, and adsorbent dosage $0.02 \mathrm{~g}$. But under the same conditions $\mathrm{ZnO}$, GO, pure carbon nanotube (CNT) and $\mathrm{ZnO} / \mathrm{CNT}$ exhibit $5.165 \%, 78.82 \%, 95.42 \%$ and $17.13 \%$ removal of $\mathrm{MB}$ respectively. Therefore, prepared $\mathrm{GO} / \mathrm{ZnO}$ exhibits the highest dye removal efficiency and it can be used for removal of industrial dyes from waste water via adsorption. In the second publication the same group of authors ${ }^{152}$ have investigated the photocatalytic activity of the $\mathrm{GO} / \mathrm{ZnO}$ nanocomposite towards the degradation of MB under UV radiation. Photocatalytic activity of the synthesized $\mathrm{GO} / \mathrm{ZnO}$ composite was again compared with that of $\mathrm{ZnO}, \mathrm{GO}$ and $\mathrm{CNT} / \mathrm{ZnO}$ and the optimum condition for removal of $\mathrm{MB}$ from waste water was found to be at $\mathrm{pH}$ 4.5. The removal efficiency of $\mathrm{MB}$ was observed to increase with increasing irradiation time and catalyst dosage. It must be noted that under optimum conditions GO results in $56.25 \% \mathrm{MB}$ degradation but CNT alone shows no degradation at all. Other materials of this series viz. ZnO, CNT/ZnO and GO/ZnO show significant photocatalytic activity and cause $98.85 \%$, 98\% and $99 \%$ of degradation of MB. It is therefore quite obvious that photocatalytic behaviour of these materials arises out of the presence of $\mathrm{ZnO}$. From this study it was concluded that $\mathrm{GO} / \mathrm{ZnO}$ can be used as an efficient photocatalyst for the decolorization process.

The synthesis technique of $\mathrm{GO} / \mathrm{ZnO}$ was further modified by Trinh et al. ${ }^{153}$ who followed a co-precipitation method and found its antibacterial activity against $E$. coli. After $80 \mathrm{~min}$ the rate of growth of $E$. coli was found to be lowest in the case of bacteria treated with $\mathrm{GO} / \mathrm{ZnO}$ compared to that treated with $\mathrm{GO}$ only. After $160 \mathrm{~min}$ the colony of bacteria treated with $\mathrm{GO} / \mathrm{ZnO}$ vanished, which suggests that the composite shows very high antibacterial activity and can be used in various antimicrobial applications in future. In a parallel publication Boukhoubza et $a l .{ }^{154}$ prepared a sandwich composite of $\mathrm{ZnO}$ nanorods (NR) between two graphene oxide layers (GO/ZnO-NRs/GO) via a hydrothermal method and confirmed the structure by XRD and SEM. The prepared sample showed improved optical properties, which can be used to develop different optoelectronic devices. In the same year another group of researchers Lee et al. ${ }^{155}$ prepared a hierarchical $\mathrm{ZnO} / \mathrm{GO}$ composite by an echo friendly precipitation method and found that specific capacitance of $\mathrm{GO} / \mathrm{ZnO}$ is higher than that of the pristine GO electrode. Capacitance retained up to $90.8 \%$ of its initial value after 5000 cycles; this suggested high stability during charge/ discharge processes, which is in fact characteristic of good supercapacitors.

In an almost recent publication Zehra Durmus et al. ${ }^{156}$ have prepared a GO/ZnO composite by a two-step sol-gel deposition method and checked the photocatalytic activity of the composite by applying it to the degradation of basic fuchsin dye under UV light. The activity of the nanocomposite depends on various factors like concentration of dye, amount of catalyst, temperature, $\mathrm{pH}$, and mixing conditions. Catalytic properties of the $\mathrm{GO} / \mathrm{ZnO}$ nanocomposite showed an improved degradation activity compared to $\mathrm{GO}$ and $\mathrm{ZnO}$ nanoparticles. In a very recent report $^{157}$ and one similar earlier report ${ }^{158}$ the as synthesized GO/ ZnO nanoparticles were combined with in situ grown PdNP (from $\mathrm{PdCl}_{2}$ ), $\mathrm{AgNP}$ (from reduction of $\mathrm{AgNO}_{3}$ ) and CuNP (from reduction of $\mathrm{CuSO}_{4}$ ). While embedded CuNP resulted in almost $50 \%$ lowering of photocatalytic activity (measured via $\mathrm{MB}$
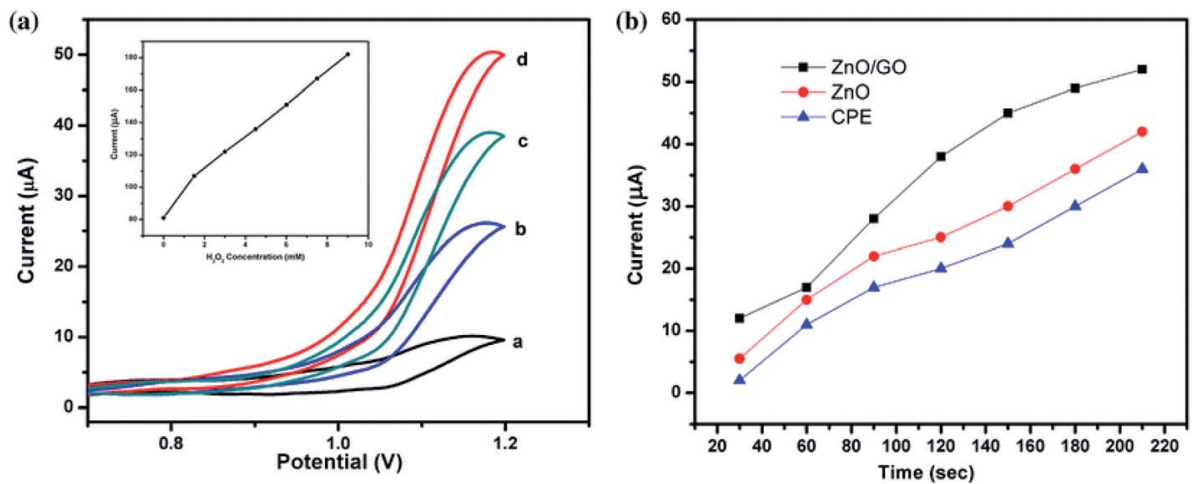

Fig. 9 (a) Cyclic voltammogram obtained at $\mathrm{GO} / \mathrm{ZnO} / \mathrm{CPE}$ in the (a) absence and presence of (b) $1.5 \mathrm{mM}$, (c) $3 \mathrm{mM}$, and (d) $4.5 \mathrm{mM} \mathrm{H} \mathrm{O}_{2}$. The inset is the corresponding calibration curve between the current response and concentration of $\mathrm{H}_{2} \mathrm{O}_{2}$. (b) Amperometric response of different electrodes against $\mathrm{H}_{2} \mathrm{O}_{2} \mathrm{GO}-\mathrm{ZnO}$ and use of the electrode material for the construction of $\mathrm{a} \mathrm{H}_{2} \mathrm{O}_{2}$ sensor [this figure has been reproduced from ref. 150 with permission from Springer, Copyright 2016]. 
degradation), both PdNP and AuNP resulted in a large improvement of the capability. These foreign nanoparticles inhibited the recombination of photogenerated electrons and holes, resulting in improved photocatalysis. For PdNP formation of Schottky contact with $\mathrm{ZnO}$ was another reason for superior activity, while for CuNP low conductivity and larger size distribution might have an adverse effect on photocatalytic properties.

\section{5. $\quad \mathrm{GO}-\mathrm{Fe}_{2} \mathrm{O}_{3} / \mathrm{Fe}_{3} \mathrm{O}_{4}$ nanocomposite}

$\mathrm{Fe}(\mathrm{III})$ oxides and hydroxides, collectively known as Hydrous Ferric Oxides (HFO), are known as excellent oxidizing agents for several compounds; they are also n-type semiconductors possessing a band gap ranging from very low $(<0.1 \mathrm{eV})$ to medium high $(2.2 \mathrm{eV})$ energy values, depending on the crystal structure, crystallinity level and crystal size of the specific HFO. ${ }^{159}$ It has been demonstrated that HFO can be photo catalytically active ${ }^{\mathbf{1 6 0}}$ in the visible light range. Out of the HFO series $\mathrm{Fe}_{2} \mathrm{O}_{3}(2.2 \mathrm{eV})$ has drawn the attention of researchers due to its extraordinary physicochemical properties and has got application in various fields like catalysis, water splitting, ${ }^{\mathbf{1 6 1}}$ lithium ion batteries, ${ }^{\mathbf{1 6 2}}$ electrochemical chromium sensing, ${ }^{\mathbf{1 6 3 , 1 6 4}}$ etc. It is Singh et al. ${ }^{\mathbf{1 6 5}}$ who were the pioneers of the synthesis of $\mathrm{GO}-\mathrm{Fe}_{2} \mathrm{O}_{3}$ nanocomposite. The process was treatment of GO sheets with ferric acetate followed by heat treatment and in situ exfoliation by $\mathrm{Fe}_{2} \mathrm{O}_{3}$. The composite was found to contain both $\alpha$ and $\gamma$ phases of $\mathrm{Fe}_{2} \mathrm{O}_{3}$ with disruption of the layered structure of GO. Later on Sheng Guo et al. ${ }^{166}$ introduced the preparation of $\mathrm{GO}-\mathrm{Fe}_{2} \mathrm{O}_{3}$ nanocomposites by an easy and scalable impregnation process at low temperature $\left(60^{\circ} \mathrm{C}\right)$ and used the product as a heterogeneous catalyst for the photo degradation of RhB dye and 4nitrophenol in aqueous solution. They further evaluated the effect of varying $\mathrm{pH}$ (2.09-10.09) on the degradation process of $\mathrm{RhB}$ and found that the most efficient (90.9\%) decolouration occurs at $\mathrm{pH}$ 10.09. This is indicative of the fact that the catalyst can overcome the limitation of a narrow $\mathrm{pH}$ range of homogeneous Fenton reaction. They finally checked the reusability of the catalyst and found that even after seven recycles of $\mathrm{RhB}$ degradation the catalyst shows 99\% photocatalytic activity, which indicates an excellent stability and potential of the catalyst. Paulose et al. ${ }^{167}$ on the other hand could synthesize a $\mathrm{GO}-\mathrm{Fe}_{2} \mathrm{O}_{3}$ hybrid with catalytic properties for decomposition of $\mathrm{NH}_{4} \mathrm{ClO}_{4}$, a rocket propellant oxidiser. They studied the effect of $\mathrm{GO}: \mathrm{Fe}_{2} \mathrm{O}_{3}$ ratio on the catalytic efficiency and a $3 \%$ addition of the 1:1 hybrid was found to lower the decomposition temperature by $45^{\circ} \mathrm{C}$.

The one-step in situ synthesis technique of the GO-iron oxide composite became perfect when oxidation of graphite to GO was complemented by reduction of $\mathrm{Fe}(\mathrm{VI})$ (from $\mathrm{K}_{2} \mathrm{FeO}_{4}$ ) to $\mathrm{Fe}$ (III) $\left(\mathrm{Fe}_{2} \mathrm{O}_{3}\right)$ proposed by Mura et al. ${ }^{168}$ Graphene oxide flakes with a low oxidation degree, decorated with iron oxide were obtained in a one-step reaction. The resulting nanocomposite was analysed to be a material for water depollution. Real water samples containing different types of emerging pollutants (organic dyes, pesticides, and pharmaceutical drugs) have been efficiently (up to $99 \%$ ) decontaminated in a few minutes. The nanocomposite is paramagnetic and can be easily removed from water with a magnet after depollution. The materials have shown one of the best decontamination performances reported in the scientific literature so far.

It is already discussed that GO has a wide range of functional groups, such as epoxy, hydroxyl, and carboxyl groups, which render it strongly hydrophilic and endow it with capabilities of retention of metals, biomolecules, fluorescent molecules, drugs, and inorganic nanoparticles. These properties of GO when integrated with magnetic properties give rise to high sorption capacity of GO and the separation convenience of magnetic materials. Magnetite $\left(\mathrm{Fe}_{3} \mathrm{O}_{4}\right)$ is an important iron oxide with low toxicity and strong magnetic nature that has received wide application in medicine and biotechnology. Extensive studies have proved that magnetite/graphene nanocomposites exhibit better performances in the removal of contaminants from large volumes of wastewater. Moreover when the size of magnetite reduces to $30 \mathrm{~nm}$ or smaller it loses its ferromagnetic nature and becomes super paramagnetic. This implies that the particles are not attracted to each other any longer and there is no chance of agglomeration. ${ }^{\mathbf{1 6 6}} \mathrm{Combi}$ nation of these functional nanoparticles with GO has become a very promising material for different applications including drug delivery and dye removal. X. Yang et al. ${ }^{\mathbf{1 6 9}}$ were the first to report the synthesis of $\mathrm{GO}-\mathrm{Fe}_{3} \mathrm{O}_{4}$ nanocomposites following a simple in situ chemical deposition method. A mixture of $\mathrm{FeCl}_{3}$, $6 \mathrm{H}_{2} \mathrm{O}$ and $\mathrm{FeCl}_{2}, 4 \mathrm{H}_{2} \mathrm{O}$ solution was added to the GO suspension under a $\mathrm{N}_{2}$ atmosphere to get the superparamagnetic composite, effective for loading and delivery of an anti-cancer drug (DXR) (to a degree as high as $1.08 \mathrm{mg} \mathrm{mg}^{-1}$ ). The synthesis method was further modified by the use of $\mathrm{FeSO}_{4}$ $\cdot 7 \mathrm{H}_{2} \mathrm{O}$ in the presence of ammonia solution to get the multifunctional nanocomposite capable of removing $\mathrm{Cu}^{2+}$ and fulvic acid (FA). ${ }^{170}$ Later on Shen et al. ${ }^{171}$ have followed a one-pot solvothermal process for fabrication of graphene $/ \mathrm{Fe}_{3} \mathrm{O}_{4}$ and $\mathrm{GO}$ / $\mathrm{Fe}_{3} \mathrm{O}_{4}$ hybrid materials and studied their superparamagnetic behaviour, which makes them excellent materials for future application in nano-biotechnology. In a parallel work He et al. ${ }^{172}$ discussed the attachment and covalent bonding between the GO nanosheet and $\mathrm{Fe}_{3} \mathrm{O}_{4}$ nanoparticles. They also found the dye adsorption capacity of the nanocomposite using neutral red and MB dyes. After two years Ma et al. could functionalize the GOmagnetite hybrid (GO-IONP) with polyethylene glycol (PEG) and could utilize it to design a nanocomposite stable under physiological conditions, suitable for high drug loading and magnetically targeted drug delivery. ${ }^{173}$ In another contemporary work ${ }^{\mathbf{1 6 9}}$ a GO-Fe $\mathrm{O}_{4}$ nanocomposite with well dispersed $\mathrm{Fe}_{3} \mathrm{O}_{4}$ NP was synthesised and used as a heterogeneous Fenton-like catalyst for the degradation of acid orange 7 dye (AO7). ${ }^{174}$ The reaction was systematically investigated under various experimental conditions viz. nanocomposite dosage, $\mathrm{pH}$, temperature, oxidant and dye concentrations. The best results showed a fast $80 \%$ AO7 degradation in $\sim 20 \mathrm{~min}$, whilst $~ 98 \%$ degradation was observed after $180 \mathrm{~min}$ reaction time. Later on the same group has highlighted the synergistic effect between structural and functional aspects of $\mathrm{GO}$ and $\mathrm{Fe}_{3} \mathrm{O}_{4}$ components. ${ }^{175}$ 
The $\mathrm{GO}-\mathrm{Fe}_{3} \mathrm{O}_{4}$ nanocomposites synthesised by coprecipitation resulted in formation of two distinct structures dependent upon the GO loading. In low GO loading (up to $10 \mathrm{wt} \%$ ) intercalation of $\mathrm{GO}$ within $\mathrm{Fe}_{3} \mathrm{O}_{4}$ nanoparticles was possible, resulting in higher surface area up to $409 \mathrm{~m}^{2} \mathrm{~g}^{-1}$. High GO loading (beyond $10 \mathrm{wt} \%$ ) led to the aggregation of $\mathrm{Fe}_{3} \mathrm{O}_{4} \mathrm{NP}$ and the undesirable stacking of GO sheets. The presence of strong interfacial interactions ( $\mathrm{Fe}-\mathrm{O}-\mathrm{C}$ bonds) between both components at low GO loading leads to $20 \%$ higher degradation of $\mathrm{AO} 7$ than the $\mathrm{Fe}_{3} \mathrm{O}_{4}$ nanoparticles in heterogeneous Fentonlike reaction. In the consecutive year Yang et al. ${ }^{\mathbf{1 7 6}}$ prepared a $\mathrm{GO}-\mathrm{Fe}_{3} \mathrm{O}_{4}$ composite and described its application in $\mathrm{pH}$ dependant targeted drug delivery to the tumour cells following controlled release of an anticancer drug doxorubicin hydrochloride (DOX). Initially a superparamagnetic (SPM) GO- $\mathrm{Fe}_{3} \mathrm{O}_{4}$ nanohybrid was prepared via a simple and effective chemical precipitation method. Then folic acid was conjugated onto $\mathrm{Fe}_{3} \mathrm{O}_{4}$ nanoparticles via the chemical linkage with amino groups of the 3-aminopropyl triethoxysilane (APS) modified SPM-GO- $\mathrm{Fe}_{3} \mathrm{O}_{4}$ nanohybrid, to give the multi-functionalized GO as shown in Fig. 10A. The drug loading capacity of this multifunctionalized GO is as high as $0.387 \mathrm{mg}^{-1}$ and the drug release depends strongly on $\mathrm{pH}$ values as shown in Fig. 10B(i). Cell uptake studies indicate that the multi-functionalized GO can specifically transport the drugs to tumor cells and show toxicity to HeLa cells after loading Dox. All these results make it possible to use GO as an ideal multi-functionalized drug-carrier for tumor combination therapy (Fig. 10B(ii)). After few years Urbas et al. ${ }^{177}$ prepared a $\mathrm{GO}-\mathrm{Fe}_{3} \mathrm{O}_{4}$ nanocomposite and found its superior biocompatibility to pristine GO and iron oxide nanoparticles in hyperthermia treatment. Very shortly Jiao et al. ${ }^{178}$ introduced a novel method of preparation of $\mathrm{GO}-\mathrm{Fe}_{3} \mathrm{O}_{4}$ by utilising the physical affinity of $\mathrm{Fe}_{3} \mathrm{O}_{4}$ nanoparticles for sulphonated GO. The product nanocomposite showed nearly $60 \%$ and $100 \%$ removal of cationic RhB and MB after the $6^{\text {th }}$ cycle, so the material stands as a very efficient dye adsorbent suitable for removal of cationic dyes ( $\mathrm{MB}$ and $\mathrm{RhB}$ ) from water.

Later on, $\mathrm{GO}-\mathrm{Fe}_{3} \mathrm{O}_{4}$ magnetic nanocomposites were designed by $\mathrm{Y}$. Dong et al. $^{\mathbf{1 7 9}}$ who demonstrated intrinsic peroxidase-like activity of the NC and its enhanced affinity toward $\mathrm{H}_{2} \mathrm{O}_{2}$. The nanocomposites retain their magnetic properties and can be effectively separated using a magnet. Significantly, they were proved to be novel peroxidase representatives, which could quickly catalyze the oxidation of the peroxidase substrate 3,3,5,5-tetramethylbenzidine (TMB) in the presence of $\mathrm{H}_{2} \mathrm{O}_{2}$, producing a blue colored solution. Song et al. ${ }^{180}$ added a new dimension to the nanocomposites as they used an iron transporting protein lactoferrin (Lf) as a targeted ligand to prepare a $\mathrm{Lf}-\mathrm{GO}-\mathrm{Fe}_{3} \mathrm{O}_{4}$ composite; the product was used as a targeted drug delivery system for delivering an anticancer drug DOX to the tumourous cell of the brain. The release of the system was pH dependant (as before) and DOX@Lf-GO- $\mathrm{Fe}_{3} \mathrm{O}_{4}$ was found to show higher efficiency than free DOX and DOX@GO- $\mathrm{Fe}_{3} \mathrm{O}_{4}$. Afterwards El-Shafai et al. ${ }^{181}$ further modified the system by combining with $\mathrm{ZrO}_{2}$ and prepared two nanocomposites: (a) GO- $\mathrm{Fe}_{3} \mathrm{O}_{4}$ and (b) $\mathrm{GO}-\mathrm{Fe}_{3} \mathrm{O}_{4}-\mathrm{ZrO}_{2}$. The nanocomposites have smaller band gap compared to GO, resulting in increased adsorption properties and photocatalytic activity towards decomposition of the cationic dye RhB. From the experiments it was observed that $80 \%, 90 \%$ and $98 \%$ of RhB dye degradation were observed in the presence of $\mathrm{GO}, \mathrm{Fe}_{3} \mathrm{O}_{4}$, and $\mathrm{Fe}_{3} \mathrm{O}_{4}-\mathrm{ZrO}_{2}$ respectively. Therefore introduction of $\mathrm{ZrO}_{2}$ certainly improved the dye degradation efficiency of the material and the value obtained is much higher than other reported values. Antibacterial activity of the prepared samples was examined and $\mathrm{GO}-\mathrm{Fe}_{3} \mathrm{O}_{4}$ was found to possess a significant inhibitory effect against $E$. coli, while pure GO and $\mathrm{GO}-\mathrm{Fe}_{3} \mathrm{O}_{4}-$ $\mathrm{ZrO}_{2}$ had not. None of these nanocomposites had any antibacterial activity against staph bacteria (Staphylococcus variety).

Functionality of GO could be improved ${ }^{\mathbf{1 8 2}}$ by combining it with super paramagnetic $\mathrm{Fe}_{3} \mathrm{O}_{4} \mathrm{NP}$ so that it could serve as a biocompatible magnetic drug delivery agent and magnetic resonance contrast agent for MRI. The synthesized GO- $\mathrm{Fe}_{3} \mathrm{O}_{4}$ hybrid has an average particle size of $260 \mathrm{~nm}$ and shows low cytotoxicity compared to GO. $\mathrm{Fe}_{3} \mathrm{O}_{4}$ nanoparticles provide superparamagnetic properties for magnetically targeted drug delivery of non-covalently conjugated hydrophobic doxorubicin, allowing simple manipulation by the magnetic field and magnetic resonance imaging. $\mathrm{GO}-\mathrm{Fe}_{3} \mathrm{O}_{4}$ shows successful fluorescence-tracked transport of the drug with substantial loading and 2.5-fold improved efficacy. $\mathrm{GO}-\mathrm{Fe}_{3} \mathrm{O}_{4}$ retains $\mathrm{pH}$ sensing capabilities of GO used in this work to detect cancerous versus healthy environments in vitro and exhibits visible fluorescence for bioimaging.

The superparamagnetic property of $\mathrm{GO}-\mathrm{Fe}_{3} \mathrm{O}_{4}$ nanocomposites was further utilized for removal of cadmium ions $\left(\mathrm{Cd}^{2+}\right)$ from water. ${ }^{183}$ The material was fabricated via a coprecipitation method with different precursor ratios, from which a suitable ratio of $\mathrm{Fe}_{3} \mathrm{O}_{4} / \mathrm{GO}$ for $\mathrm{Cd}^{2+}$ ion adsorption (4:1) was selected. The composite was found to be a highly efficient $\mathrm{Cd}^{2+}$ adsorbent from water with a BET specific surface area of $180.84 \mathrm{~m}^{2} \mathrm{~g}^{-1}$. GO nanosheets in the material were found to be decorated with $\mathrm{Fe}_{3} \mathrm{O}_{4}$ nanoparticles $(10-15 \mathrm{~nm})$. The adsorption data of the sample followed pseudo-secondorder kinetics and Langmuir isotherm models with the maximum adsorption capacity of $52.083 \mathrm{mg} \mathrm{g}^{-1}$ at $\mathrm{pH} 8$. Recently (2020) Wang et al. ${ }^{184}$ reported a high magnetization (58.42 emu $\mathrm{g}^{-1}$ ) of the $\mathrm{GO} / \mathrm{Fe}_{3} \mathrm{O}_{4}$ nanocomposite even after coating of $\mathrm{Fe}_{3} \mathrm{O}_{4}$ with $\mathrm{GO}$; appreciable drug (temozolomide) loading capacity and satisfactory drug release (under slight acidic conditions) were also obtained. In a concentration range 40-120 $\mu \mathrm{g} \mathrm{ml}^{-1}$ the GO- $\mathrm{Fe}_{3} \mathrm{O}_{4}$ hybrid shows no toxicity against C6 glioma cells but shows a good inhibitory effect on the rat glioma cells when complexed with temozolomide. This result indicates its successful application in targeted drug delivery to cancerous cells. Another group of researchers ${ }^{\mathbf{1 8 5}}$ investigated two kinds of GO-magnetite nanocomposites with a similar core-shell structure but having different interactions (electrostatic or covalent) between cores and shells. This difference in interaction has an effect on regeneration performance and adsorption-desorption of $\mathrm{MB}$ and $\mathrm{Pb}(\mathrm{II})$. It is seen that the composite with electrostatic interaction shows lower regeneration performance than the composite with covalent interaction. 

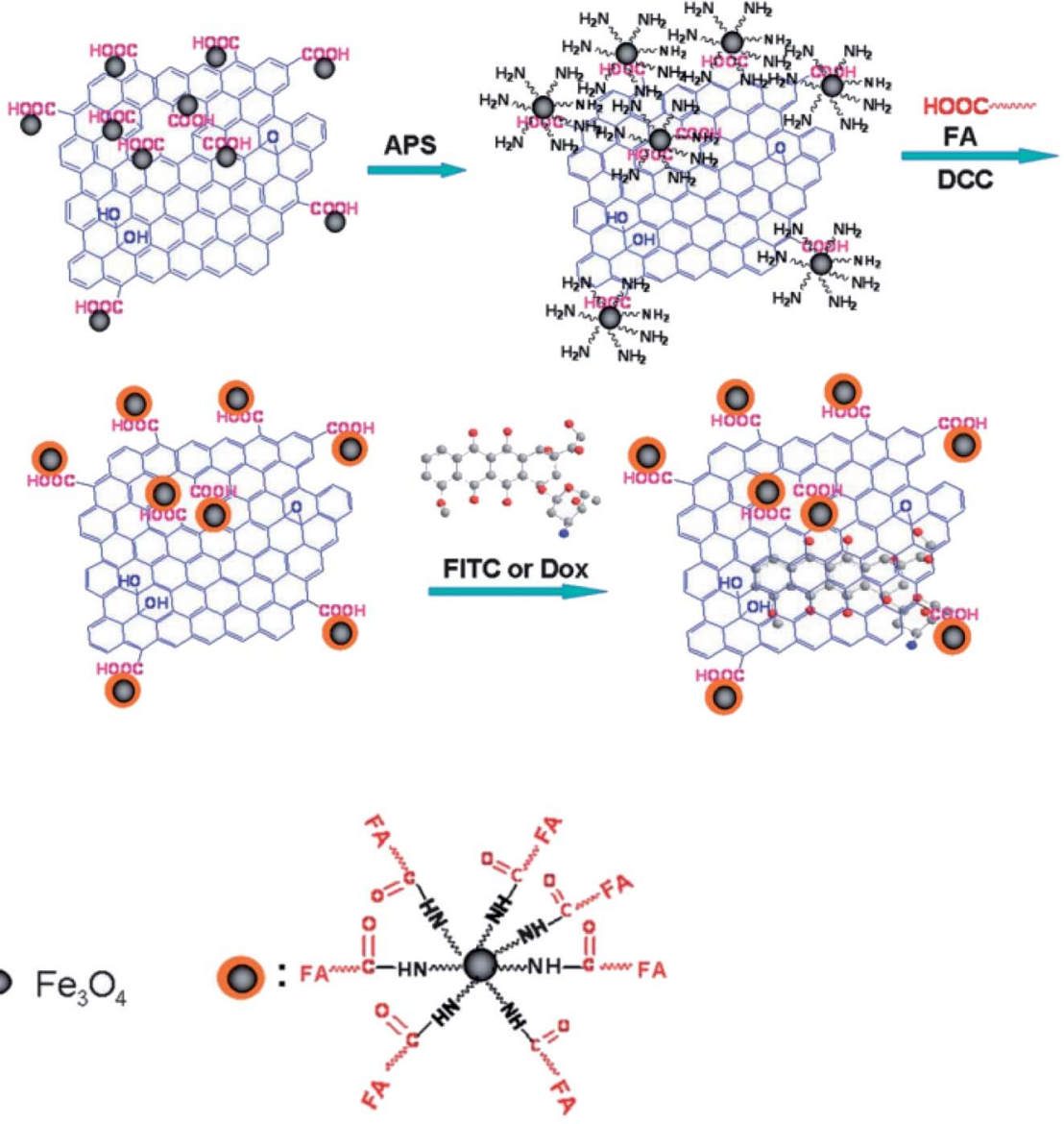

(A)

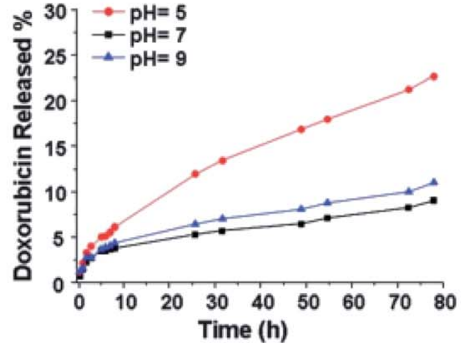

(B) (i)

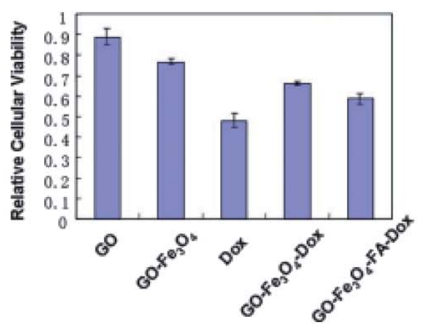

(ii)

Fig. 10 (A) The preparation of the multi-functionalized GO-based anticancer drug-carrier with dual-targeting function and pH sensitivity. (B) (i) The release of Dox on $\mathrm{GO}-\mathrm{Fe}_{3} \mathrm{O}_{4}-\mathrm{FA}$ at different $\mathrm{pH}$ values. (ii) Relative cellular viability of $\mathrm{HeLa}$ cells after treatment with $\mathrm{GO}$, $\mathrm{GOFe}_{3} \mathrm{O}_{4}$, Dox, $\mathrm{GO}-\mathrm{Fe}_{3} \mathrm{O}_{4}-\mathrm{Dox}$ and $\mathrm{GO}-\mathrm{Fe}_{3} \mathrm{O}_{4}-\mathrm{FA}-\mathrm{Dox}$ [this figure has been reproduced from ref. 176 with permission from RSC, Copyright 2011].

\subsection{GO-NiO nanocomposite}

Nickel oxide $(\mathrm{NiO})$ has attracted the attention of researchers due to its large surface area, low cost, good chemical stability, large band gap (3.6-4 eV), and excellent optical, magnetic and ecofriendly characteristics. Preparation of $\mathrm{NiO}$ is a multi-step process in which nickel acetate, urea, PEG-600, and water are stirred at room temperature followed by autoclaving for $12 \mathrm{~h}$ at $160{ }^{\circ} \mathrm{C}$ to get a solid precipitate; the latter is then centrifuged, washed and dried under vacuum followed by calcination at $600{ }^{\circ} \mathrm{C}$ to get the $\mathrm{NiO}$ in hand. There are many works on graphene based $\mathrm{NiO}$ materials and their application in various fields. But very few works are reported on graphene oxide-NiO composites. It is only in the year 2015 when Rong et al. ${ }^{\mathbf{1 8 6}}$ first prepared the GO/NiO nanocomposite via the hydrothermal method. In this method separate dispersions of GO (prepared by the Hummers' method using natural graphite powder) and $\mathrm{NiO}$ were mixed and heated at $85{ }^{\circ} \mathrm{C}$ to get the NiO/GO nanocomposite in hand. They applied the material for the removal of MB dye from water. Very high (97.54\%) removal efficiency under visible light irradiation was observed in $120 \mathrm{~min}$ at $\mathrm{pH}$. An 
optimum dose of nanocomposite of $20 \mathrm{mg}$ was found to have an important application for the waste water treatment containing MB dye. The synthesis was further modified by Jilani et al. ${ }^{187}$ who reported a new technique for preparation of $\mathrm{GO} / \mathrm{NiO}$ by spin coating and radio frequency sputtering. They prepared different nanocomposites by changing deposition time and compared their photocatalytic activities with that of pure $\mathrm{NiO}$ nanoparticles towards degradation of an organic pollutant 2chlorophenol (2-CP). From the experiments it was seen that the $\mathrm{GO} / \mathrm{NiO}$ nanocomposite obtained after 400 seconds deposition time exhibits the highest efficiency compared to others and shows good reusability after three cycles; the product might have application in purification of wastewater.

In a different approach ${ }^{188} \mathrm{NiO}-\mathrm{NP}(\sim 50 \mathrm{~nm})$ were in situ grown on GO sheets following a chemical reaction of $\mathrm{Ni}\left(\mathrm{NO}_{3}\right)_{2}$ with $\mathrm{NaOH}$ and hydrazine hydrate. The GO-NiO nanoparticles were further combined with polyaniline (PAn) via the interfacial polymerization technique to make a solid with very special $\mathrm{NH}_{3}$ sensing properties. PAn itself has inherent $\mathrm{NH}_{3}$ sensing capability, which is much improved in the composite. Following the improved electrical conductivity and UV-vis studies it can be assumed that the NiO-GO component takes part in electron delocalization of PAn, which is the reason behind the improved $\mathrm{NH}_{3}$ sensing capability too. GO-NiO $(\sim 20 \mathrm{~nm})$ combined with $\beta$ cyclodextrin (CD) can also make a very good photocatalyst for degradation of cationic dyes, e.g. MB and methyl violet (MV), ${ }^{189}$ under sunlight. Here, $\beta$-CD enhances interaction with the dye molecules by intercalation in its cup-shaped framework. NiO and $\mathrm{ZnO}$ have been simultaneously combined with GO via the co-precipitation technique to give rise to a novel hybrid mesostructure in a recent report by Obodo et al. ${ }^{\mathbf{1 9 0}}$ The specific nanostructure offers a large conductivity and remarkable supercapacitance due to the presence of GO and a high active surface area due to a strong synergistic effect from $\mathrm{NiO}$ and $\mathrm{ZnO}$ interactions. There was also an improvement in the specific capacitance and conductivity of the nanocomposite due to the addition of GO.

\subsection{GO-CdO, GO-ZrO $\mathrm{Zr}_{2}$ and $\mathrm{GO}-\mathrm{TiO}_{2}$ nanocomposite}

Cadmium oxide is an n-type semiconductor with a large band gap of $2.27 \mathrm{eV}$, a good catalyst for dye degradation. There are so many reports on different metal oxide based GO nanocomposites and their application but it is only recently some researchers selected $\mathrm{CdO}$ for preparing GO/CdO nanocomposites for the first time. J. Ahmad et al. ${ }^{\mathbf{1 9 1}}$ reported enhanced photocatalytic activity of a series of CdO/GO nanocomposites for the degradation of organic pollutants like $\mathrm{MB}$, RhB and methyl orange (MO) compared to pure CdO nanoparticles so that they can be used for removal of organic pollutants from waste water.

$\mathrm{ZrO}_{2}$ is a very important material due to its low production cost, low toxicity, good photothermal and chemical stability, and excellent corrosion resistance, which promotes its use in various fields like removal of fluoride ions, ${ }^{192}$ electrochemical and biochemical sensors, ${ }^{193}$ degradation of organic pollutants, ${ }^{194}$ etc. It can be applied as a heterogeneous catalyst with both oxidizing and reducing properties. Luo et al. ${ }^{195}$ were the first to prepare a graphene oxide-hydrated zirconium oxide nanocomposite and applied the same to remove As(III) and As(v) simultaneously from drinking water. Mudila et al. ${ }^{\mathbf{1 9 6}}$ prepared $\mathrm{GO} / \mathrm{ZrO}_{2}$ and found its good thermal stability, cyclic ability, specific capacitance and its application as a good supercapacitor. Applications of different GO-based nanomaterials in energy storage/supercapacitors are collected in Table 4. In the consecutive year B. Prasanti and T. Damodharam ${ }^{197}$ prepared the same nanocomposite by the hydrothermal method in short time and applied it for waste water treatment by removing (98\%) chromium(vi) with excellent adsorption capacity under UV light. Another group of researchers ${ }^{\mathbf{1 9 8}}$ followed the coprecipitation method for preparing a $\mathrm{GO}-\mathrm{ZrO}_{2}$ nanocomposite and investigated its significant photocatalytic activity under visible light irradiation towards $\mathrm{RhB}$ and $\mathrm{MB}$. The photocatalytic efficiency of the synthesized GO- $\mathrm{ZrO}_{2} \mathrm{NC}$ and $\mathrm{ZrO}_{2}$ was evaluated using $\mathrm{RhB}$ and $\mathrm{MB}$ dye solutions as model organic pollutants. Comparative photo degradation ability of pure $\mathrm{ZrO}_{2}$ and $\mathrm{GO}-\mathrm{ZrO}_{2}$ NC towards degradation of $\mathrm{RhB}$ and $\mathrm{MB}$ dye solution under visible light irradiation is also studied by them.

$\mathrm{TiO}_{2}$ is the most common and cheapest photocatalyst. Hong et al. ${ }^{199}$ first prepared $\mathrm{GO}-\mathrm{V}_{2} \mathrm{O}_{5}$ and $\mathrm{GO}-\mathrm{TiO}_{2}$ by simple mixing of aqueous dispersions without using any additional agents. These nanocomposites show an increased hydrogen storage capacity compared to pristine $\mathrm{GO}, \mathrm{V}_{2} \mathrm{O}_{5}$ and $\mathrm{TiO}_{2}$. In a remarkable work on this topic Stengl et al. ${ }^{200}$ prepared a $\mathrm{GO}-\mathrm{TiO}_{2}$ nanocomposite and found its photocatalytic activity towards the photodegradation of butane in the gas phase. Later on improved photocatalytic activity of $\mathrm{TiO}_{2}-\mathrm{GO}$ nanocomposites was reported by two contemporary publications. Yadav et al. ${ }^{\mathbf{2 0 1}}$ followed the solvothermal method to prepare an anatase $\mathrm{TiO}_{2}$ loaded GO nanocomposite (GOT) with different fractions (\%) of GO loading; among all these nanocomposites GOT-0.25 with $0.25 \%$ GO showed the highest photocatalytic activity towards photo-degradation of benzene gas.

Membrane separation is an efficient technology for purifying water without damaging the contaminants. Hierarchical membranes can operate in a continuous manner and have promising catalyst exposure and catalyst immobilization. Nair

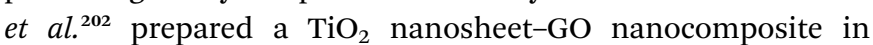
hierarchical membranes for the first time and investigated its enhanced photocatalytic activity towards removing Congo red dye from polluted water. Sharma et al. ${ }^{\mathbf{2 0 3}}$ reported a simple, economic and eco-friendly synthesis method to prepare $\mathrm{TiO}_{2}$ using a green alga (Chlorella pyrenoidosa) loaded on GO sheets. The prepared nanocomposite was applied to the photodegradation of crystal violet dye in water under visible light. The nanocomposite exhibited photocatalytic efficiency even higher than that of pure $\mathrm{TiO}_{2}$ with a good reusability of a number of cycles as shown in Fig. 11 and can be applied for water purification via removal of environmental contaminants.

In a parallel stream of work Liu et al. ${ }^{204}$ reported the preparation of the film of a black titania-graphene oxide nanocomposite, which was wrapped over an expandable polyethylene (EPE) foam surface and used for solar steam generation. The nanocomposite was exhibited as a highly 
Table 4 GO-MO hybrids with catalytic and energy storage properties (solar cells, supercapacitors, $\mathrm{H}$-storage, and Li ion batteries)

\begin{tabular}{|c|c|c|c|}
\hline Composition & Synthesis/structure & Utility & Ref. \\
\hline GO-Mg & $-\mathrm{C}-\mathrm{O}-\mathrm{Mg}$ bond & Hydrogen storage via adsorption & 71 and 72 \\
\hline GO-Pd & Hydrothermal method & Non-linear optical device & \\
\hline $\mathrm{GO} / \mathrm{V}_{2} \mathrm{O}_{5}, \mathrm{GO} / \mathrm{TiO}_{2}$ & GO decorated by metal oxide nanoparticles & Hydrogen storage & 73 and 74 \\
\hline $\mathrm{GO} / \mathrm{Zn}_{2}-\mathrm{GeO}_{4}$ & & Li-ion batteries & 76 \\
\hline $\mathrm{GO} / \mathrm{MnO}_{2}$ & & Supercapacitor & 80 \\
\hline GO-ZnO nanorod & GO-ZnO-NR-GO sandwich structure & Optoelectronic property & 154 \\
\hline GO-ZnO & Hierarchical nanocomposite & Supercapacitor & 155 \\
\hline $\mathrm{GO}-\mathrm{ZnO} / \mathrm{NiO}$ & Co-precipitation, novel mesostructure & Good supercapacitance & 190 \\
\hline GO-PAn, GO-PPy & Chemical oxidative polymerization & Energy storage, supercapacitor & $255,262-264$ and 269 \\
\hline Nanofilm & LbL and LB technique & & \\
\hline
\end{tabular}

efficient solar absorber, which enhanced the efficiency of photothermal conversion to $69.1 \%$ under the solar illumination of 1 $\mathrm{kW} \mathrm{m}^{-2}$. Moreover the system exhibited remarkable cycle stability. PMMA is a very important polymer due to its optical, electrical and mechanical properties and good thermal stability. Alamgir et al. ${ }^{205}$ selected PMMA to embed $\mathrm{TiO}_{2}$ and graphene oxide as fillers to prepare two composites viz. PMMA/GO and $\mathrm{PMMA} / \mathrm{GO} / \mathrm{TiO}_{2}$ and found the latter composite to exhibit better elastic properties and better hardness than the former, which improved its efficiency in dental application.

\subsection{GO-MG/magnesia/MgO nanocomposite}

Molecular hydrogen adsorption by carbon nanomaterials, including graphene, GO, fullerene and CNT, has so far been studied widely. $\mathrm{H}_{2}$ adsorption capability of GO frameworks has already been discussed. ${ }^{67-74}$ As for the metal-doped GO, there are a lot of positively charged metal atoms and negatively charged oxygen atoms on the graphene sheets. Usually an electrical field is developed around the metal ion and oxygen to adsorb hydrogen molecules; the metal site is more active to adsorb hydrogen than oxygen sites and the hydroxyl group present on the GO surface lowers the hydrogen storage due to the formation of water. It is Chu Chen et al. ${ }^{71}$ who reported the
Mg-doped GO composite for hydrogen storage. $\mathrm{H}_{2}$ can be strongly adsorbed on Mg-doped GO with a binding energy of $0.38 \mathrm{eV} / \mathrm{H}_{2}$ because $\mathrm{Mg}$ and $\mathrm{O}$ can jointly produce a stronger electric field and polarize $\mathrm{H}_{2}$ along almost the same direction. In this theoretical study reduction of hydroxyl by $\mathrm{Mg}$ metal and the formation of $-(\mathrm{C}-\mathrm{O})-\mathrm{Mg}$ bonds have been shown to increase hydrogen storage. When eight hydrogen molecules are adsorbed by Mg doped GO [Fig. 12] a high value of (5.3 wt\%) hydrogen storage is reached at $200 \mathrm{~K}$ without any pressure.

Later on Liu et al. ${ }^{206}$ prepared a $\mathrm{Mg}(\mathrm{OH})_{2}-\mathrm{GO}$ composite via a hydrothermal method and applied it as the adsorbent to remove Congo red from water. The physical adsorption of Congo Red (CR) dye took place on the nanocomposite and it happened due to electrostatic interaction between the moieties with opposite charge. In 2018 D. Huang et al. ${ }^{207}$ prepared double oxide of $\mathrm{Fe}-\mathrm{Mg}$ hydroxide nanoparticles and uniformly loaded it on GO by the co-precipitation method. The prepared nanocomposite showed high adsorption capacity to heavy metals and selectivity towards $\mathrm{Pb}^{2+}$ and $\mathrm{Cu}^{2+}$. This magnetic adsorbent can be used for separating the heavy metals from polluted water.

Magnesium oxide ( $\mathrm{MgO})$ is an easily available alkaline earth metal oxide with a high surface reactivity, high adsorption capacity, and ease of production. Over time $\mathrm{MgO}$ nanoparticles
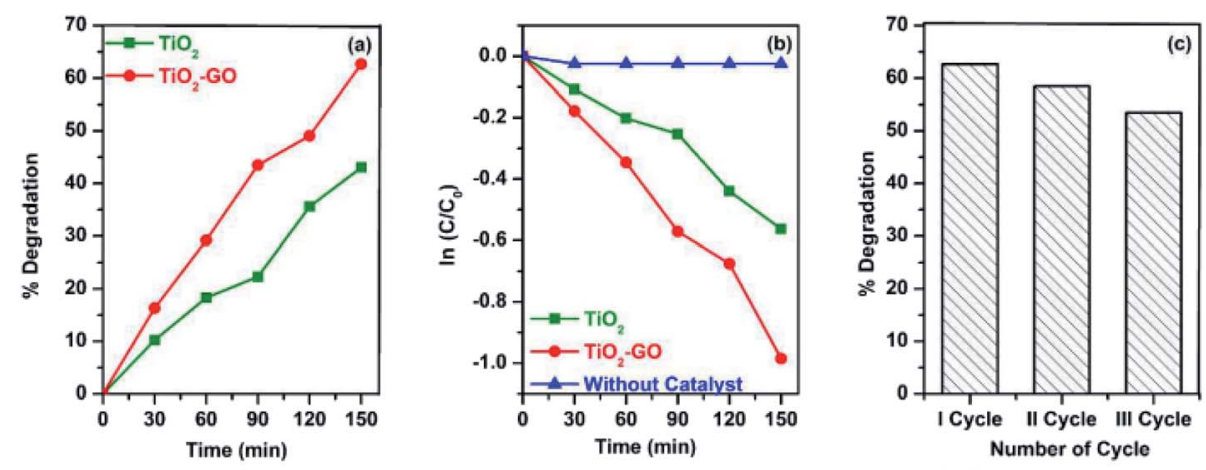

Fig. 11 (a) Photodegradation efficiency of $\mathrm{CV}$ dye using $\mathrm{TiO}_{2}$ nanoparticles and $\mathrm{TiO}_{2}-\mathrm{GO}$ nanocomposites, (b) pseudo-first-order kinetic model for the photodegradation of $\mathrm{CV}$ dye and (c) reusability of $\mathrm{TiO}_{2}-\mathrm{GO}$ nanocomposites up to 3 cycles [this figure has been reproduced from ref. 203 with permission from Elsevier, Copyright 2019]. 


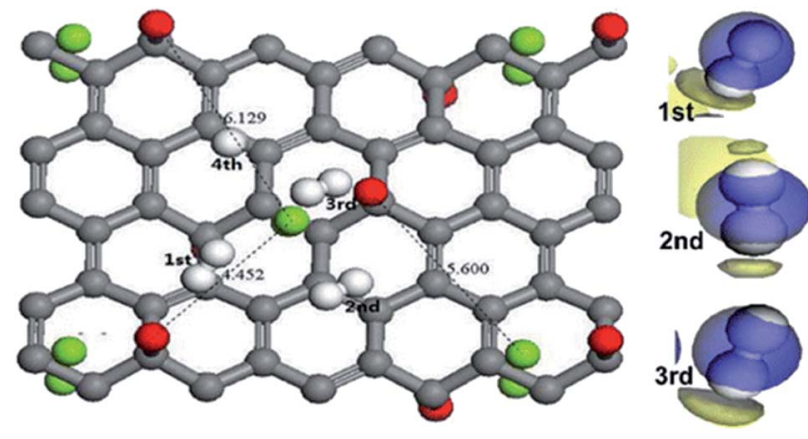

Fig. 12 Structural representation of the adsorption of eight $\mathrm{H}_{2}$ molecules (white balls) on the GO surface [this figure has been reproduced from ref. 71 with permission from American Chemical Society, Copyright 2013].

(MgO NPs) have been used for the removal of organic molecules viz. catechol, phenol, fluoride, formaldehyde and dyes from waste water. ${ }^{208-210}$ Thus, considering the decoration of MgO NPs over the GO platform and the resulting synergistic advantage $\mathrm{GO} / \mathrm{MgO}$ nanocomposites can be considered as a potential adsorbent for removal of pollutants. M. Heidarizad et al. ${ }^{211}$ were the first to introduce a $\mathrm{GO}-\mathrm{MgO}$ nanocomposite with a substantial dye (MB) absorption property. Following a simple impregnation technique they could insert $\mathrm{MgO} \mathrm{NP}(\sim 20 \mathrm{~nm})$ in the GO structure. The GO-MgO nanocomposite with a ratio of $5: 1$ exhibited a maximum dye adsorption capacity of $833 \mathrm{mg}$ $\mathrm{g}^{-1}$, which is higher than that of any previously reported GObased materials; this makes it a promising adsorbent for wastewater treatment. Later on the same group has explored ${ }^{\mathbf{2 1 2}}$ the catalytic property of the nanocomposite for ozonation of phenol in a laboratory scale batch reactor. The results showed that the catalytic ozonation significantly improved the mineralization of phenol compared to that without the catalyst. In parallel the hydrothermal method was followed by Kimiagar et $a .^{213}$ to combine $\mathrm{MgO}$ with GO. The effect of growth temperature on the structural, linear, and nonlinear optical (NLO) parameters was investigated. The third-order NLO susceptibility of $\mathrm{MgO}-\mathrm{GO}$ nanocomposites was measured in the order of $10^{-9}$ esu. The results showed that MgO-GO structures have negative nonlinearity and they possess potential applications in NL photonic devices.

Solvothermal and sol-gel synthesis techniques were combined to synthesize a $\mathrm{GO}-\mathrm{MgO}$ nanosorbent in the presence of polyethylene glycol (PEG). This nanosorbent was used to remove $\mathrm{Cu}^{2+}$ ions from aquatic media and then the parameters that affect the elimination process were perfectly used. ${ }^{214}$ Very recently ${ }^{215} \mathrm{GO} / \mathrm{MgO}$ nanocomposites have been prepared via a simple solvothermal method and have exhibited good absorption capacity to CR. Adsorption (\%) and absolute quantity were found to be $97.84 \%$ and $684.85 \mathrm{mg} \mathrm{g}^{-1}$, respectively, which are superior to those of other adsorbents.

\section{GO based composites with organic counterparts}

\subsection{GO-EDTA}

Ethylenediamine tetraacetic acid (EDTA) is a common hexadentate ligand that can form stable chelates with the metal ions. So it can be suitably used for removal of metal ions from water. When EDTA is combined with GO its removal efficiency is significantly increased. In a report Madadrang et al. ${ }^{216}$ linked EDTA with GO by silanization reaction in which $N$-trimethoxysilylpropyl EDTA (EDTA-silane) reacts with the hydroxyl groups present in GO. The prepared GO-EDTA becomes a very good adsorbent for removing $\mathrm{Pb}(\mathrm{II})$; an adsorption capacity as high as $479 \pm 46 \mathrm{mg} \mathrm{g}^{-1}$ was reached within 20 minutes and at pH 6.8 [Fig. 13]. Moreover, it can be reused after treatment with $\mathrm{HCl}$, which suggests that the GO-EDTA material can be applied for removal of toxic heavy metals and to clean up the environment very efficiently.

After two years Carpio et al. ${ }^{217}$ prepared GO-EDTA and studied its absorption capacity towards heavy metal ions. For the first time they applied the material as a $\mathrm{Cu}^{2+}$ adsorbent and as an antibacterial agent against Gram positive (BS) and Gram negative (Cupriavidus metallidurans) bacteria. The material was found as a very efficient adsorbent of $\mathrm{Cu}$ (II) and $\mathrm{Pb}$ (II) metals under different conditions like concentration, $\mathrm{pH}$ and contact time. The material showed higher adsorption capacity than activated carbon and better antibacterial activity against Gramnegative and Gram-positive bacteria than GO alone. However,
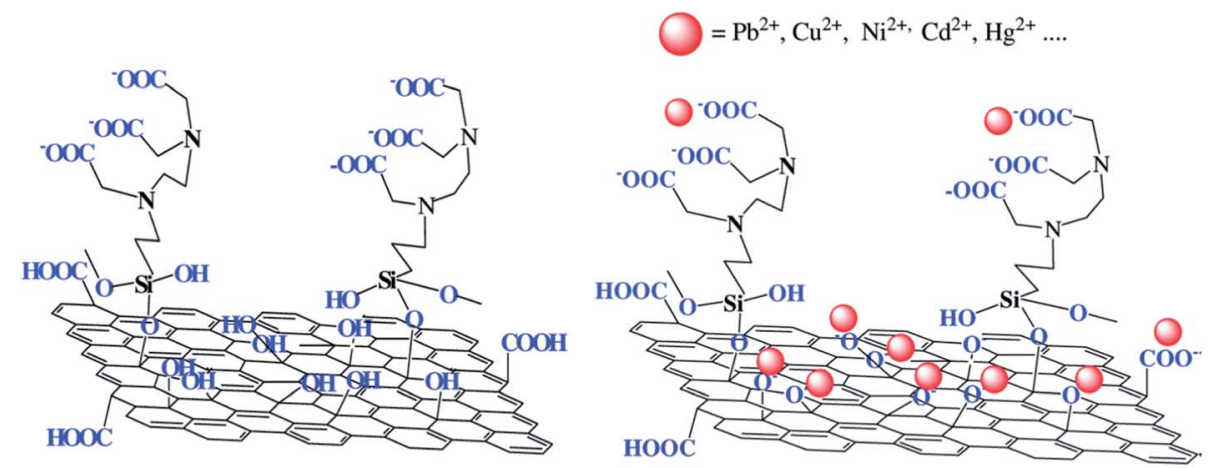

Fig. 13 Structure of GO-EDTA and interaction with metal ions [this figure has been reproduced from ref. 216 with permission from ACS, Copyright 2012]. 
no toxicity to human cells was observed, which offers potential multifunctional use of the material in fabricating devices for biomedical, catalytic, water treatment, microbial control, and metal binding applications.

Later on Zhao et al. ${ }^{218}$ prepared ETDA modified GO (GOEDTA) and amine-silane modified GO (GO-amine) and investigated that the prepared derivatives are very good adsorbents for removing $\mathrm{Ni}$ (II) from water. The incorporation of amine and EDTA groups significantly increase the adsorption capacity of GO and the derivatives can be used to control water pollution by removing $\mathrm{Ni}$ (II) ions as shown in Fig. 14. In the same year Cui et $a .^{219}$ for the first time synthesised $\mathrm{Fe}_{3} \mathrm{O}_{4}$ loaded on GO, i.e. magnetic GO (mGO), and anchored it with EDTA. The prepared EDTA-mGO showed excellent adsorption properties and removal efficiency of heavy metals $\mathrm{Pb}$ (II), $\mathrm{Hg}$ (II) and $\mathrm{Cu}(\mathrm{II})$. It was observed that EDTA-mGO displayed higher adsorption ability than EDTA-GO, mGO and EDTA- $\mathrm{Fe}_{3} \mathrm{O}_{4}$. Even after five recycles the material largely retains its removal efficiency, which suggests the material as an efficient adsorbent for removing heavy metals.

GO was also used as a semiconductor functionalized with various photosensitizers, among which porphyrin (PP) derivatives and their corresponding metal complexes offer several advantages, including their strong absorptivity in a visible region, thermal stability, photostability and versatile modification with GO through covalent and noncovalent interactions. The synthesis of these hybrid structures based on graphene materials and porphyrins follows the fundamental concepts of the interaction both between the aromatic platforms of components and functional substituents grafted to the porphyrin ring and carbon substrate. Self-assembly of such functionalized porphyrin derivatives gives rise to ordered porous surface structures or metal-organic frameworks (MOF) through metal ion-organic ligand coordination. In a series of works tetraphenyl and tetrakis-hydroxyphenyl derivatives of PP (TPP and THPP) along with their Co and Zn-complexes have been used to design metal-organic frameworks with improved performance compared to GO towards photocatalytic, fuel cell and gas separation applications. ${ }^{220}$ In a series of works tetraphenyl and tetrakis-hydroxyphenyl derivative of PP (TPP, THPP) along with their Co and $\mathrm{Zn}$-complexes has been used to design metal-organic framework with GO having improved performance than GO itself towards photocatalysis, electrocatalysis, fuel cell, methane sorbent and gas separation applications. ${ }^{220}$

\subsection{GO-chitosan}

Chitosan (CS) is a linear polysaccharide that is composed of randomly distributed D-glucosamine (deacetylated unit) and $\mathrm{N}$ acetyl-D-glucosamine (acetylated unit). Chitosan is a renewable natural biopolymer, which has excellent biodegradability, biocompatibility and antibacterial property due to the presence of various chelating groups like amino and hydroxyl groups. With the help of such groups it has strong efficiency of removing metal ions and anionic dyes by electrostatic interaction. On the other hand due to the presence of oxygen containing groups GO has strong affinity towards positively charged ions and organic compounds and very low affinity for anionic dyes due to repulsive electrostatic interaction. Combination of CS with GO modifies the absorption ability of GO as the prepared GO-CS composite material exhibits strong adsorption capacity for removing both anionic and cationic dyes and at the same time for metal ions. This eco-friendly composite hydrogel
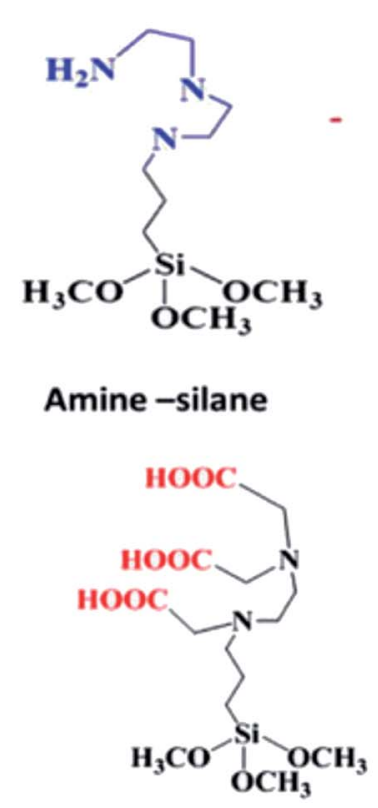

EDTA-silane
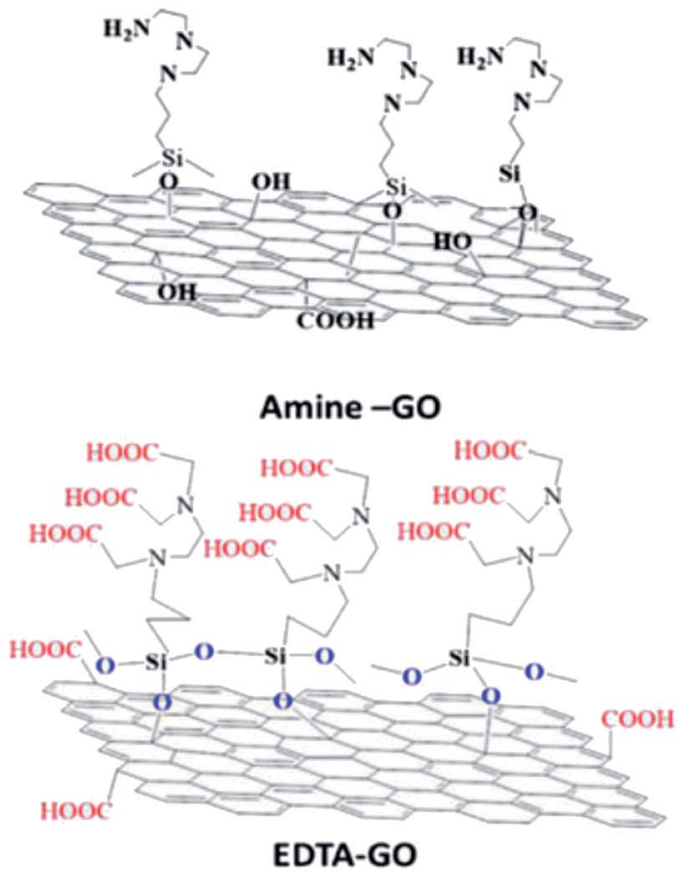

Fig. 14 Structure of EDTA-silane, EDTA-G, amine-silane and amine-GO [this figure has been reproduced from ref. 218 with permission from Elsevier, Copyright 2015]. 
can be widely used to depollute water by removing contaminants and toxic heavy metal ions. It can also be used for water purification by the filtration method.

Yang et al. ${ }^{221}$ first reported a simple method of preparation of a GO-chitosan composite in an aqueous medium via selfassembly. In this method aqueous GO dispersion is mixed with chitosan solution in aqueous acetic acid and stirred for $24 \mathrm{~h}$, after which the homogeneous GO/CS mixture was poured into a glass plate to form a film. The prepared composite with $1 \%(\mathrm{w} / \mathrm{w})$ of GO showed improved tensile strength and Young's modulus and increased elongation at break compared to pure chitosan. In another work Han et al. ${ }^{222}$ prepared a GO-CS composite film by mixing the aqueous solution of both in the presence of dilute acetic acid.

The prepared composite film showed enhanced strength and thermal stability compared to pure chitosan. Interestingly in this report the composite film showed higher tensile strength in the wet state ( 3 times) than in the dry state ( 1.7 times) compared to pure chitosan. Preparation of GO-CS films was further modified by Zuo et al. ${ }^{223}$ through the formation of amide linkage between carboxylic acid groups of GO and amine groups of CS. This is a sort of crosslinking that made the composite film exhibit increased tensile strength (2.5 folds) and Young's modulus (4.6 folds) respectively compared to the pristine chitosan composite. Glass transition temperature of the GO-CS film $\left(158{ }^{\circ} \mathrm{C}\right)$ also becomes higher than that of pure chitosan $\left(118{ }^{\circ} \mathrm{C}\right)$, indicating higher thermal stability of the composite, which was important for its application in biosensors, water treatment, drug delivery and food packaging.

The crosslinking between GO and CS was further improved by Chen et $a .^{224}$ who could design a $3 \mathrm{D}$ network by mutual crosslinking of GO and CS [Fig. 15]. The composite was synthesized in the form of a mechanically strong hydrogel due to hydrogen bonds and electrostatic interactions between GO and CS. This eco-friendly composite hydrogel was applied for the first time to remove organic dyes, both cationic (MB) and anionic (eosin $\mathrm{Y}$ ) origin showing a very high adsorption capacity $\left(>300 \mathrm{mg} \mathrm{g}^{-1}\right)$.

It was also used as an adsorbent of heavy metal ions viz. $\mathrm{Cu}(\mathrm{II})$ and $\mathrm{Pb}(\mathrm{II})$ from water. In future it can be used in water purification columns for removing toxic dyes and metal ions. In the successive year Zhao et al. ${ }^{225}$ prepared a GO-CS composite hydrogel and found its good removal efficiency towards three organic dyes namely Congo red, rhodamine B and methylene blue, which indicates its promising application in waste water treatment and for removal of toxic dyes. As GO-CS has evolved from a film to a 3-D hydrogel like material, the dye uptake property might have a relationship with the structure and morphology of the GO-CS, which was explored by the group of $\mathrm{M}$ Abolhassani et al. ${ }^{226}$ in consecutive years. They have prepared two types of GO/CS composites, one with granular GO of diameter $0.3-0.7 \mu \mathrm{m}$ and another with nanoscale GO of $90 \mathrm{~nm}$ diameter. In both the composite the ratio of CS/GO was $5: 1 \mathrm{w} / \mathrm{w}$ and the morphology and behaviour of the composite towards cationic and anionic dyes were depending on the size of GO. It is found that for the cationic dye (MB) 95\% removal happened with both composites, while for the anionic dye
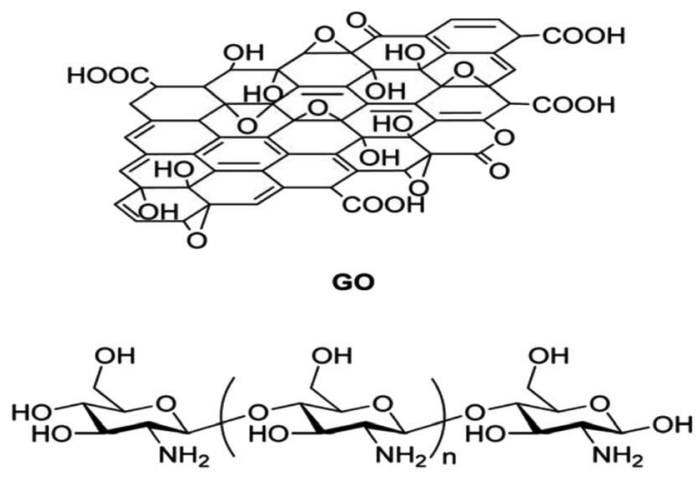

CS
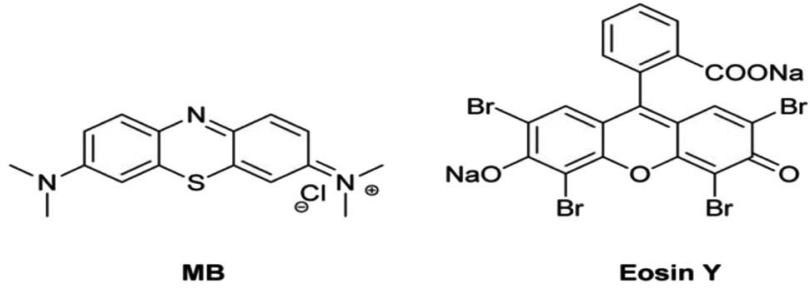

Fig. 15 Chemical structure of GO, CS, MB and eosin $Y$ [this figure has been reproduced from ref. 223 with permission from RSC, Copyright 2013].

(MOR) sorption happened largely (68-99\%) for granular GO, while only $29-64 \%$ adsorption occurred for nano sized GO. It was also observed that composites with variable morphology and increased surface area possess much higher adsorption capacity than GO towards MB dye. Thi et $a .^{227}$ synthesised a chitosan/GO composite and found its adsorption ability towards methylene blue. Crosslinking of GO via CS at an elevated temperature $\left(120^{\circ} \mathrm{C}\right)$ resulted in improved mechanical strength and thermal stability and good antimicrobial properties against Gram positive bacteria (B. subtillis) and Gram negative bacteria (E. coli) as observed by Grande et al. ${ }^{228}$ Later on, Sabzevari et al. ${ }^{229}$ prepared a GO-chitosan composite with variable morphology and increased surface area and found its much higher adsorption capacity than GO towards MB dye.

The modifications in the hydrogel and relevant improvement in properties are still prevalent. Very recently another group of researchers prepared GO-CS hydrogels and found their high adsorption ability towards both cationic dyes and anionic dyes. They investigated good removal efficiency of the prepared composite against two cationic dyes - MB and RhB and two anionic dyes - MOR and CR; after four successive uses the ability of the composite remained unaltered. ${ }^{230}$ One very important modification to GO-CS has been carried out very recently (2020) when Croitoru et al. ${ }^{231}$ have introduced EDTA to the GO-CS composite and prepared a GO/CS/EDTA composite film that exhibited very high adsorption ability towards $\mathrm{Pb}^{2+}$. This composite could be used for removal of both dye and metal ion contaminants from water.

Recently Arun G. K. et al. ${ }^{232}$ prepared polymer laminates with an E-glass fibre reinforced graphene oxide composite by varying the amount of graphene oxide $(1,1.5,2,2.5$ and 3 by weight (\%)) 
in composites. The laminate containing $2.5 \mathrm{wt} \%$ of graphene oxide showed improved mechanical properties compared to other laminates having different weight percentages. The laminate (with $2.5 \mathrm{wt} \% \mathrm{GO}$ ) exhibited higher ductile property, tensile strength, and elongation and was also the hardest material compared to other laminates.

\section{GO-polymer composite}

In the GO based composites as discussed so far, GO due to its large surface area and the functional groups present acts as a dispersant, stabilizer and/or crosslinker, etc. However, there is a separate class of composites in which GO is used as a filler. These are GO-polymer composites without which the discussion on GO-based composites cannot be complete.

Because of their good conductivity, thermal stability, and excellent mechanical strength, graphene and its derivatives are considered as important filler materials for polymer composites. The properties and performances of graphene-polymer composites not only depend on the quality of the graphene filler and polymer matrix, but also on the dispersity of the filler, the bonding between the filler and matrix, and the ratio of the filler to matrix. These factors are mainly determined by the fabrication processes. Similar to the conventional polymer processing, the methods applied for the fabrication of graphene-polymer composites are also classified as (i) solution mixing, (ii) melt blending, and (iii) in situ polymerization. The three techniques have their own advantages and limitations but they were followed for combination of a large variety of polymers with GO.

\subsection{GO with engineering polymers: PVA, PU, PMMA, and PVC}

The solution mixing technique is one of the most commonly used methods for preparation of polymer-GO composites since this is a straightforward and user friendly technique that needs no special instrumental support. Only major concern in this is the solubility of the polymer and dispersity of the GO in the polymer solution. As GO has a good dispersity in water, it is easy to mix up aqueous GO dispersion with water soluble polymers such as poly vinyl alcohol (PVA), poly vinyl acetate (PVAc), poly(2-acrylamido-2-methyl-1-propanesulfonic acid) (PAMPS), etc. following simple solution blending as well as vacuum filtration techniques to form GO based composites. ${ }^{233-237}$ PVA is a very important, low cost, water soluble polymer, which is available in a wide range of molecular weight and has versatile applications. Imparting good mechanical strength to this polymer without hampering its qualities has remained a challenge to the materials scientists over ages. $\mathrm{Xu}$ et al. ${ }^{233}$ have followed the vacuum filtration technique to prepare a strong and ductile PVA-GO composite with a layered structure. The technique was found to be suitable for organizing GO sheets in a near-parallel manner so that a layered structure is evolved. $3 \%$ GO in this report was found to be enough for improvement of both yield strength and elongation (\%) at break (flexibility) of the pristine PVA film to a good extent. Afterwards Hwang et al. ${ }^{238}$ prepared a composite film of PVA and polydopamine-treated
GO (dG-O) and found great enhancement of tensile strength, elongation at break and Young's modulus of PVA after incorporation of dG-O. The composite was applied for humidity sensing.

Structure and mechanical properties of dGO-PVA composite films and their application as a humidity sensor measured through the variation in resistance are shown in Fig. 16. Later on R. Mahendran et al. ${ }^{239}$ used the ultrasonication method followed by mechanical stirring to prepare a GO/PVA/PAMPS (graphene oxide/poly vinyl chloride/PAMPS) composite by solution casting and using deionized water as the solvent. PAMPS is a highly water soluble material with poor mechanical stability. So, PAMPS was blended with PVA to prepare a flexible, thermally stable material with improved mechanical stability. By adding very little quantity $(0.5 \mathrm{wt} \%)$ of GO into the PVA/ PAMPS matrix Young's modulus was found to be enhanced by four times that of the pristine PVA/PAMPS matrix. Moreover the proton conductivity and ion exchange capacity were also increased by loading GO on the polymer matrix. Cheng et al. ${ }^{\mathbf{2 4 0}}$ added hydroxyapatite (HA) to the GO/PVA system to prepare a GO/HA/PVA nanocomposite with much higher tensile strength, elongation and Young's modulus than the HA/PVA matrix. The GO/HA/PVA composite was applied as a good biomedical coating material for bone implants, dental replacements and other surgical purposes.

Considering the poor dispersity of GO in organic solvents, combining organo-soluble polymers with GO has long been a challenge. This problem was overcome to some extent by forming a metastable dispersion of GO in some co-solvents of polymers (e.g. DMF or THF) using the ultrasonication method to get the composite film. The latter method was successful for preparing composites of GO and poly ( $\varepsilon$-caprolactone) (PCL), ${ }^{234}$ polyurethane (PU), ${ }^{235}$ poly methyl methacrylate (PMMA) ${ }^{237}$ and polyaniline (PAn). ${ }^{236}$ It was however important to modify the GO sheet itself by intruding different functional groups so that its dispersity is improved and/or its reaggregation could be prevented. For example, functionalization of GO with phenyl isocyanate improved its dispersity in polystyrene (PS) solution in DMF. In two parallel publications ${ }^{241,242}$ Huang et al. had developed a specially designed polyelectrolyte $\left(\mathrm{PFVSO}_{3}\right)$ with charged $-\mathrm{SO}_{3}$ groups and a triblock copolymer (PEG-OPE) that is attached to the GO and makes it soluble in different polar solvents (DMF, THF, alcohols, etc.) including water.

Polyvinyl chloride (PVC) is another very important widely used polymer due to its low cost, chemical stability, easy processability, low flammability and wide applications in material industry like plastic molds, pipes, fibers, electric cables, etc. The combination of graphene oxide with PVC can open up possibilities to make nanocomposites with improved physicochemical properties. Deshmukh et $a .^{243}$ have prepared a GO/PVC composite by solution blending in THF; surface properties and wettability of the nanocomposite as a function of GO loading were studied by determining the contact angle of composite films. It was seen that the surface roughness, work of adhesion and surface energy are increased with an increase in GO loading and contact angle values were decreased with increasing fraction of GO. Joshi et al. ${ }^{\mathbf{2 4 4}}$ prepared a GO 

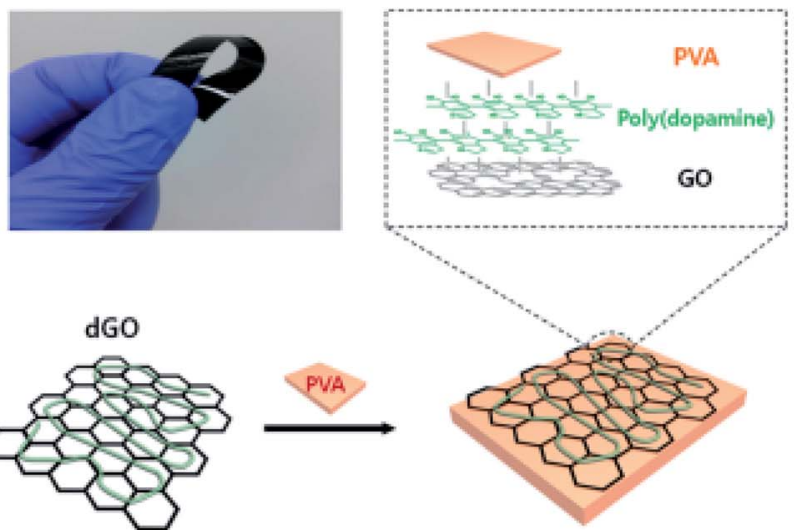

(A)

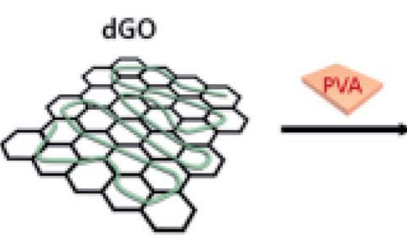

$\checkmark$ : Polydidopumine)

dGO-PVA composite

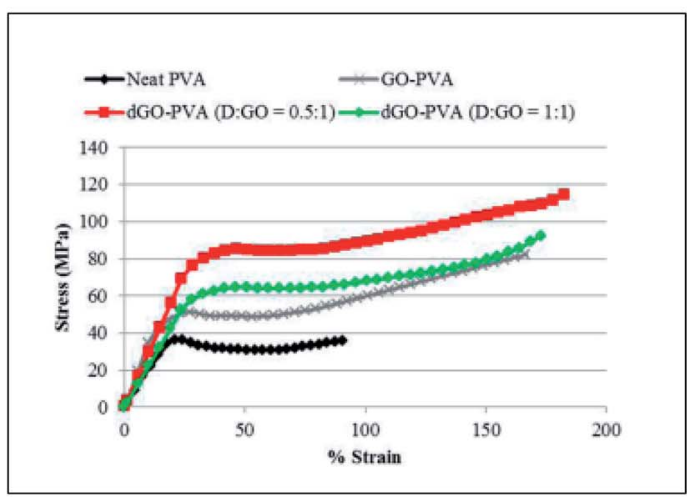

(B)
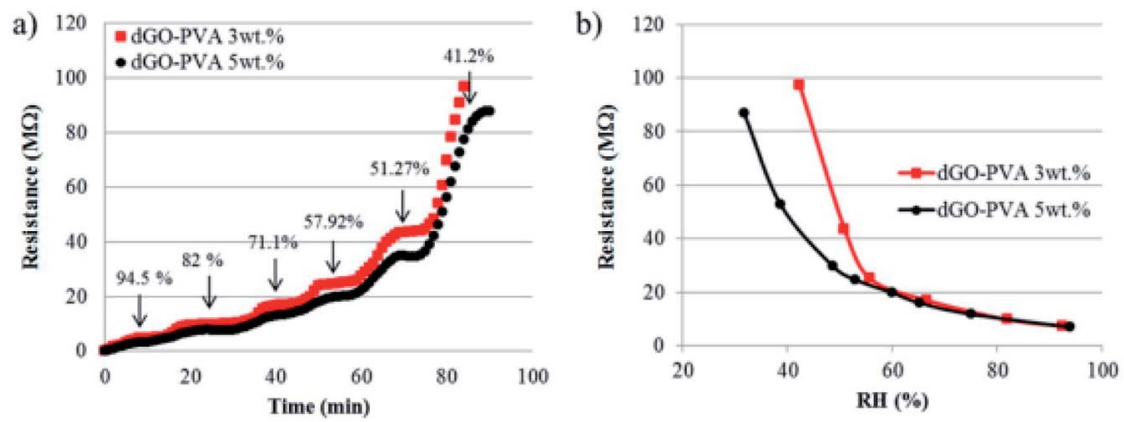

(C)

Fig. 16 (A) Photograph and proposed structure of the dGO-PVA composite film; (B) stress-strain curves of (a) neat PVA, G-O/PVA, and dG-O/ PVA composite films at 0.5 wt\% G-O or dG-O loading and (C) variation of resistance of dGO-PVA films with respect to (a) stepwise dehumidification and (b) linear humidification for different dG-O loadings [this figure has been adapted from ref. 238 with permission from American Chemical Society, Copyright 2014].

reinforced polyvinyl chloride composite by the solution blending method and confirmed the homogeneity of GO/PVC using an optical microscope where $Q$-factor was analysed using an impedance analyzer. They found that the magnitude of $Q$-factor of virgin PVC was rapidly increased to 2200 (from 100) on loading $0.5 \% \mathrm{GO}$, indicating high degree of EMI response of GO. When higher amount of GO is loaded on PVC the $Q$-factor becomes as high as 10 000. They also observed a shift of resonance frequency from $30 \mathrm{MHz}$ of virgin PVC to $100 \mathrm{kHz}$ as a function of loaded GO, which is considered as a great achievement and that makes the material suitable for various electronic applications. For their anticorrosive nature these nanocomposites were found to be more useful for marine and naval applications. In the consecutive year Lee et al. ${ }^{245}$ prepared a flexible PVC film using functionalized graphene oxidehyperbranched polyglycerol as a reinforcing filler and the prepared PVC/HGO (poly vinyl chloride/functionalized graphene oxide) nanocomposites showed a great improvement in tensile strength, durability, toughness and gas barrier properties compared to those of only plasticized PVC. As a result the 
nanocomposites become excellent materials for electrical cables, roofing covers, food wraps, blood storage bags, and synthetic leathers. Another important engineering plastics viz. polyethylene terephthalate (PET) was combined with rGO at $285{ }^{\circ} \mathrm{C}$ under high shear in a melt blending technique to give the PET-graphene composite. ${ }^{\mathbf{2 4 6}}$ However, melt compounding is not as effective as the solution mixing method, in terms of the ability to achieve good dispersity and distribution of the filler materials in the matrix. In addition, the use of high shear forces can sometimes break the filler materials, such as carbon nanotubes and graphene sheets. ${ }^{247}$

\subsection{Combination with insoluble polymers: epoxy resins and conducting polymers}

The solution blending technique, although has a wide applicability, cannot encompass two special categories of polymers viz. epoxy resins and conducting polymers. The former are a sort of thermally crosslinked polymers, which cannot be solubilized or melted. Conducting polymers (CP) on the other hand are also a very especial group of polymers with a conjugated backbone with little or no solubility in any common solvent. Combination of GO with these polymers cannot therefore be made possible using the solution (or melt) blending procedure. In the cases of these polymers an in situ synthesis technique is followed for combination with GO or similar materials. For example GO was directly mixed up with a clear epoxy resin in 1.5-6.0 vol\% at room temperature followed by the addition of the curing agent as reported by S. I. Abdullah et al. ${ }^{248}$ The solvent was then removed under vacuum to get the composite in solid (desirably film) form with improved thermal and mechanical properties. With only 1.5 vol\% loading of GO, different mechanical parameters (Young's modulus, elongation at break, etc.) were found to improve by $30-60 \%$.

On the other hand PAn is synthesized in the presence of the GO suspension to grow the composite in situ. Since the polymerization of PAn is an oxidative coupling process, the oxidative agent, such as ammonium persulfate, is added to the solution containing aniline and GO to initiate the polymerization as followed by Zhang et $a .^{249}$ and Yan et al. ${ }^{250}$ In addition to solution-based oxidation, the graphene-PAn composite can also be prepared via an in situ anodic electropolymerization method introduced by Wang et al. ${ }^{251-252}$ In the later method graphene paper (obtained via reduction of thermally expanded GO, followed by filtration and vacuum drying) is used as the working electrode (anode) of the three-electrode electrochemical cell containing the electrolyte with aniline monomers. PAn was then electrochemically deposited within the graphene paper (anodic oxidation polymerization) to produce the composite film on the electrode.

All these CP based nanocomposites obviously exhibit improved physical properties compared to the components and therefore possess upgraded application potential. For example by coating graphene nanosheets (GNS) with $\sim 2 \mathrm{~nm}$ PAn nanoparticles, a high capacitance of $1046 \mathrm{~F} \mathrm{~g}^{-1}$ was achieved compared to the $115 \mathrm{~F} \mathrm{~g}^{-1}$ for pure PAn. ${ }^{249}$ In addition to PAn nanoparticles, PANI nanofibers have also been incorporated into GO sheets, which exhibited a specific capacitance of $531 \mathrm{~F}$ $\mathrm{g}^{-1}$ at a mass ratio of $100: 1$ for PANI : GO. ${ }^{251}$ In another report, the flexible graphene paper-PAn composite has exhibited a good electrochemical capacitance of $233 \mathrm{~F} \mathrm{~g}^{-1}$, and $135 \mathrm{~F}$ $\mathrm{cm}^{-3}$ for gravimetric and volumetric capacitance, respectively. It surpasses many carbon-based flexible electrodes as a promising candidate for supercapacitors. ${ }^{252}$ Later on a facile strategy to prepare a GO/PANI nanocomposite by in situ polymerization with the assistance of supercritical carbon dioxide $\left(\mathrm{SC}-\mathrm{CO}_{2}\right)$ has been reported by $\mathrm{Xu}$ et $a .^{253}$ The GO/PANI nanocomposite exhibits better specific capacitance and cycle stability than pure PANI and GO (or the physical mixture of both) owing to the synergistic effect of GO and PANI nanoparticles, making it promising for application in electrochemical devices. In another publication Gui et al. have synthesized ${ }^{254}$ three PANIGO nanocomposite based electrode materials from aniline (ANI), GO, and ammonium persulfate (APS) in ice water by chemical polymerization varying the mass ratio (ANI : GO). These composites were found to possess exciting potentials for high performance supercapacitors or other power source systems. In a relatively different approach GO was added to a system consisting of surfactant-wrapped/doped polyaniline (PANI) and divinylbenzene (DVB). The nanocomposites prepared this way were fabricated by a simple blending, ultrasonic dispersion and curing process. The new composites show higher conductivity $\left(0.02-9.8 \mathrm{~S} \mathrm{~cm}^{-1}\right)$ than the other reported polymer systems filled with PANI $\left(10^{-9}\right.$ to $\left.10^{-1} \mathrm{~S} \mathrm{~cm}^{-1}\right)$.

Graphene oxide based nanocomposites were prepared through the in situ polymerization of aniline and pyrrole to study the interaction of graphene oxide with polyaniline (PANI) and polypyrrole (PPy) separately by Pal et al. ${ }^{255}$ It was observed that the specific capacitance of PPy coated GO improved by $\sim \mathbf{1 2 2 . 7 3 \%}$ compared to pristine GO. Moreover, the binding energy of polypyrrole-graphene oxide was found to be higher than that of polyaniline-graphene oxide because of the absence of oxygen containing functional groups. In addition, the storage capacity was effectively improved due to the synergistic effect of the polypyrrole coating on graphene oxide. Later on Saha et al. ${ }^{256}$ have reported interesting $\mathrm{pH}$ dependent tuneable photoluminescence of the GO-polyaniline nanocomposite. In one report Yang et al. ${ }^{257}$ have described a one-pot synthesis of the PPy/GO@ $\mathrm{Fe}_{3} \mathrm{O}_{4}$ magnetic nanocomposite following a chemical oxidative route followed by co-precipitation; $\mathrm{Fe}(\mathrm{III})$ played the role of an oxidizing agent as well as the precursor of $\mathrm{Fe}_{3} \mathrm{O}_{4}$. The material could be used for electrochemical sensing of hydrazine (detection limit $1.4 \mu \mathrm{m}$ ). Later on Nezhad et al. have introduced a modified chemical method to construct a magnetic nanocomposite (polypyrrole/GO@ $\mathrm{Fe}_{3} \mathrm{O}_{4}$ ). First, the GO nanosheets were fabricated through the modified Hummers' method, and then, the $\mathrm{Fe}_{3} \mathrm{O}_{4}$ nanoparticles and polypyrrole were decorated on the surface of the GO nanosheets by co-precipitation of ferrous salts and pyrrole monomer in the GO suspension. ${ }^{258}$ In the successive year a nanocomposite with a similar composition was reported by Getiren et al. ${ }^{259}$ who have explored the photothermal property of the same, having application in photothermal therapy (PTT). The temperature of the PTT agents was found to reach $55.5^{\circ} \mathrm{C}, 72.3^{\circ} \mathrm{C}$ and $83.1^{\circ} \mathrm{C}$ under the irradiation 
with an $808 \mathrm{~nm}$ NIR laser for 10 min under specified conditions. The GO-PAn nanocomposite was very often prepared by simple chemical oxidative polymerization using APS as shown in Fig. 17; the same was explored as a good adsorbent for $\mathrm{Cd}^{2+}$ by Farajvand et $a .^{260}$

By employing the above mentioned methods, GO sheets are mostly randomly stacked in the polymer matrix. To enhance the directional mechanical strength of graphene-polymer composites, layer-by-layer (LbL) assembling has been carried out to prepare free-standing composite membranes. This LbL fabrication was conducted using the Langmuir-Blodgett (LB) technique to transfer GO sheets onto multilayer films of polyelectrolytes viz. poly(allylamine hydrochloride) (PAH) and pol$y$ (sodium 4-styrene sulfonate) (PSS). ${ }^{261}$ The resulting composite membrane showed a huge improvement in the elastic modulus, from $\sim 1.5 \mathrm{GPa}$ for the pure polymer membrane to $\sim 20 \mathrm{GPa}$ for 8 vol\% graphene loading. These polyelectrolyte-based membrane materials are conductive, flexible and exhibit good mechanical properties, which can be useful in fabricating capacitive pressure sensors, supercapacitors, chemical sensors and micro-electromechanical systems (MEMS). ${ }^{262-264}$ The combination of graphene with PAn has been proved to be very fruitful in fabrication of biosensors. Large surface area of graphene and GO combined with electrical conductivity and redox activity of PAn results in effective enzyme loading and efficient wiring to the electrode. Fabrication of a glucose biosensor from GO-PAn is schematically shown in Fig. 17. In a significant work Wei et al. ${ }^{265}$ have incorporated GO-PAn in a thermoresponsive hydrogel (PAMPSA) to design a NIR-responsive biosensor that reversibly absorbs and releases Bovine Serum Albumin (BSA) in the absence and presence of light $(808 \mathrm{~nm})$. In a recent publication Morteza et al. have synthesized methacrylate functionalized GO (MeGO) and has combined the same with PAn; this combination has been applied for fabrication of a highly efficient biosensor for determination of ascorbic acid. ${ }^{266-267}$

In a very recent article Danio et al. ${ }^{268}$ have reported the GOPAn nanofilm formed by LbL self-assembly of functionalized GO (PAH : GO) and PAn (PANI : PAAMPSA) on the $\mathrm{Si}^{-\mathrm{SiO}_{2}}$ surface. Two different enzymes (urease and penicillinase) are separately immobilized on the top of a five-bilayer stack of the

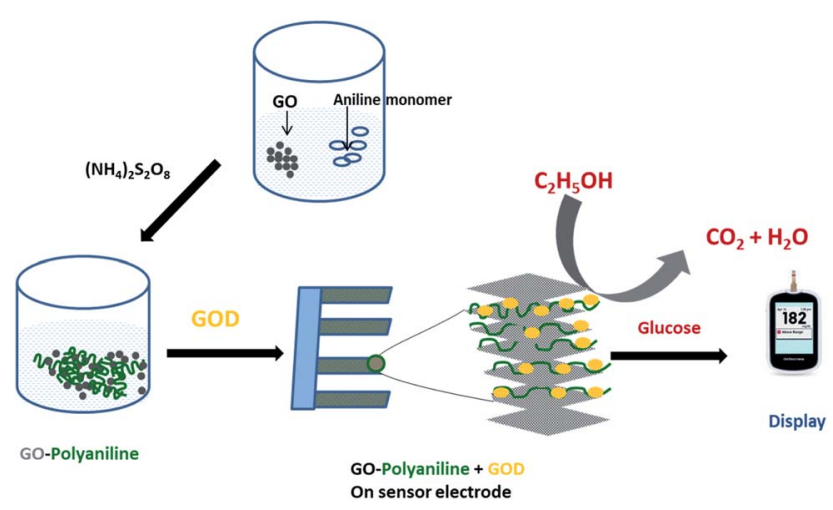

Fig. 17 Synthesis of GO-PAn and immobilization of glucose oxidase (GOD) on GO-PAn for the fabrication of a glucose biosensor.
PAH : GO/PANI : PAAMPSA-modified electrolyte-insulatorsemiconductor (EIS) chip, forming a biosensor for detection of urea and penicillin, respectively. A $15 \%$ increase in the average sensitivity of the modified biosensors (EIS-nanofilm-enzyme) is found compared to the EIS-enzyme electrode. The nanofilm therefore acts as a stable bioreceptor onto the EIS chip, improving the output signal in terms of sensitivity and stability.

Earlier it was observed that GO-PPy can form flexible and binder-free electrode materials for the fast development of smart supercapacitor devices. ${ }^{269}$ In a simple and effective strategy a flexible composite membrane of reduced graphene oxide and polypyrrole nanowires (RGO-PPy) was fabricated via in situ reduction of GO and self-assembly of the component. By direct coupling of two membrane electrodes, symmetrical supercapacitors could be fabricated without the use of a binder and conductive additive. The supercapacitor was able to offer large areal capacitance $\left(175 \mathrm{mF} \mathrm{cm}^{-2}\right)$ and excellent cycling stability ( $\sim 93 \%$ capacitance retention after 5000 chargedischarge cycles). In a recent work a polypyrrole/graphene oxide (PPy/GO) composite electrode was prepared by one-step electrochemical codeposition on a nickel foam electrode. ${ }^{270}$ Spherical PPy particles were found to be deposited on the surface of GO and the GO-PPy composite was used as the cathode for the capacitive deionization (CDI) process for removing different heavy metal ions, with adsorption capacity in the order $\mathrm{Ag}^{+}<$ $\mathrm{Cd}^{2+}<\mathrm{Cu}^{2+}<\mathrm{Pb}^{2+}<\mathrm{Fe}^{3+}$. Therefore, the PPy/GO composite electrode is proved to be a promising high-performance material for CDI. Further research and development is going on to incorporate PAn, PPy and other conducting polymers in GO (or vice versa) more effectively in order to improve the properties and to find out new applications.

\section{Conclusion}

It is therefore obvious that since the arrival of GO, the field of GO-based nanohybrids has flourished enough to present a separate class of materials. Over the last one decade this sector has been regularly enriched with inclusion of novel hybrid materials with improved functionality and application. Soon after the discovery of GO, different research groups have jumped into the field and have tried combining a broad spectrum of external materials with GO sheets. Most of the attempts were successful because of the flexibility of GO to be combined with materials of versatile origin. As a result, a large variety of hybrids were designed after incorporating different metal and metal oxide NP, organic ligands, etc. into GO as well as after incorporation of GO itself into polymeric matrices. Most of these combinations have successfully complemented the properties of GO and hence within few years the frontier of GO based nanohybrid materials was largely expanded and novel applications were suggested. This review has carefully witnessed the progress in this field and has taken into account all these developments chronologically.

After the thorough survey of the materials developed in this field it can be concluded that the synthesis technique in each case has been gradually modified over time with a parallel improvement in performance of the materials. On the other 
hand multicomponent hetero-structures with improved functionalities also evolved in which two or three different oxides were combined with GO. Although GO is endowed with large surface area, it has hardly been exploited as an inert support to the functional NP and the latter was also hardly used for increasing surface area only. Rather an obvious synergistic effect has taken place between the GO and the NP components, which is the key to the evolution of these hybrid materials with improved performance. The coupling of GO with photoactive metal oxide semiconductors synergistically enhances the photocatalytic activity of metal oxides for the degradation of various waterborne pollutants viz. a wide range of organic dyes and pathogens. The large surface area of GO is however retained and even expanded in the 3D networks formed in the ligand modified nanocomposites viz. GO-EDTA and GO-CS. Adsorption of heavy metal ions and organic molecules via electrostatic or chemical interactions, and drug loading/delivery are also facilitated by the large surface area of GO based hybrids discussed here. Effective PTT and biosensing applications added to the antibacterial and dye degradation are also based on such mutual interaction between the GO and PAn/PPy.

Summarily, the unique properties of GO, in combination with MO-NP, ligand and polymers induce high adsorption capacity, extended light absorption range and improved charge separation properties, which are exploited in water purification, biomedical fields and energy storage devices. Therefore GO based hybrids until now appear to be very promising materials although lots of limitations are yet to overcome for optimizing their performance. In order to reach the field of commercial application GO-based hybrids have to compete with the existing materials, which requires easy and cost effective synthesis of the materials. For the adsorbents and sensors, selectivity criteria must also be improved. Therefore complete understanding of various phenomena and properties related to GO is needed to design more efficient devices. However, research in this field is yet in an initial stage and confined/limited in the laboratory regime only. This review can be an input to the sum of efforts for understanding various phenomena and properties related to the GO-based nanohybrids, which include external components of diverse nature.

While the earlier authors have very often reviewed the GOMO based materials with respect to their applications, the present review has taken a different approach. It is focused to the chronological development of individual materials viz. GO, GO-MO (CuO, MgO, ZnO, etc.), GO-ligand (GO-chitosan/EDTA) and GO-polymer (PVA, PMMA, PAn, and PPy) hybrids. Updated account of the evolution of the synthesis methodologies, properties and applications of individual materials (since their arrival up to very recent time) has been discussed in the present literature, which is not available until now. It is not possible to cite all published works in this field; we have however tried to cover most of the important and highly cultivated materials and their evolution in this context. We hope this exhaustive review will be quite helpful to the scientists working in the relevant fields.

\section{Abbreviations}

$\begin{array}{ll}\text { GO } & \text { Graphene oxide } \\ \text { RGO } & \text { Reduced graphene oxide } \\ \text { MO } \mid & \text { Metal oxide } \\ \text { NP } & \text { Nanoparticles } \\ \text { EGO } & \text { Exfoliated graphene oxide } \\ \text { RB } & \text { Rhodamine B } \\ \text { MLB } & \text { Methyl blue } \\ \text { MOR } & \text { Methyl orange } \\ \text { MB } & \text { Methylene blue } \\ \text { NCS } & \text { Nanocomposites } \\ \text { EDTA } & \text { Ethylenediaminetetraacetic acid } \\ \text { CS } & \text { Chitosan } \\ \text { Pst } & \text { Pseudomonas syringae pv. tomato } \\ \text { SA } & \text { Staphylococcus aureus } \\ \text { BS } & \text { Bacillus subtilis } \\ \text { E. coli } & \text { Escherichia coli } \\ X . \text { oryzae } & \text { Xanthomonas oryzae } \\ \text { P. aeruginosa } & \text { Pseudomonas aeruginosa } \\ \text { DOX } & \text { Doxorubicin hydrochloride } \\ \text { BSA } & \text { Bovine serum albumin } \\ \text { PMMA } & \text { Poly methyl methacrylate } \\ \text { PVA } & \text { Polyvinyl alcohol } \\ \text { PVC } & \text { Polyvinyl chloride } \\ \text { PET } & \text { Polyethylene terephthalate } \\ \text { PPy } & \text { Polypyrrole } \\ \text { PAn } & \text { Polyaniline } \\ \text { MEMS } & \text { Micro-electromechanical systems } \\ \text { PPT } & \text { Photo-thermal therapy } \\ & \end{array}$

\section{Conflicts of interest}

Authors declare no conflicts of interest.

\section{References}

1 K. S. Novoselov, A. K. Geim, S. V. Morozov, D. Jiang, Y. Zhang, S. V. Dubonos, I. V. Grigorieva and A. A. Firsov, Science, 2004, 306, 666-669.

2 K. S. Novoselov, D. Jiang, F. Schedin, T. J. Booth, V. V. Khotkevich, S. V. Morozov and A. K. Geim, Proc. Natl. Acad. Sci. U. S. A., 2005, 102, 10451-10453.

3 K. S. Novoselov, A. K. Geim, S. V. Morozov, D. Jiang, M. I. Katsnelson, I. V. Grigorieva, S. V. Dubonos and A. A. Firsov, Nature, 2005, 438, 197-200.

4 Y. Zhang, J. W. Tan, H. L. Stormer and P. Kim, Nature, 2005, 438, 201-204.

5 M. D. Stoller, S. Park, Y. Zhu, J. An and R. S. Rudoff, Nano Lett., 2008, 8, 3498-3502.

6 J. U. Lee, D. Yoon and H. Cheong, Nano Lett., 2012, 9, 44444448.

7 C. Lee, X. D. Wei, J. W. Kysar and J. Hone, Science, 2008, 321, 385-388.

8 A. A. Balandin, Nat. Mater., 2011, 10, 569-581. 
9 A. A. Balandin, S. Ghosh, W. Bao, I. Calizo, D. Teweldebrhan, F. Miao and C. N. Lau, Nano Lett., 2008, 8, 902-907.

10 A. S. Mayorov, R. V. Gorbachev, S. V. Morozov, L. Britnell, R. Jalil, L. A. Ponomarenko, P. Blake, K. S. Novoselov, K. Watanabe, T. Taniguchi and A. K. Geim, Nano Lett., 2011, 11, 2396-2399.

11 R. R. Nair, P. Blake, A. N. Grigorenko, K. S. Novoselov, T. J. Booth, T. Stauber, N. M. R. Peres and A. K. Geim, Science, 2008, 320, 1308.

12 H. Kim, C. Mattevi, H. J. Kim, A. Mittal, K. A. Makhoyan, R. E. Riman and M. Chawolla, Nanoscale, 2013, 5, 1236512374.

13 Z. Yin, S. Wu, X. Zhou, X. Huang, Q. Zhang, F. Boey and H. Zhang, Small, 2010, 6, 307-312.

14 M. F. El-Kady, V. Strong, S. Dubin and R. B. Kaner, Science, 2012, 335, 1326-1330.

15 M. Liang and L. Zhi, J. Mater. Chem., 2009, 19, 5871-5878.

16 P. Blake, P. D. Brimicombe, R. R. Nair, T. J. Booth, D. Jiang, F. Schedin, L. A. Ponomarenko, S. V. Morozov, H. F. Gleeson and E. W. Hill, Nano Lett., 2008, 8, 1704-1708.

17 K. C. Kemp, H. Seema, M. Saleh, N. H. Le, K. Mahesh, V. Chandra and K. S. Kim, Nanoscale, 2013, 5, 3149-3171.

18 A. K. Mishra and S. Ramaprabhu, Desalination, 2011, 282, 39-45.

19 C. Shan, H. Yang, J. Song, D. Han, A. Ivaska and L. Niu, Anal. Chem., 2009, 81, 2378-2382.

20 F. Schedin, A. Geim, S. Morozov, E. Hill, P. Blake, M. Katsnelson and K. Novoselov, Nat. Mater., 2007, 6, 652-655.

21 C. N. R. Rao, A. K. Sood, K. S. Subrahamanyam and A. Gobindaraj, Angew. Chem., Int. Ed., 2009, 48, 7752-7777.

22 V. Singh, D. Joung, L. Zhai, S. Das, S. I. Khondaker and S. Seal, Prog. Mater. Sci., 2011, 56, 1178-1271.

23 K. Yang, L. Feng, X. Shi and Z. Liu, Chem. Soc. Rev., 2013, 42, 530-547.

24 M. Khan, J. Mater. Chem. A, 2015, 3, 18753.

25 D. Li, M. B. Muller, S. Gilje, R. B. Kaner and G. G. Wallace, Nat. Nanotechnol., 2008, 3, 101-105.

26 S. Park, J. H. An, I. W. Jung, R. D. Piner, S. J. An, X. S. Li, A. Velamakanni and R. S. Ruoff, Nano Lett., 2009, 9, 15931597.

27 X. Y. Qi, K. Y. Pu, H. Li, X. Z. Zhou, S. X. Wu, Q. L. Fan, B. Liu, F. Boey, W. Huang and H. Zhang, Angew. Chem., Int. Ed., 2010, 49, 9426.

28 X. Y. Qi, K. Y. Pu, X. Z. Zhou, H. Li, B. Liu, F. Boey, W. Huang and H. Zhang, Small, 2010, 6, 663.

29 S. Park, J. An, R. D. Piner, I. Jung, D. Yang, A. Velamakanni, S. T. Nguyen and R. S. Ruoff, Chem. Mater., 2008, 20, 6592.

30 S. Niyogi, E. Bekyarova, M. E. Itkis, J. L. McWilliams, M. A. Hamon and R. C. Haddon, J. Am. Chem. Soc., 2006, 128, 7720 .

31 D. W. Boukhvalov and M. I. Katsnelson, J. Am. Chem. Soc., 2008, 130, 10697-10701.

32 D. R. Dreyer, A. D. Todd and C. W. Bielawski, Chem. Soc. Rev., 2014, 43, 5288-5301.
33 J. A. Yan, L. Xian and M. Y. Chou, Phys. Rev. Lett., 2009, 103, 0868027.

34 D. Chen, H. Feng and J. Li, Chem. Rev., 2012, 112, 60276053.

35 X. Huang, Z. Yin, S. Wu, X. Qi, Q. He, Q. Zhang, Q. Yan, F. Boey and H. Zhang, Small, 2011, 7, 1876-1902.

36 R. K. Upadhyay, N. Soin and S. Sinha Roy, RSC Adv., 2014, 4, 3823-3851.

37 Y. Wang, S. Li, H. Yang and J. Luo, RSC Adv., 2020, 10, 15328-15345.

38 S. Park and R. S. Ruoff, Nat. Nanotechnol., 2009, 4, 217-224.

39 H. A. Becerril, J. Mao, Z. Liu, R. M. Stoltenberg, Z. Bao and Y. Chen, ACS Nano, 2008, 2, 463-470.

40 J. D. Renteria, S. Ramirez, H. Malekpour, B. Alonso, A. Centeno, A. Zurutuza, A. I. Cocemasov, D. L. Nika and A. A. Balandin, Adv. Funct. Mater., 2015, 25, 4664-4672.

41 D. A. Jasim, N. Lozano and K. Kostarelos, 2D Mater., 2016, 3, 014006.

42 G. P. Kotchey, B. L. Allen, H. Vedala, N. Yanamala, A. A. Kapralov, Y. Y. Tyurina, J. K. Seetharaman, V. E. Kagan and A. Star, ACS Nano, 2011, 5, 2098-2108.

43 S. Priyadarsini, S. Mohanty, S. Mukherjee, S. Basu and M. Mishra, J. Nanostruct. Chem., 2018, 8, 128-137.

44 D. R. Dreyer, S. Park, C. W. Bielawski and R. S. Ruoff, Chem. Soc. Rev., 2010, 39, 228-240.

45 P. Dutta, D. Nandi, S. Datta, S. Chakraborty, N. Das, S. Chatterjee, U. C. Ghosh and A. Halder, J. Lumin., 2015, 168, 269-275.

46 G. Eda, G. Fanchini and M. Chhowalla, Nat. Nanotechnol., 2008, 3, 270-274.

47 G. Eda and M. Chhowalla, Adv. Mater., 2010, 22, 2392-2415.

48 J. Robertson, Mater. Sci. Eng., A, 2002, 37, 129-281.

49 H. Chen, M. B. Müller, K. J. Gilmore, G. G. Wallace and D. Li, Adv. Mater., 2008, 20, 3557-3561.

50 C. Chen, Q. H. Yang, Y. Yang, W. Lv, Y. Wen, P. X. Hou, M. Wang and H. M. Cheng, Adv. Mater., 2009, 21, 30073011.

51 Q. Zheng, Y. Geng, S. Wang, Z. Li and J. K. Kim, Carbon, 2010, 48, 4315-4322.

52 L. Liu, J. Zhang, J. Zhao and F. Liu, Nanoscale, 2012, 4, 59105916.

53 Y. Gao, L. Q. Liu, S. Z. Zu, K. Peng, D. Zhou, B. H. Han and Z. Zhang, ACS Nano, 2011, 5, 2134-2141.

54 F. Perrozzi, S. Prezioso and L. Ottaviano, J. Phys.: Condens. Matter, 2015, 27, 013002.

55 Z. Luo, P. M. Vora, E. J. Mele, A. T. C. Johnson and J. M. Kikkawaa, Appl. Phys. Lett., 2009, 94, 111909.

56 B. Konkena and S. Vasudevan, J. Phys. Chem. Lett., 2014, 5, $1-7$.

57 J. Shang, L. Ma, J. Li, W. Ai, T. Yu and G. G. Gurzadyan, Sci. Rep., 2012, 2, 792.

58 C. Galande, A. D. Mohite, A. V. Naumov, W. Gao, L. Ci, A. Ajayan, H. Gao, A. Srivastava, R. Bruce Weisman and P. M. Ajayan, Sci. Rep., 2011, 1, 85.

59 S. Y. Wu, S. Soo, A. An and J. Hulme, Int. J. Nanomed., 2015, 10, 9-24. 
60 K. Krishnamoorthy, N. U. Masuthan, R. Mohan, J. Lee and S. J. Kim, Sci. Adv. Mater., 2012, 4, 1-7.

61 S. S. Nanda, D. K. Yi and K. Kim, Sci. Rep., 2016, 6, 28443. 62 N. Zhang, J. Hou, S. Chen, C. Xiong, H. Liu, Y. Jin, J. Wang, Q. He, R. Zhao and Z. Nie, Sci. Rep., 2016, 6, 28045.

63 D. K. Gupta, R. S. Rajaura and K. Sharma, Int. J. Environ. Sci. Technol., 2015, 1, 16-24.

64 I. Barbolina, C. R. Woods, N. Lozano, K. Kostarelos, K. S. Novoselov and I. S. Roberts, 2D Mater., 2016, 3, 025025.

65 F. Li, X. Jiang, J. Zhao and S. Zhang, Nano Energy, 2015, 16, 488-515.

66 C. X. Guo, Y. Wang and C. M. Li, ACS Sustainable Chem. Eng., 2013, 1, 14-18.

67 S. Patchkovskii, J. S. Tse, S. N. Yurchenko, L. Zhechkov, T. Helne and G. Seifert, Proc. Natl. Acad. Sci. U. S. A., 2005, 102, 10439-10444.

68 Y. Chan and J. M. Hill, Nanotech., 2011, 22, 305403-305410.

69 B. H. Kim, W. G. Hong, H. Y. Yu, Y. K. Han, S. M. Lee and S. J. Chang, Phys. Chem. Chem. Phys., 2012, 14, 1480-1484.

70 J. M. Kim, W. G. Hong, S. M. Lee, S. J. Chang, Y. Jun, B. H. Kim and H. J. Kim, Int. J. Hydrogen Energy, 2014, 39, 3799-3804.

71 C. Chen, J. Zhang, B. Zhang and H. M. Duan, J. Phys. Chem. C, 2013, 117, 4337-4344.

72 L. Wang, F. H. Yang, R. T. Yang and M. A. Miller, Ind. Eng. Chem. Res., 2009, 48, 2920-2926.

73 W. G. Hong, B. H. Kim, S. M. Lee, H. Y. Yu, Y. J. Yun, Y. Jun, J. B. Lee and H. J. Kim, Int. J. Hydrogen Energy, 2012, 37, 7594-7599.

74 L. Wang, K. Lee, Y. Y. Sun, M. Lucking, Z. Chen, J. J. Zhao and S. B. Zhang, ACS Nano, 2009, 3, 2995-3000.

75 H. Wang, L. F. Cui, Y. Yang, H. S. Casalongue, J. T. Robinson, Y. Liang, Y. Cui and H. Dai, J. Am. Chem. Soc., 2010, 132, 13978-13980.

76 F. Zou, X. Hu, L. Qie, Y. Jiang, X. Xiong, Y. Qiao and Y. Huang, Nanoscale, 2014, 6, 924-930.

77 L. Fei, Q. Lin, B. Yuan, G. Chen, P. Xie, Y. Li, Y. Xu, S. Deng, S. Smirnov and H. Luo, ACS Appl. Mater. Interfaces, 2013, 5, 5330-5335.

78 I. V. Lightcap and P. V. Kamat, Acc. Chem. Res., 2013, 46, 2235-2243.

79 L. Ji, M. Rao, H. Zheng, L. Zhang, Y. Li, W. Duan, J. Guo, E. J. Cairns and Y. Zhang, J. Am. Chem. Soc., 2011, 133, 18522-18525.

80 S. Chen, J. Zhu, X. Wu, Q. Han and X. Wang, ACS Nano, 2010, 4, 2822-2830.

81 M. Seredych and T. J. Bandosz, J. Phys. Chem. C, 2007, 111, 15596-15604.

82 M. Seredych and T. J. Bandosz, J. Phys. Chem. C, 2010, 114, 14552-14560.

83 M. Seredych, O. Mabayoje and T. J. Bandosz, J. Phys. Chem. C, 2012, 116, 2527-2535.

84 M. Seredych, O. Mabayoje and T. J. Bandosz, Langmuir, 2012, 28, 1337-1346.

85 M. Seredych, O. Mabayoje and T. J. Bandosz, Chem. Eng. J., 2013, 223, 442-453.
86 T. Yumura and A. Yamasaki, Phys. Chem. Chem. Phys., 2014, 16, 9656-9666.

87 L. Wang, J. Zhao, L. Wang, T. Yan, Y. Y. Sun and S. B. Zhang, Phys. Chem. Chem. Phys., 2011, 13, 21126-21131.

88 C. Chen, K. Xu, X. Ji, L. Miao and J. Jiang, Phys. Chem. Chem. Phys., 2014, 16, 11031-11036.

89 G. Zhao, J. Li, X. Ren, C. Chen and X. Wang, Environ. Sci. Technol., 2011, 45, 10454-10462.

90 S. T. Yang, S. Chen, Y. Chang, A. Cao, Y. Liu and H. Wang, J. Colloid Interface Sci., 2011, 359, 24-29.

91 G. K. Ramesha, A. Vijaya, H. B. M. Kumara and S. Sampath, J. Colloid Interface Sci., 2011, 361, 270-277.

92 S. Stankic, S. Suman, F. Haque and J. Vidic, J. Nanobiotechnol., 2016, 14, 73.

93 K. Yang, L. Feng, X. Shi and Z. Liu, Chem. Soc. Rev., 2013, 42, 530-547.

94 O. Akhavan and E. Ghaderi, ACS Nano, 2010, 4, 5731-5736. 95 X. Huang, Z. Yin, S. Wu, X. Qi, Q. He, Q. Zhang, Q. Yan, F. Boey and H. Zhang, Small, 2011, 7, 1876-1902.

96 H. Mohammed, A. Kumar, E. Bekyarova, Y. A. Hadeethi, X. Zhang, M. Chen, M. S. Ansari, A. Cochis and L. Rimondini, Front. Bioeng. Biotechnol., 2020, DOI: 10.3389/fbioe.2020.00465.

97 L. Richtera, D. Chudobova, K. Cihalova, M. Kremplova, V. Milosavljevic, P. I. Kopel, I. Blazkova, D. Hynek, V. Adam and R. Kizek, Materials, 2015, 8, 2994-3011.

98 J. Ahmad and K. Majid, Polym. Bull., 2021, 78, 3889-3911.

99 A. Jana, E. Scheer and S. Polarz, Beilstein J. Nanotechnol., 2017, 8, 688-714.

100 M. A. Kausor and D. Chakrabortty, Inorg. Chem. Commun., 2021, 129, 108630.

101 P. T. Yin, S. Shah, M. Chhowalla and K. Bum Lee, Chem. Rev., 2015, 115, 2483-2531.

102 A. Khan, J. Wang, J. Li, X. Wang, Z. Chen, A. Alsaedi, T. Hayat, Y. Chen and X. Wang, Env. Sci. Poll. Res., 2017, 24, 7938-7958.

103 S. K. Hazra and S. Basu, C, 2017, 3, 29, DOI: 10.3390/ c3040029.

104 F. Parnianchi, M. Nazari, J. Maleki and M. Mohebi, Int. Nano Lett., 2018, 8, 229-239.

105 W. Cui, M. Li, J. Liu, B. Wang, C. Zhang, L. Jiang and Q. Cheng, ACS Nano, 2014, 8, 9511-9517.

106 Z. S. Wu, G. Zhou, L. C. Yin, W. Ren, F. Li and H. M. Cheng, Nano Energy, 2012, 1, 107-131.

107 J. Zhu, G. Zeng, F. Nie, X. Xu, S. Chen, Q. Hana and X. Wang, Nanoscale, 2010, 2, 988-994.

108 A. Penashteh, M. Fazlollahmousavi and M. Safi Rahmanifar, Electrochim. Acta, 2013, 88, 347-357.

109 J. Song, L. Xu, C. Zhou, R. Xing, Q. Dai, D. Liu and H. Song, ACS Appl. Mater. Interfaces, 2013, 5, 12928-12934.

110 Y. Li, D. Yang and J. Cui, RSC Adv., 2017, 7, 38853-38860.

111 S. R. K. Kumar, G. P. Mamatha, H. B. Muralidhara, M. S. Anantha, S. Yallappa, B. S. Hungund and K. Y. Kumar, J. Sci. Adv. Mat. Devices, 2017, 2, 493-500.

112 K. Ganeshan, V. K. Jyoyi, A. Natarajan, A. Rajaram, S. Ravichandran and S. Ramlingam, Arabian J. Chem., 2020, 13, 6802-6814. 
113 K. Zhang, J. M. Suh, T. H. Lee, J. H. Cha, J. W. Choi, H. W. Jang, R. S. Varma and M. Shokouhimehr, Nano Convergence, 2019, 6, 6.

114 A. Bhattacharjee, B. Morya and C. Ghoroi, Coll. Interface Sci. Commun., 2020, 35, 100239.

115 B. Prashanti, I. Sreevani, B. Suresh and T. Damodharam, Appl. Ecology Environmental Sci., 2019, 7, 176-181.

116 A. Tkach, A. Matsukovich, N. Krekoten, L. Tabulina, V. Labunov and D. Radziuk, ACS Appl. Nano Mater., 2020, 3(6), 5593-5604.

117 Z. Zhang, L. Sun, Z. Wu, Y. Liu and S. Li, New J. Chem., 2020, 44, 6420-6427.

118 N. M. R. Laverde, A. Pruna, J. Cembrero, J. O. Messana and F. Manjón, Bol. Soc. Esp. Ceram., 2019, 58, 263-273, DOI: 10.1016/j.bsecv.2019.06.002.

119 H. Kato, H. Kobayashi and A. Kudo, J. Phys. Chem. B, 2002, 106, 12441-12447.

120 P. Wang, B. B. Huang, X. Y. Qin, X. Y. Zhang, Y. Dai, J. Y. Wei and M. H. Whangbo, Angew. Chem., Int. Ed., 2008, 47, 7931-7933.

121 Z. G. Yi, J. H. Ye, N. Kikugawa, T. Kako, S. X. Ouyang, H. Stuart-Williams, H. Yang, J. Y. Cao, W. J. Luo, Z. S. Li, Y. Liu and R. L. Withers, Nat. Mater., 2010, 9, 559-564.

122 Y. P. Bi, S. X. Ouyang, N. Umezawa, J. Y. Cao and J. H. Ye, J. Am. Chem. Soc., 2011, 133, 6490-6492.

123 X. F. Wang, S. F. Li, H. G. Yu, J. G. Yu and S. W. Liu, Chem.Eur. J., 2011, 17, 7777-7780.

124 G. Wang, X. C. Ma, B. B. Huang, H. F. Cheng, Z. Y. Wang, J. Zhan, X. Y. Qin, X. Y. Zhang and Y. Dai, J. Mater. Chem., 2012, 22, 21189-21194.

125 X. Wang, H. Yua, R. Liu, P. Wang and J. Yu, Appl. Catal., B, 2012, 111-112, 326-333.

126 W. P. Xu, L. C. Zhang, J. P. Li, Y. Lu, H. H. Li, Y. N. Ma, W. D. Wang and S. H. Yu, J. Mater. Chem., 2011, 21, 4593.

127 J. Ma, J. Zhang, Z. Xiong, Y. Yong and X. S. Zhao, J. Mater. Chem., 2011, 21, 3350.

128 J. Cui and Y. Liu, RSC Adv., 2015, 5, 85748-85755.

129 Y. Liang, D. Yang and J. Cui, New J. Chem., 2017, 41, 1369213699.

130 K. A. Fernando, V. G. Watson, X. Wang, N. D. McNamara, M. C. J. Chum, D. W. Bair, B. A. Miller and C. E. Bunker, Langmuir, 2014, 30, 11776-11784.

131 T. T. T. Vi and S. J. Lue, IOP Conf. Ser.: Mater. Sci. Eng., 2017, 162, 012033.

132 T. T. T. Vi, S. R. Kumar, B. Rout, C. H. Liu, C. B. Wong, C. W. Chang, C. H. Chen, D. W. Chen and S. J. Lue, Nanomat., 2018, 8, 163.

133 S. Jaworski, M. Wierzbicki, E. Sawosz, A. Jung, G. Gielerak, J. Biernat, H. Jaremek, W. Łojkowski, B. Woźniak, J. Wojnarowicz, L. Stobiński, A. Małolepszy, M. M. Pawlicka, M. Łojkowski, N. Kurantowicz and A. Chwalibog, Nanoscale Res. Lett., 2018, 13, 116.

134 Q. Liang, Y. Shi, W. Ma, Z. Li and X. Yang, Phys. Chem. Chem. Phys., 2012, 14, 15657-15665.

135 M. Z. Penglei and C. M. Liu, Langmuir, 2012, 28(7), 33853390.
136 S. Wang, C. Liu, L. Zheng, C. Lin, P. Kuang, X. Fu and N. Si, New J. Chem., 2016, 40, 1323-1329.

137 Z. Ji, X. Shen, J. Yang, Y. Xu, G. Zhu and K. Chen, Eur. J. Inorg. Chem., 2013, 6119-6125.

138 J. Ahmad and K. Majid, Adv. Composites and Hybrid Mater., 2018, 1, 374-388.

139 R. Ran, X. Meng and Z. Zhang, Appl. Catal., B, 2016, 196, 115.

140 Y. Y. Bai, F. R. Wang and J. K. Liu, Ind. Eng. Chem. Res., 2016, 55(37), 9873-9879.

141 S. Kumari, P. Sharma, S. Yadav, J. Kumar, A. Vij, P. Rawat, S. Kumar, C. Sinha, J. Bhattacharya, C. M. srivastava and S. Majumder, ACS Omega, 2020, 5, 5041-5047.

142 A. V. A. Mariadoss and M. H. Wang, J. Photochem. Photobiol., B, 2020, 210, 111984, DOI: 10.1016/ j.jphotobiol.2020.111984.

143 N. El-Shafai, M. E. El Khouly, M. El Kemari, M. Ramadan, I. Eldesoukey and M. Masoud, RSC Adv., 2019, 9, 37043714 .

144 Z. Wenbin, J. W. Zhu and X. Wang, Mater. Sci. Forum., 2011, 688, 228-232.

145 B. Li, T. Liu, Y. Wang and Z. Wang, J. Coll. Interface Sci., 2012, 377, 114-121.

146 S. M. Jilani and P. Banerji, ACS Appl. Mater. Interfaces, 2014, 6, 16941-16948.

147 R. Atchudan, T. Nesakumar, J. I. Edison, S. Perumal, D. Karthikeyan and Y. R. Lee, J Photochem Photobiol. B, 2016, 162, 500-510.

148 Y. W. Wang, A. Cao, Y. Jiang, X. Zhang, J. H. Liu, Y. Liu and H. Wang, ACS Appl. Mater. Interfaces, 2014, 6, 2791-2798.

149 L. Zhong and K. Yun, Int. J. Nanomedicine, 2015, 10, 79-92.

150 E. Salih, M. Mekawy, R. Y. A. Hassan and I. M. El-Sherbiny, J Nanostruct. Chem., 2016, 6, 137-144.

151 S. A. Hosseini, S. Mashaykhi and S. Babaei, S. Afr. J. Chem., 2016, 69, 105-112.

152 S. A. Hosseini and S. Babaei, J. Braz. Chem. Soc., 2017, 28(2), 299-307.

153 L. T. Trinh, L. A. B. Quynh and N. H. Hieu, Int. J. Nanotechnol., 2018, 15, 108-117.

154 I. Boukhoubza, M. Khenfouch, M. Achehboune, B. Mothudi, I. Zorkani and A. Jorio, J. Phys.: Conf. Ser., 2018, 984, 012005.

155 K. S. Lee, C. W. Park, S. J. Lee and J. D. Kim, J. Alloys Compd., 2018, 739, 522-528.

156 Z. Durmus, B. Z. Kurt and A. Durmus, ChemistrySelect, 2019, 4, 271-278.

157 N. A. F. Al-Rawashdeh, O. Allabadi and M. T. Aljarrah, ACS Omega, 2020, 5, 28046-28055.

158 L. Zhang, L. Du, X. Yu, S. Tan, X. Cai, P. Yang, Y. Gu and W. Mai, ACS Appl. Mater. Interfaces, 2014, 6, 3623-3629.

159 R. M. Cornell and U. Schwetmann, The Iron Oxide, WileyVCH (Winheim), 2nd edn, 2003.

160 X. Zhou, H. Yang, C. Wang, X. Mao, Y. Wang, Y. Yang and G. Liu, J. Phys. Chem. C, 2010, 114, 17051-17061.

161 M. A. Gondal, A. Hameed, Z. H. Yamani and A. Suwaiyan, Appl. Catal., A, 2004, 268, 159-167. 
162 X. J. Zhu, Y. W. Zhu, S. Murali, M. D. Stoller and R. S. Ruoff, ACS Nano, 2011, 5, 3333-3338.

163 A. K. Gupta and M. Gupta, Biomater., 2005, 26, 3995-4021. 164 M. Mahmoudi, A. S. Milani and P. Stroeve, Int. J. Biomed. Nanosci. Nanotechnol, 2010, 1, 164-201.

165 V. K. Singh, M. K. Patra, M. Manoth, G. S. Gowd, S. R. Vadera and N. Kumar, New Carbon Mater., 2009, 24, 147-152.

166 G. Sheng, G. Zhang, Y. Guo and J. C. Yu, Carbon, 2013, 60, 434-444.

167 S. Paulose, R. Raghavan and B. K. George, RSC Adv., 2016, 6, 45977-45985.

168 S. Mura, Y. Jiang, I. Vassalini, A. Gianoncelli, I. Alessandri, G. Granozzi, L. Calvillo, N. Senes, S. Enzo, P. Innocenzi and L. Malfatti, ACS Appl. Nano Mater., 2018, 1(12), 6724-6732.

169 X. Yang, X. Zhang, Y. Ma, Y. Huang, Y. Wang and Y. Chen, J. Mater. Chem., 2009, 19, 2710-2714.

170 J. Li, S. Zhang, C. Chen, G. Zhao, X. Yang, J. Li and X. Wang, ACS Appl. Mater. Interfaces, 2012, 4, 4991-5000.

171 X. Shen, J. Wu, S. Bai and H. Zhou, J. Alloys Compd., 2010, 506, 136-140.

172 F. He, J. Fan, D. Ma, L. Zhang, C. Leung and H. L. Chan, Carbon, 2010, 48, 3139-3144.

173 X. Ma, H. Tao, K. Yang, L. Feng, L. Cheng, X. Shi, Y. Li, L. Guo and Z. Liu, Nano Res., 2012, 5, 199-212, DOI: 10.1007/s12274-012-0200-y.

174 A. Jubir, C. Yacou, X. Zhang and J. C. D. da Costa, J. Environ. Chem. Eng., 2014, 2, 1881-1888.

175 N. Zubir, C. Yacou and J. Motuzas, Sci. Rep., 2014, 4, 4594. 176 X. Yang, Y. Wang, X. Huang, Y. Ma, Y. Huang, R. Yang, H. Duan and Y. Chen, J. Mater. Chem., 2011, 21, 3448-3454.

177 K. Urbas, M. Aleksandrzak, M. Jedrzejczak, R. Rakoczy, X. Chen and E. Mijowska, Nanoscale Res. Lett., 2014, 9, 656.

178 T. Jiao, Y. Liu, Y. Wu, Q. Zhang, X. Yan, F. Gao, A. J. P. Bauer, J. Liu, T. Zeng and B. Li, Sci. Rep., 2015, 5, 12451.

179 Y.-l. Dong, H.-g. Zhang, Z. U. Rahaman, L. Su, X. j. Chen, J. Hu and X. g. Chen, Nanoscale, 2012, 4, 3969-3976.

180 M. M. Song, H. L. Xu, J. X. Liang, H. Hui, Xiang, R. Liu and Y. X. Shen, Mater. Sci. Eng., C, 2017, 77, 904-911.

181 N. M. El-Shafai, M. E. El-Khouly, M. El-Kemary, M. S. Ramadan and M. S. Masoud, RSC Adv, 2018, 8, 13323-13332.

182 R. G. Rodriguez, E. Campbell and A. Naumov, PLoS One, 2019, 6, DOI: 10.1371/journal.pone.0217072.

183 L. T. M. Thy, N. H. Thuong, T. H. Tu, H. M. Nam, N. H. Hieu and M. T. Phong, Adv. Nat. Sci.: Nanosci. Nanotechnol., 2019, 10, 025006.

184 L. H. Wang, L. Sui, P. H. Zhao and H. D. Ma, Pharmazie, 2020, 75, 313-317.

185 Z. Hu, X. Zhang, J. Li and Y. Zhu, Front. Chem., 2020, 8, 150, DOI: $10.3389 /$ fchem.2020.00150.

186 X. Rong, F. Qiu, C. Zhang, L. Fu, Y. Wang and D. Yang, Powder Technology, 2015, 275, 322-328.

187 A. Jilani, M. H. D. Othman, M. O. Ansari, R. Kumar, I. U. Khan, M. S. A. Wahab, A. Alshahrie, M. A. Barakat and T. A. Kurniawan, J. Mater. Sci., 2018, 53, 15034-15050.
188 S. Ahmad, M. M. A. Khan and F. Mohammad, ACS Omega, 2018, 3, 9378-9387.

189 R. Dewangan, A. Hashmi, A. Asthana, A. K. Singh and M. A. B. Hasan Susan, Int. J. Environ. Anal. Chem., 2020, 1-20, DOI: 10.1080/03067319.2020.1802443.

190 R. M. Obodo, A. C. Nwanya, M. Arshad, C. Iroegbu, I. Ahmad, R. U. Osuji, M. Maaza and F. I. Ezema, Int. J. Energy. Res., 2020, 1-11, DOI: 10.1002/er.5091.

191 J. Ahmad and K. Majid, New J. Chem., 2018, 42, 3246-3259. 192 J. Zhang, N. Chen, M. Li, P. Su and C. Feng, React. Funct. Polym., 2017, 114, 127-135.

193 H. Teymourian, A. Salimi and S. Firoozi, Electrochim. Acta, 2014, 143, 196-206.

194 B. R. Singh, M. Shoeb, W. Khan and A. H. Naqvi, J. Alloys Compd., 2015, 651, 598-607.

195 X. Luo, C. Wang, L. Wang and F. Deng, Chem. Eng. J., 2013, 220, 98-106.

196 H. Mudila, S. Ranaand and M. G. H. Zaidi, J. Ana. Sci. Tech., 2016, 7, 3, DOI: 10.1186/s40543-016-0084-7.

197 B. Prashanti and T. Damodhara, J. Nanosci. Tech., 2017, 3, 256-259.

198 R. S. Das, S. K. Warkhade, A. Kumar and A. V. Wankhade, Res. Chem. Intermed., 2019, 45, 1689-1705.

199 W. G. Hong, B. H. Kim, S. M. Lee, H. Y. Yu, Y. J. Yun, Y. Jun, J. B. Lee and H. J. Kim, Int. J. Hydrogen Energy, 2012, 37, 7594-7599.

200 V. Stengl, S. Bakardjieva, T. M. Grygar, J. Bludska and M. Kormunda, Chem. Cent. J., 2013, 7, 41, DOI: 10.1186/ 1752-153x-7-41.

201 H. M. Yadav and J. S. Kim, J. Alloys Compd., 2016, 688, 123129.

202 A. K. Nair and P. E. J. Babu, Surf. Coat. Technol., 2017, 320, 259-262.

203 M. Sharma, K. Behl, S. Nigam and M. Joshi, Vacuum, 2018, 156, 434-439.

204 X. Liu, B. Hou, G. Wang, Z. Cui, X. Zhu and X. Wanga, J. Mater. Res., 2018, 33, 674-684.

205 M. Alamgir, K. S. Tiwari, A. Mallick and G. C. Nayak, IOP Conf. Ser.: Mater. Sci. Eng., 2018, 377, 012082.

206 M. Liu, J. Xu, B. Cheng, W. Ho and J. Yu, J. Appl. Surf. Sci., 2015, 332, 121-129.

207 D. Huang, B. Li, M. Wu, S. Kuga and Y. Huang, J. Chem. Eng. Data, 2018, 63, 2097-2105.

208 G. Moussavi and M. Mahmoudi, J. Hazard Mater., 2009, 168, 806-812.

209 I. V. Mishakov, A. F. Bedilo, R. M. Richards, V. V. Chesnokov, A. M. Volodin, V. I. Zaikovskii, R. A. Buyanov and K. J. Klabunde, J. Catal., 2002, 206, 4048.

210 L. X. Li, D. Xu, X. Q. Li, W. C. Liu and Y. Jia, New J. Chem., 2014, 38, 5445-5452.

211 M. Heidarizad and S. Sevinc Sengor, J. Mol. Liquid., 2016, 224, 607-617.

212 M. Heidarizad and S. Sevinç Şengör, Proc. World Environ. Water Resources Congress, Sacramento, California, 2017, pp. 21-25, DOI: 10.1061/9780784480595.018. 
213 S. Kimiagar and F. Abrinaei, Nanophotonics, 2017, 7, 243251.

214 S. Samadi and M. Abbaszadeh, Bull. Soc. R. Sci. Liège., 2017, 86(special issue), 271-280.

215 T. Guo and C. Bulin, Res. Chem. Int., 2020, 47, 945-971, DOI: $10.1007 / \mathrm{s} 11164-020-04310-9$.

216 C. J. Madadrang, H. Y. Kim, G. Gao, N. Wang, J. Zhu, H. Feng, M. Gorring, M. L. Kasner and S. Hou, ACS Appl. Mater. Interfaces, 2012, 4, 1186-1193.

217 I. E. M. Carpio, J. D. Mangadlao, H. N. Nguyen, R. C. Advincula and D. F. Rodrigues, Carbon, 2014, 77, 289-301.

218 C. Zhao, L. Ma, J. You, F. Qu and R. D. Priestley, Desalin. Water Treat., 2015, 57, 1-10, DOI: 10.1080/ 19443994.2015.1025438.

219 L. Cui, Y. Wang, L. Gao, L. Hu, L. Yan, Q. Wei and B. Du, Chem. Eng. J., 2015, 281, 1-10.

220 V. V. Arslanov, M. A. Kalinina, E. V. Ermakova, O. A. Raitman, Y. G. Gorbunova, O. E. Aksyutin, A. G. Ishkov, V. A. Grachev and A. Y. Tsivadze, Russ. Chem. Rev., 2019, 88, 775-799 (and references therein).

221 X. Yang, Y. Tu, L. Li Song, M. Shang and X. M. Tao, ACS Appl. Mater. Interfaces, 2010, 2, 1707-1713.

222 D. Han, L. Yan, W. Chen and W. Li, Carbohydr. Polym., 2011, 83, 653-658.

223 P. P. Zuo, H. F. Feng, Z. Z. Xu, L. F. Zhang, Y. L. Zhang, W. Xia and W. Q. Zhang, Chem. Cent. J., 2013, 7, 39-40.

224 Y. Chen, L. Chen, H. Bai and L. Li, J. Mater. Chem. A, 2013, 1, 1992-2001.

225 H. Zhao, T. Jiao, L. Zhang, J. Zhou, Q. Zhang, Q. Peng and X. Yan, Sci. China Mater., 2015, 58, 811-818.

226 M. Abolhassani, C. S. Griggs, L. A. Gurtowski, J. A. MatteiSosa, M. Nevins, V. F. Medina, T. A. Morgan and L. F. Greenlee, ACS Omega, 2017, 2, 8751-8759.

227 N. T. M. Huyen, P. T. T. Trang, N. M. Dat and N. H. Hieu, AIP Conf. Proc., 2017, 1878, 020013.

228 C. D. Garande, J. Mangadlao, J. Fan, A. D. Leon, J. D. Ospina, J. G. Rojas, D. F. Rodrigues and R. Advincula, Macromol. Symp., 2017, 374, 16001141600122.

229 M. Sabzevari, D. E. Cree and L. D. Wilson, ACS Omega, 2018, 3, 13045-13054.

230 T. S. Vo, T. T. B. C. Vo, J. W. Suk and K. Kim, Nano Convergence, 2020, 7, 4, DOI: 10.1186/s40580-019-0215-0.

231 A. M. Croitoru, A. Ficai, D. Ficai, R. Trusca, G. Dolete, E. Andronescu and S. C. Turculet, Materials, 2020, 13, 1687, https://www.mdpi.com/1996-1944/13/7/1687.

232 G. K. Arun, N. Sreenivas, K. B. Reddy, K. S. K. Reddy, M. E. S. Kumar and R. Pramod, IOP Conf. Ser.: Mater. Sci. Eng., 2018, 310, 012158.

233 Y. X. Xu, W. J. Hong, H. Bai, C. Li and G. Q. Shi, Carbon, 2009, 47, 3538-3543.

234 D. Y. Cai and M. Song, Nanotech., 2009, 20, 315708, DOI: 10.1088/0957-4484/20/31/315708.

235 D. Y. Cai, K. Yusoh and M. Song, Nanotech., 2009, 20, 085712, DOI: 10.1088/0957-4484/20/8/085712.
236 Q. Wu, Y. X. Xu, Z. Y. Yao, A. R. Liu and G. Q. Shi, ACS Nano, 2010, 4, 1963-1970.

237 T. Ramanathan, S. Stankovich, D. A. Dikin, H. Liu, H. Shen, S. T. Nguyen and L. C. Brinson, J. Polym. Sci., Part B: Polym. Phys., 2007, 45, 2097-2112.

238 S. H. Hwang, D. Kang, R. S. Ruoff, H. S. Shin and Y. B. Park, ACS Nano, 2014, 8, 6739-6747.

239 R. Mahendran, D. Sridharan, K. Santhakumar and G. Gnanasekaran, J. Nanosci., 2016, 6410295, DOI: 10.1155/2016/6410295.

240 Q. Cheng, Q. Lan, C. Liu, J. Zhao, J. Liang, S. Tang and Y. C. Cao, J. Alloys Compd., 2017, 2, 1-7.

241 W. Huang, X. Y. Qi, K. Y. Pu, H. Li, X. Z. Zhou, S. X. Wu, Q.-L. Fan, B. Liu, F. Boey and H. Zhang, Angew. Chem., Int. Ed., 2010, 49, 9426-9429.

242 W. Huang, X. Y. Qi, K. Y. Pu, X. Z. Zhou, H. Li, B. Liu, F. Boey and H. Zhang, Small, 2010, 6, 663-669.

243 K. Deshmukh, S. M. Khatake and G. M. Joshi, J. Polym. Res., 2013, 20, 286, DOI: 10.1007/s10965-013-0286-2.

244 G. M. Joshi and K. Deshmukh, J. Electron. Mater., 2014, 43, 1161-1165.

245 K. W. Lee, J. W. Chung and S. Y. Kwak, ACS Appl. Mater. Interfaces, 2017, 9, 33149-33158.

246 H. B. Zhang, W. G. Zheng, Q. Yan, Y. Yang, J. W. Wang, Z. H. Lu, G. Y. Ji and Z. Z. Yu, Polymer, 2010, 51, 1191-1196.

247 A. Dasari, Z. Z. Yu and Y. W. Mai, Polymer, 2009, 50, 41124121.

248 S. I. Abdullah and M. N. M. Ansari, $H B R C$ J., 2015, 11, 151156.

249 K. Zhang, L. L. Zhang, X. S. Zhao and J. S. Wu, Chem. Mater., 2010, 22, 1392-1401.

250 J. Yan, T. Wei, B. Shao, Z. J. Fan, W. Z. Qian, M. L. Zhang and F. Wei, Carbon, 2010, 48, 487-493.

251 H. L. Wang, Q. L. Hao, X. J. Yang, L. D. Lu and X. Wang, ACS Appl. Mater. Interfaces, 2010, 2, 821-828.

252 H. L. Wang, Q. L. Hao, X. J. Yang, L. D. Lu and X. Wang, Electrochem. Commun., 2009, 11, 1158-1161.

253 G. Xu, N. Wang, J. Wei, L. Lv, J. Zhang, Z. Chen and Q. Xu, Ind. Eng. Chem. Res., 2012, 51(44), 14390-14398.

254 D. Y. Gui, C. Liu, F. Chen and J. Liu, Appl. Surf. Sci., 2014, 307, 172-177.

255 K. Pal, V. Panwar, S. Bag, J. Manuel, J. H. Ahn and J. K. Kim, RSC Adv., 2015, 5, 3005-3010.

256 P. Saha, D. K. Pyne, M. Pal, S. Datta, P. K. Das, P. Dutta and A. Halder, J. Lumin., 2017, 181, 138-146.

257 J. Yang, Q. Sheng, X. Zhang, S. Zheng and J. Zheng, Microchim. Acta, 2017, 184, 2219-2226.

258 A. A. Nezhad, M. Alimoradi and M. Ramezani, Mater. Res. Express, 2018, 5, 0255089, DOI: 10.1088/2053-1591/aaab1d.

259 B. Getiren, Z. Ciplac, C. Gokalp and N. Yildiz, J. Appl. Polym. Sci., 2019, 137, 48837, DOI: 10.1002/app.48837.

260 M. Farajvand, K. Farajzadeh and G. Faghani, Mater. Res. Express, 2018, 5, 075017, DOI: 10.1088/2053-1591/aace3a.

261 A. K. Sarkar and J. D. Hong, Langmuir, 2012, 28(34), 1263712646. 
262 X. Cheng, V. Kumar, T. Y. Zeki, T. Goto, T. Takahashi, J. Koyanagi, L. Wu and R. Wang, Composites, Part A, 2016, 82, 100-107.

263 N. E. Eltayeb and A. Khan, J. Mater. Res. Technol., 2020, 9, 10459-10467.

264 H. Gul, A. H. A. Shah, U. Crewer and S. Bilal, Nanomaterials, 2020, 10, 118, DOI: 10.3390/nano10010118.

265 Y. Wei, Q. Zheng, M. Wang, J. Huang, X. Guo and L. Wang, Biosens. Bioelectron., 2019, 131, 156-164.

266 S. M. Naghib, Y. Zare and K. Y. Rhee, Nanotechnol. Rev., 2020, 9, 53-60.
267 N. S. Morteza, B. F. Rahmanian, M. Z. Yasser and R. K. Yop, Nanotechnol. Rev., 2020, 9, 760-767.

268 D. A. Oliveira, D. Molinnus, S. Begging, J. R. Siqueira Jr and M. J. Schoning, Phys. Status Solidi A, 2021, DOI: 10.1002/ pssa.202000747.

269 J. Zhang, P. Chen, H. L. O. Bernice and M. B. Chan-Park, Nanoscale, 2013, 5, 9860-9866.

270 J. Xue, Q. Sun, Y. Zhang, W. Mao, F. Li and C. Yin, ACS Omega, 2020, 19, 10995-11004, https://pubs.acs.org/ action/showCitFormats?doi=10.1021/

acsomega.0c00817\&ref $=$ pdf. 